\title{
Structural Behavior and Shear Bond Capacity of Composite Slabs with High Performance Concrete
}

By

Faheem Abdul

B. Eng. Civil, N.E.D University of Engineering \& Technology,

Karachi, Pakistan 1994

\author{
A project presented to Ryerson University \\ in partial fulfillment of the requirements of the degree of \\ Master of Engineering \\ in the Program of Civil Engineering
}

Toronto, Ontario, Canada 2011

CFaheem Abdul, 2011 


\section{Author's Declaration}

$I$ hereby declare that I am the sole author of this project.

I authorize Ryerson University to lend this project to other institutions or individuals for the purpose of scholarly research.

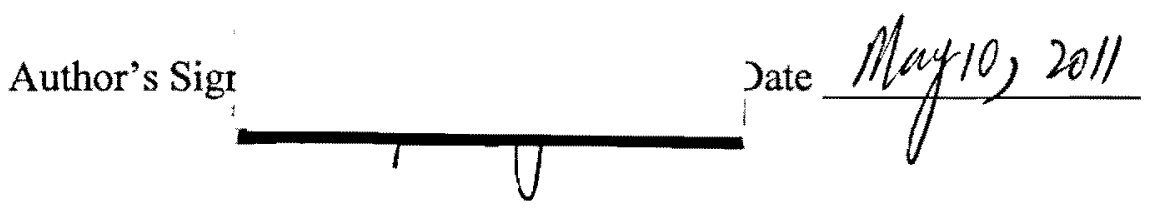

I further authorize Ryerson University to reproduce this project by photocopying or by other means, in total or in part, at the request of other institutions or individuals for the purpose of scholarly research.

Author's Signature Date 


\section{Borrowers}

Ryerson University requires the signatures of all persons using or photocopying this project. Please sign below and give address and date.

\begin{tabular}{|c|c|c|c|}
\hline Name & $\begin{array}{l}\text { Signature of } \\
\text { Borrower }\end{array}$ & Address & Date \\
\hline & & & \\
\hline & & & \\
\hline & & & \\
\hline & & & \\
\hline & & & \\
\hline & & & \\
\hline & & & \\
\hline & & & \\
\hline & & & \\
\hline & & & \\
\hline & & & \\
\hline & & & \\
\hline & & & \\
\hline. & & & \\
\hline
\end{tabular}




\begin{abstract}
Structural Behavior and Shear Bond Capacity of Composite Slabs with High Performance Concrete
\end{abstract}

Faheem Abdul

2011, M.Eng. Department of Civil Engineering, Ryerson University

Many research works have been conducted on the behavior of composite slabs with profiled steel deck to study the longitudinal shear bond resistance using the $\mathrm{m}-\mathrm{k}$ method. In this study, experimental investigations are conducted to evaluate the shear bond characteristics of composite slabs. 15 composite slabs are tested to study the effect of different high performance concrete (HPC) mixes namely engineered cementitious composites (ECC) and self-consolidating concrete (SCC), diverse profile sheets (with embossments or without embossments) and variable shear span on load-deflection characteristics, stress-strain development in concrete/steel, cracking/crack propagation and failure modes. The values of shear bond parameters ( $\mathrm{m}$ and $\mathrm{k}$ ) derived from the test results can be used for the design of composite slabs. 


\section{Acknowledgement}

I would like to take this opportunity to express my sincere and deepest gratitude to my supervisor Dr. Khandaker Anwar Hossain for his dedication, guidance, support and patience during the development of this project. This project is the result of the belief and encouragement of my supervisor that made this project possible. I would like to thank Dr. Anwar Hossain for his kind words and always willingness to help, that pulled me through this project.

I would like to thank Ryerson's Civil Engineering Technicians - especially Mohamad Aldardari and Nidal Jaalouk, for always being there and their prompt help with laboratory equipments and procedures. The financial supports from the Dr. A. Hossain and Ryerson University are greatly appreciated. I would like to acknowledge the support of Canam Canada from providing the profiled steel deck for the research

Finally, special gratitude goes to my family. Without their constant love, support and sacrifices my success would not be possible. 


\title{
Dedication
}

\author{
To My Family
}

$\mathcal{L}$

To My Teacher who Guide me on my Path 


\section{Table of Contents}

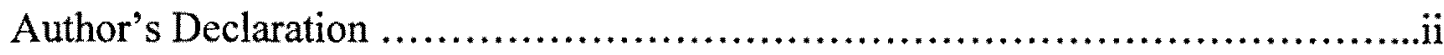

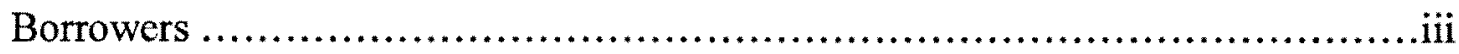

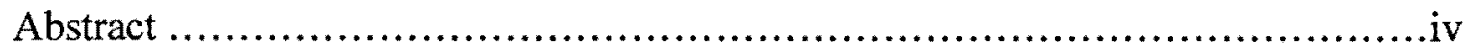

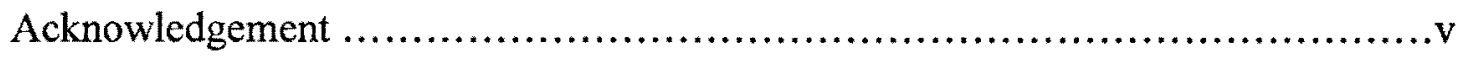

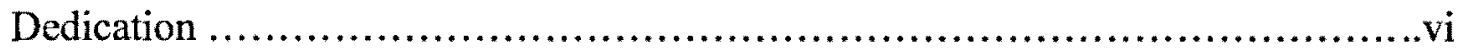

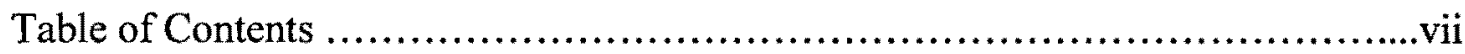

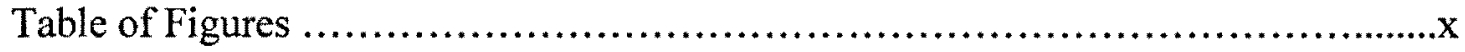

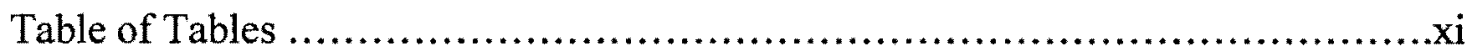

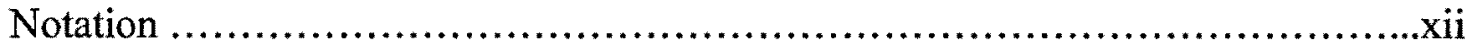

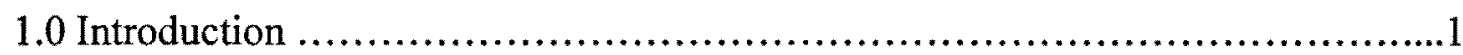

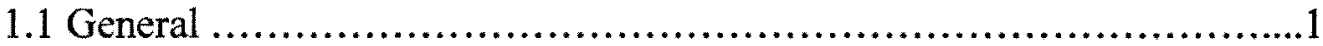

1.2 Scope and Objective of the project .....................................

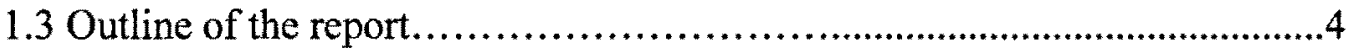

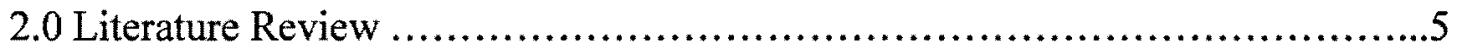

2.1 Composite Slab Development .........................................5

2.2 Benefits of Composite Slab Construction ............................... 8

2.3 Behavior of Composite Slabs........................................12

2.4 Composite Slab Efficiency.............................................14

2.5 Design of Decking \& Slab ............................................

2.5.1 Steel Decking ..........................................15

2.5.2 Profile Steel Sheeting ....................................16

2.5.3 Design of Composite Slab................................18

2.5.3.1 Longitudinal shear in Composite Slabs................19

2.5.3.2 The $\mathrm{m}-\mathrm{k}$ or Shear -bond Test..........................20

2.5.3.3 Defects of m-k Method...............................23

2.5.3.4 Partial-interaction Design............................24 


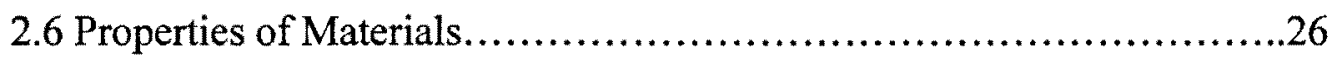

2.7 Criteria of Testing Composite Slabs.................................27

2.7.1 Limit State of Strength...................................28

2.7.2 Loads and Safety Criterion................................28

2.7.3 Resistance Factors ......................................28

2.7.4 Shear-Bond Resistance................................ 28

2.7.5 Flexural Resistance...................................... 30

2.7.6 Factored Moment Resistance..............................31

2.7.6.1 Under Reinforced Slabs.................................. 31

2.7.6.2 Over Reinforced Slabs.................................... 31

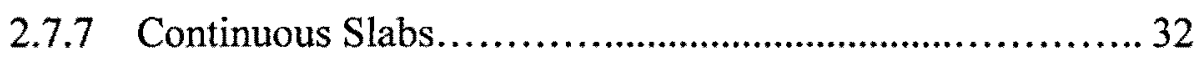

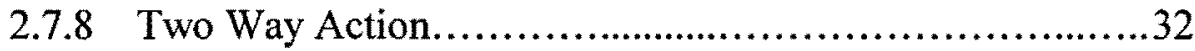

2.7.9 Punching Shear Resistance ....................................... 33

2.7.10 Deflection Criteria....................................................... 33

2.7.10.1 Flexural Properties.............................. 33

2.7.10.2 Deflection Limitations.............................. 34

2.7.10.3 NBC Concentrated Load Criteria.............. 35

2.7.10.4 Repeated or Vibratory Loading................. 37

2.7.10.5 Shrinkage \& Crack Control R/F................37

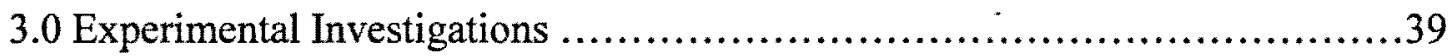

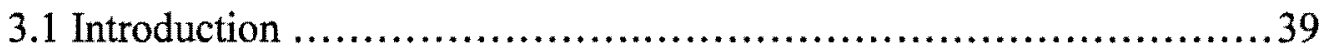

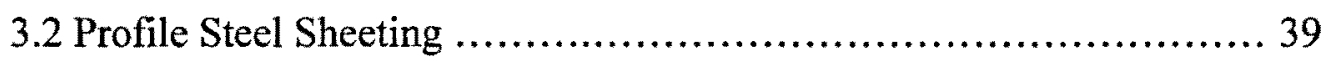

3.2.1 Specification of Sheet Type-A........................... 39

3.2.2 Specification of Sheet Type-B......................... 41

3.3 HBC Concrete Materials............................................44

3.4 Composite Slabs Details , Instrumentation \& Testing ...................43

3.5 Results and Discussions..........................................46

3.5.1 General Observations .....................................46

3.5.2 Load Deflection Behavior......................................49

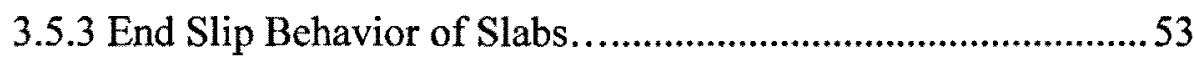

3.5.4 Strain development at the Concrete Surface .................57 
3.5.5 Strain development in Profiled Steel Sheet .................. 61

3.5.6 Evaluation of $\mathrm{m}-\mathrm{k}$ Value \& shear bond stress................ 63

4.0 Conclusions and Future Recommendations ...............................68

4.1 Conclusions ............................................... 68

4.2 Recommendations for Future Studies ..........................69

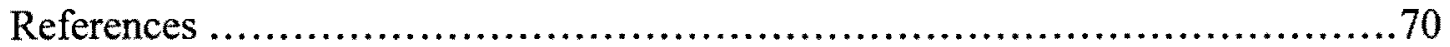




\section{List of Figures}

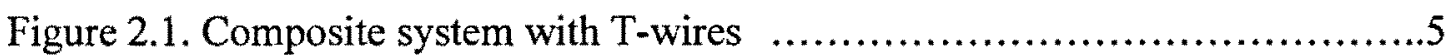

Figure 2.2. Composite slab showing embossments, shear studs \& reinforcements....7

Figure 2.3. Typical decking layout for a composite floor..........................

Figure 2.4. Mode of failure of composite slab ................................12

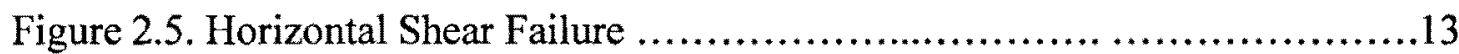

Figure 2.6. Re-entrant Profiles Sheeting.....................................17

Figure 2.7. Trapezoidal Profiles Sheeting ....................................................18

Figure2.8. Cross - Section for Mechanical interlock ............................19

Figure 2.9. Cross - Section of Composite slab .....................................20

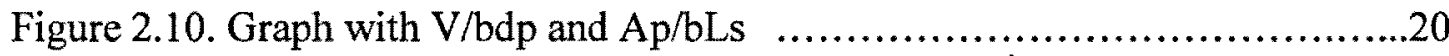

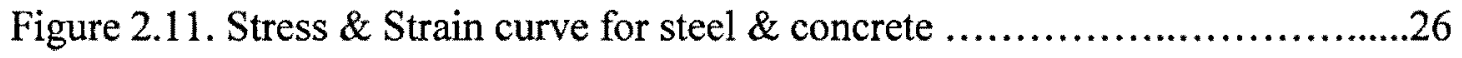

Figure 2.12. Loading Condition ................................................36

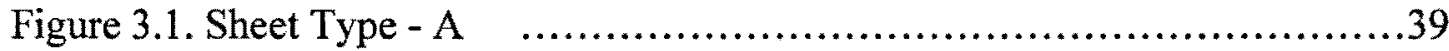

Figure 3.2. Sheet Type - A (Photograph) .....................................40

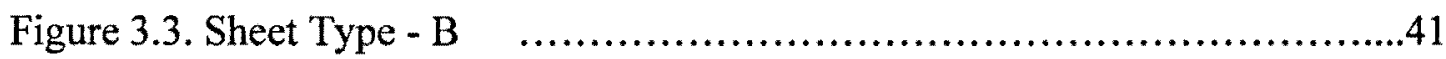

Figure 3.4. Sheet Type - B (Photograph) ...................................42

Figure 3.5. Composite Slab specimens........................................43

Figure 3.6. Typical Sample Cross-Section .....................................44

Figure 3.7(a). Experimental set-up for the composite slab ........................45 
Figure 3.7(b). Experimental set-up for the composite slab

Figure 3.8. Failure mode of composite slabs ................................47

Figure 3.9. Failure of composite slabs.......................................48

Figure 3.10. Load Deflection Behavior .......................................49

Figure 3.11. Load Deflection Behavior of composite slabs........................50

Figure 3.12. Effect of Shear Span and concrete type on Deflection................48

Figure 3.13. End Slip b/w steel and concrete in composite slabs......................53

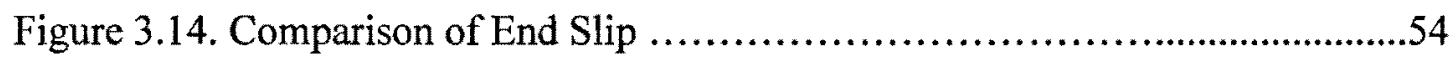

Figure 3.15. Load - Slip relationship in Composite Slabs...................................55

Figure 3.16. Strain development in Concrete .........................................58

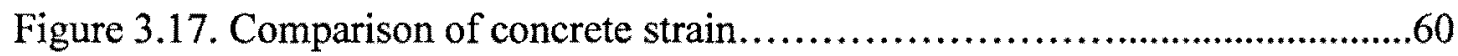

Figure 3.18. Strain development in Steel sheet............................................61

Figure 3.19. Comparison of Steel strain..................................................63

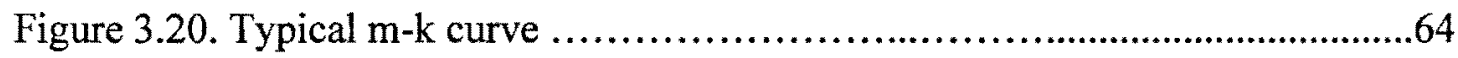

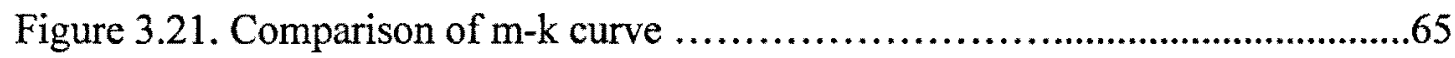

Figure 3.22. Computed shear bond capacity \& experimental shear capacity...........66

Figure 3.23. Shear bond capacity of composite slabs................................................67 


\section{List of Tables}

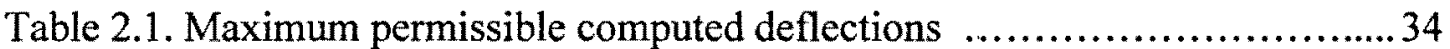

Table 2.2. Minimum shrinkage and temperature reinforcement .................. 37

Table 3.1. Composite slab specifications $\quad$..................................43

Table 3.2. Dimensions of test composite slabs ...................................45

Table 3.3. Experimental shear force, end slips and failure modes....................57

Table 3.4. $\mathrm{m} \& \mathrm{k}$ values and shear bond capacity................................65 


\section{Notation}

Ap Cross sectional area of profile steel sheet

Bs Width of the composite slab centroid of profile sheet

$\mathrm{d}_{\mathrm{s}} \quad$ Effective depth of slab

fcm Compressive strength of concrete

$\mathrm{L}_{\mathrm{v}} \quad$ Effective shear span length

m Empirical value of Mechanical interlocking between concrete \& sheet

VE Maximum experience Shear force

$\tau u, R D \quad$ Shear bond capacity

K Empirical value of friction between concrete \& sheet

L Centre line span of a simply supported slab

As $\quad$ Area of steel deck, $\mathrm{mm}^{2} / \mathrm{m}$ of slab width

b Unit width of compression face of composite slab (1000 mm)

bo Perimeter of critical section, $\mathrm{mm}$

c Distance from extreme compression fibre to composite neutral axis, mm

d Distance from extreme compression fibre to centroid of steel deck, $\mathrm{mm}$

$\mathrm{E}_{\mathrm{c}} \quad$ Modulus of elasticity of concrete, $\mathrm{MPa}$ (see CSA-A23.3-04)

$\mathrm{E}_{\mathrm{s}} \quad$ Modulus of elasticity of steel deck, $(203000 \mathrm{MPa})$

$\mathrm{f}_{\mathrm{c}^{\prime}} \quad$ Specified compressive strength of concrete, $\mathrm{MPa}$

$\mathrm{f}_{\mathrm{y}} \quad$ Specified yield strength of steel deck, MPa 
Moment of inertia of composite section based on cracked section and equivalent area of concrete, $\mathrm{mm} 4 / \mathrm{m}$ of slab width

Moment of inertia used for deflection calculations $=(\mathrm{Ic}+\mathrm{Iu}) / 2$

Iu Moment of inertia of composite section based on uncracked section and equivalent area of concrete, $\mathrm{mm} 4 / \mathrm{m}$ slab width

$\mathrm{k} 1, \mathrm{k} 2 \mathrm{k} 3, \mathrm{k} 4 \quad$ Shear-bond coefficients obtained from a multi-linear regression analysis of test data from three or more deck thicknesses

k5,k6 Shear-bond coefficients obtained from a linear regression analysis of test data for one individual deck thickness

1 '

Shear span of composite slab, $\mathrm{mm}$

$\mathrm{M}_{\text {ro }} \quad$ Factored moment resistance of over reinforced composite slab, N.m $/ \mathrm{m}$ of slab width

$\mathrm{M}_{\mathrm{ru}} \quad$ Factored moment resistance of under reinforced composite slab, N.m/m of slab width

$\mathrm{T} \quad$ Base steel design thickness, $\mathrm{mm}$

Vr Factored shear-bond resistance, $\mathrm{N} / \mathrm{m}$ of slab width

Vt Tested shear-bond resistance, $\mathrm{N} / \mathrm{m}$ of slab width

Vpr $\quad$ Factored punching shear resistance, $\mathrm{N}$ 


\section{Chapter 1: Introduction}

\subsection{General}

Steel-concrete composite systems (also called mixed or hybrid systems) have seen widespread use in recent decades because of the benefits of combining the two construction materials. Today, the use of composite floor slab systems in construction is common practices.

As defined by ASCE (1992) "A composite slab system is one comprising of normal weight or lightweight structural concrete placed permanently over cold-formed steel deck in which the steel deck performs dual roles of acting as a form for the concrete during construction and as positive reinforcement for the slab during service". Amongst the numerous advantages of composite slabs over reinforced concrete slabs are lightweight and easy handling in erection of steel decks. The deck also acts as temporary formwork for the fresh concrete, which saves time and reduces construction costs. Once the concrete has cured and the components become a composite system, the cold-formed steel deck serves as positive slab reinforcement.

Other advantages of the system that attract structural engineers are elimination or significant reduction of the positive moment reinforcement and formwork for concrete casting. This is in contrast to the early use (before 1950) of the steel deck-concrete floor, where the concrete was used only as a filling material as was reported by Widaja (1997). 
The knowledge of the composite interaction as well as the elemental behavior involved in the system has progressed rapidly during the past two decades. Much effort has been put forth to model the behavior of the system. Research on the elemental tests, full scale tests, numerical methods and mechanical models to predict the behavior of composite slab systems has therefore been conducted worldwide particularly in the U.S., Canada, Europe and Australia (Abdullah, 2004).

There are two methods for composite slab design that are widely followed. These are the shear bond method also known as the m-k method and the partial shear connection (PSC) method, both published in Eurocode 4 (1994). These design methods need parameters those have to be obtained from full scale bending tests that are expensive and time consuming. Economic means to deduce the required design parameters are continuously been sought after by researchers. Elemental push-off test are usually conducted to determine the shear interaction between the steel deck and the concrete. This relationship is used as an input parameter for numerical analysis. By doing this, the need for full scale bending tests could be avoided. However, studies have shown that the push tests cannot represent the true behavior of the shear interaction involving different slabs.

The shear bond between the profiled steel sheeting and concrete is difficult to predict theoretically since it is dependent upon several inter-related parameters including the geometry and flexibility of the profiled steel sheet itself. Given that the profiled steel sheeting is a ductile material and the conventional concrete is a brittle material, it is necessary to have some experimental relationship between these two medium of material. 
Limited research has been conducted to envisage the behavior of composite slabs with different profile steel sheeting and newly emerging high performance concrete (HPCs). The better shear bond interaction between steel sheet and HPC can significantly improve the structural performance of composite slabs in addition to improve durability. Therefore, the performance of composite slabs with different HPCs and varied profile steel sheeting is important to determine shear parameters $\mathrm{m}$ and $\mathrm{k}$ and this project is focused on this aspect.

\subsection{Scope and Objective of the Project}

Design of composite slabs can be achieved by using $\mathrm{m}-\mathrm{k}$ method, if $\mathrm{m}$ (parameter that defines shear bond due to mechanical interlock between steel and concrete) and $\mathrm{k}$ (parameter that defines shear bond due to friction between steel and concrete) values are known from experiments. $\mathrm{m}$ and $\mathrm{k}$ values change with different concrete and different steel sheets. Composite slabs with better structural performance can be obtained by using newly developed high performance concretes (HPCs) especially self-consolidating concrete (SCC) and highly ductile Engineered Cementitious Composites (ECC). It is therefore, important to study the behavior of composite slabs with HPCs and to determine the values of shear bond parameters ( $\mathrm{m}$ and $\mathrm{k}$ ) for the design purposes.

The aim of this research is to study the

- Effect of different concrete mixes (ECC and SCC),

- Diverse profile sheets and

- Variable shear span length on load-deflection characteristics, 
- Stress-strain development in concrete/steel, cracking/crack propagation and failure modes of composite slabs through experimental investigations.

- Shear bond parameters ( $\mathrm{m}$ and $\mathrm{k}$ ) for HPCs and sheets will be derived and suggested for the design of composite slabs.

\subsection{Outline of the Report}

This study was carried out on 15 different composite slabs with two types of profile steel sheeting and two different types of HPC concrete mixes (SCC and ECC). Only material non-linearity of concrete, steel deck and shear bond interaction was considered in the analysis. The analyses were only applicable to specified trapezoidal shape cold-formed steel decks manufactured by CANAM, Canada. The detail study was limited to simply supported slabs with two points loading.

Chapter 1 presents an introduction to composite slab highlighting scope and objectives of the investigation. A literature review on composite slab is presented in Chapter 2, experimental investigations, results and discussions are provided in Chapter 3. Chapter 4 presents conclusions and recommendations for future research studies. 


\section{Chapter 2: Literature Review}

\subsection{Composite Slab Development}

The use of steel-concrete composite construction began around 1926. In the past, successful composite deck was made by welding transverse wires across the deck ribs Fig.2.1 or by punching holes in the deck to allow concrete to fill the ribs.

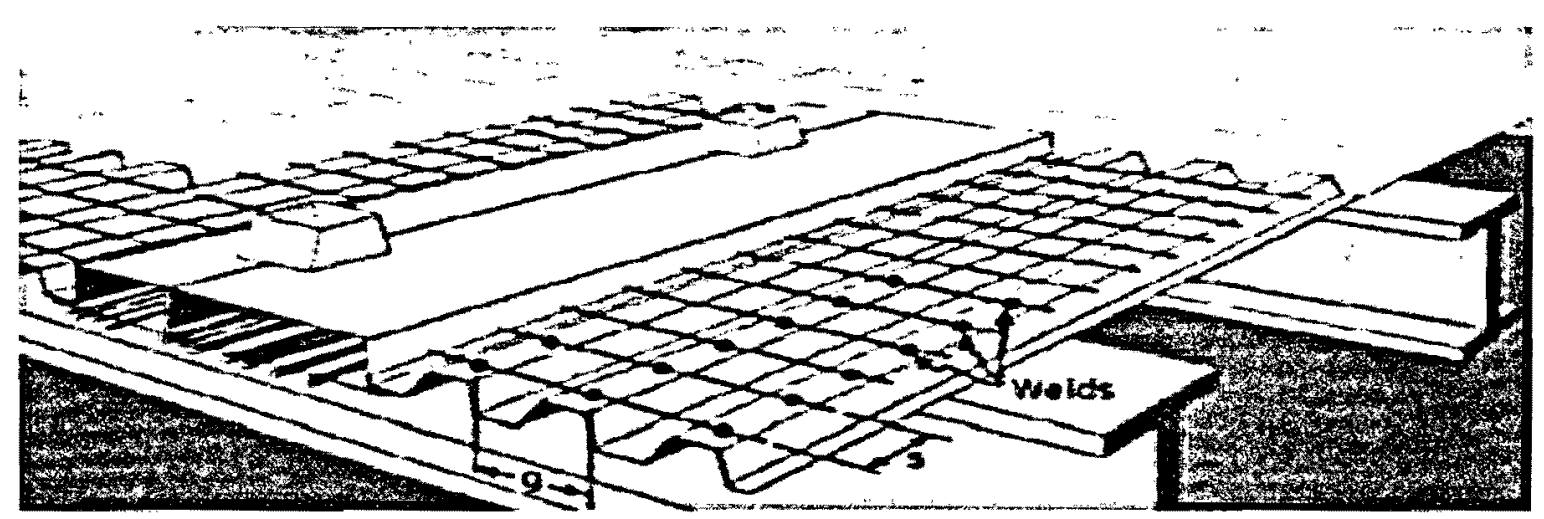

Fig.2.1 Composite system with $T$-wires (Johnson, 1994)

When steel floor deck was first introduced, it was primarily used as a permanent, or "stay-in-place" form for a reinforced concrete poured in place slab. There were certain advantages in cost and a shorter construction time for this type of concrete formwork over traditional removable formwork. There were some situations, however, where the deck did not have a concrete cover and was the sole load carrying element. The name for this type of deck is floor deck, or non-composite deck.

In the 1960's, floor deck products were developed that incorporated mechanical means of interlocking the concrete and the steel deck. By interlocking the steel deck and the concrete slab, the deck became the positive moment reinforcement in the reinforced concrete slab. In addition, the deck also acted as the formwork for the concrete. The 
resulting combined section has become known as a composite slab and the steel deck as a composite deck. The plain steel floor deck is no longer produced in any significant quantity in favor of the more efficient composite deck.

Composite slabs consist of profiled steel decking with an in-situ reinforced concrete topping. The decking not only acts as permanent formwork to the concrete, but also provides sufficient shear bond with the concrete so that, when the concrete has gained strength, the two materials act together compositely. The composite interaction may be increased by the attachment of shear connectors to the steel sheets. These connectors generally take the form of headed studs. It is standard practice for the studs to be welded to the sheet prior to placing the concrete. The shear connectors provide sufficient longitudinal shear connection between the sheet and the concrete so that they act together structurally (Widjaja and Easterling, 1996).

During recent years, composite design has been widely applied in building construction and has for many decades been the most widely used method of suspended floor construction for steel-framed buildings in North America. Within the last thirty years there have been many advances in design procedures, and a wide range of profiled sheeting has become available. The British Standard for the design of composite floors (British Standard, 1990) first appeared in 1982. There are Eurocodes for design of both the sheeting alone (British Standard, 1993), composite slab (British Standard, 1994) and the (Widjaja 1995). 
Steel deck achieves its composite bonding ability by embossments or indentations formed in the deck webs or by the deck shape as shown in Fig.2.2.

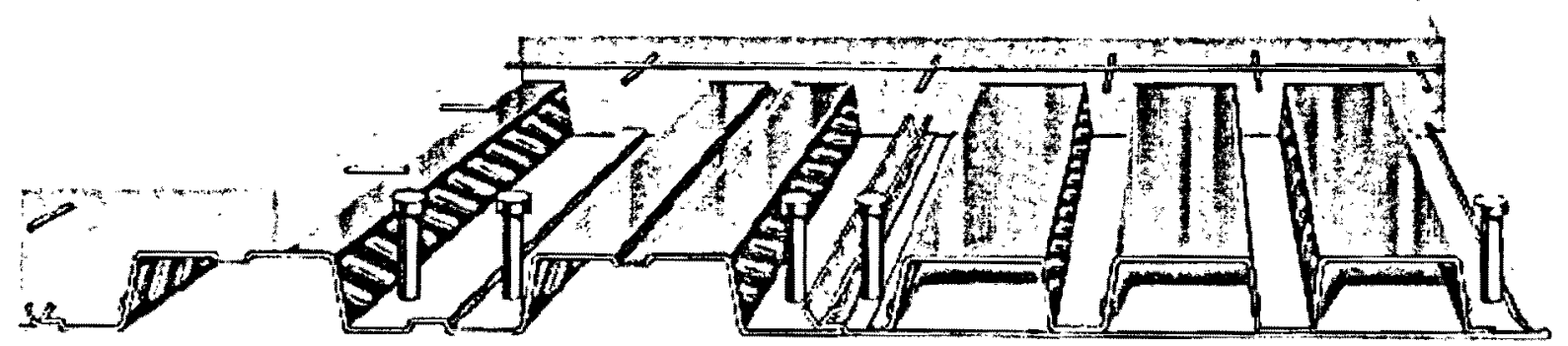

Fig.2.2: Composite slab showing embossments, shear studs and reinforcements (Johnson, 1994)

Since 1984, engineers have also used the ASCE Standard Specification for the Design and Construction of Composite Steel Deck Slabs prepared by the Steel Deck with Concrete Standard Committee.1.170. In 1991, the ASCE Standard was revised and divided into two separate Standards:

(1) Standard for the Structural Design of Composite Slabs, ANSU/ASCE 3-9111.53

(2) Standard Practice for Construction and Inspection of Composite Slabs, ANSI/ASCE 9-91.11.54 Both Standards were approved by ANSI in December 1992.

These two Standards and their Commentaries focus on the usage of composite steel-deckreinforced slabs. Standard ANSL/ASCE 3-91 addresses the design of composite slabs and Standard ANSUASCE 9-91 focuses on construction practices and inspection. Research sponsored by the Steel Deck Institute and by the American Iron and Steel Institute has shown that the shear studs (shown in Fig.2.2) used to make the beams composite also greatly enhance the composite behavior of the steel deck (European, 1981). 


\subsection{Benefits of Composite Slab Construction}

Composite slabs are commonly used (with composite beams $\&$ steel columns) in the commercial, industrial, leisure, health and residential building sectors due to the speed of construction and general structural economy that can be achieved. Although most commonly used on steel framed buildings, composite slabs may also be supported off masonry or concrete components. A typical example of the decking layout for a composite floor is shown in Fig.2.3.

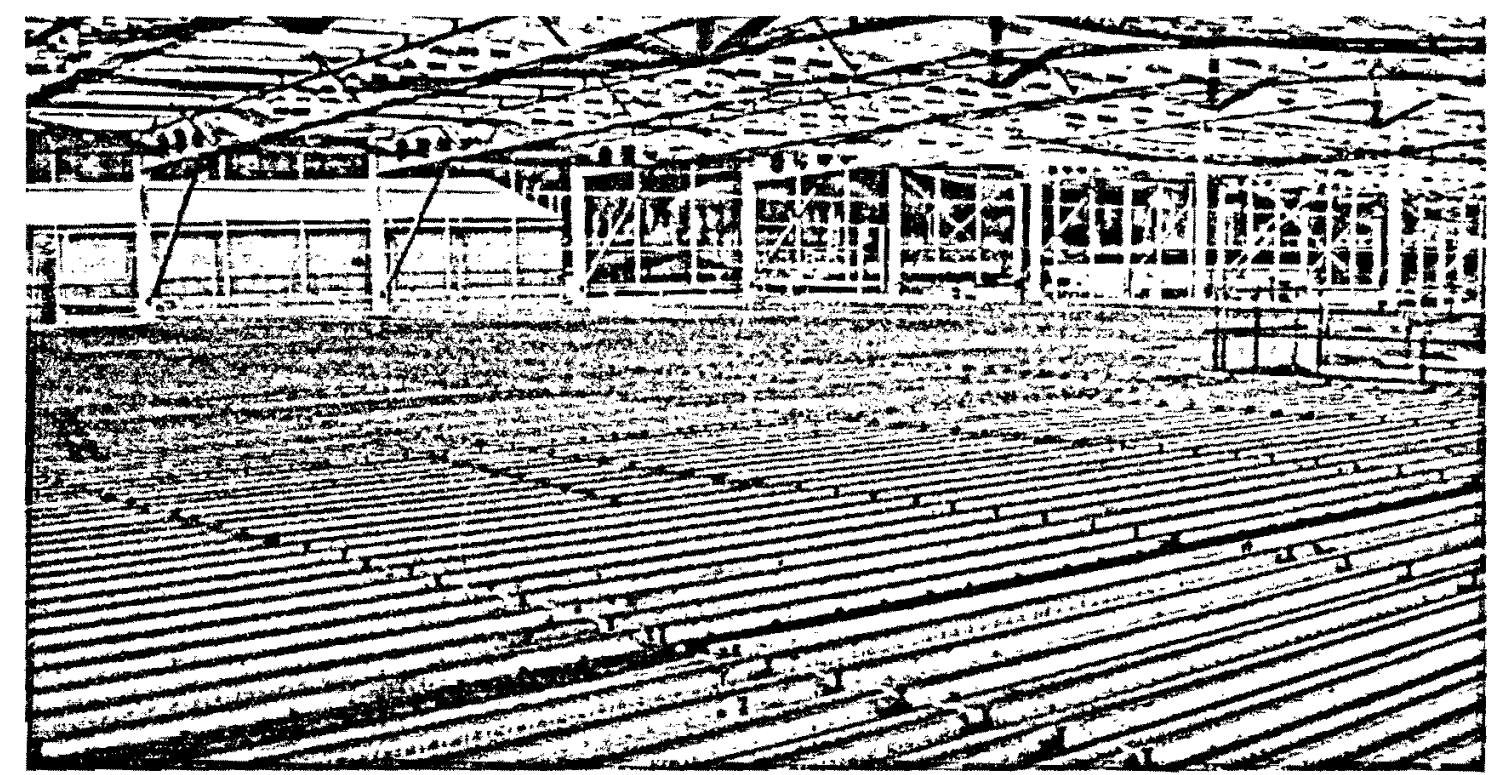

Fig.2.3: Typical decking layout for a composite floor (Rackham and Hicks, 2009)

Composite slab systems have been widely used in steel- framed structures. The system has proven to be very attractive to structural designers because of many advantages it has over conventional systems of reinforced concrete slabs. These advantages have been listed by Finzi (1968), Oudheusden (1971), Hogan (1976), Porter and Ekberg (1976), Fisher and Buettner (1979), Porter (1985). The main benefits of composite construction are: 
- Proven Durability: Steel deck has a successful service history of over 60 years, which is indicative of the products durability.

- Economy and Value: Value is determined by combining initial costs, life-cycle costs, and overall performance. Steel deck assemblies are the best value in roof and floor designs. They combine low cost with top performance.

- Speed of construction: Bundles of decking can be positioned on the structure by crane and the individual sheets then installed by hand. Using this process, crane time is minimal, and in excess of approx. $400 \mathrm{~m}^{2}$ of decking can be installed by one team in a day, depending on the shape and size of the building footprint. The use of the decking as a working platform speeds up the construction process.: Minimal reinforcement is required, and large areas of floor can be poured quickly. Floors can be concreted in rapid succession.

- Safe method of construction: The decking can provide a safe working platform and act as a safety 'canopy' to protect workers below from falling objects.

- Saving in weight: Composite construction is considerably stiffer and stronger than many other floor systems, so the weight and size of the primary structure can be reduced. Consequently, foundation sizes can also be reduced.

- Saving in transport: Decking is light and is delivered in pre-cut lengths that are tightly packed into bundles. Typically, one lorry can transport in excess of $1000 \mathrm{~m}^{2}$ of decking. Therefore, a smaller number of deliveries are required when compared to other forms of construction.

- Structural stability: The decking can act as an effective lateral restraint for the beams, provided that the decking fixings have been designed to carry the necessary 
loads and specified accordingly. The decking may also be designed to act as a large floor diaphragm to redistribute wind loads in the construction stage, and the composite slab can act as a diaphragm in the completed structure.

- Sustainability: Steel has the ability to be recycled repeatedly without reducing its inherent properties. This makes steel framed composite construction a sustainable solution. 'Sustainability' is a key factor for clients, and at least $94 \%$ of all steel construction products can be either re-used or recycled upon demolition of a building.

- Easy installation of services: Cable trays and pipes can be hung from hangers that are attached using special 'dovetail' recesses rolled into the decking profile, thereby facilitating the installation of services such as electricity, telephone and information technology network cabling. These hangers also allow for convenient installation of false ceilings and ventilation equipment. "Comparative structure cost of modern commercial buildings" (British Standard, 1994) shows solutions involving composite construction to be more economical than steel or concrete alternatives for both a conventional four storey office block and an eight storey prestigious office block with an atrium.

- Applications: Composite slabs have traditionally found their greatest application in steel framed office buildings, but they are also appropriate for the following types of building:

- Other commercial buildings

- Industrial buildings and warehouses

- Leisure

- Hospitals 


\section{- Schools}

- Cinemas

- Housing; both individual houses and residential buildings

- Refurbishment projects

Since, composite slabs comprise of profiled steel decking as the permanent formwork to the underside of concrete slabs spanning between support beams, therefore, decking acts composite with the concrete under service loading. It also supports the loads applied to it before the concrete has gained adequate strength.

The behavior of a composite profiled slab is extremely complex and the exact nature of the bond between concrete and steel is still not well understood because of the slip at the interface between the profiled sheet and the concrete element. The partial action that is partial interaction and partial shear connection, associated with the slip cause both the flexural strength and the shear strength of the composite slab to vary along its length.

Experimental work has been carried out to study the structural behavior of the composite slab on metal decking steel sheet of different concrete thickness. The slab tested for the failure for the concentrated load placed at the mid span of the slab. The results obtained from the experimental have been compared with the mathematical model. It has been found that the actual ultimate load carrying capacity of the composite slab is almost $8-9 \%$ greater than the theoretical ultimate carrying capacity of the composite slab. Also the failure of slab occurred due to slippage between concrete and steel sheet. 


\subsection{Behavior of Composite Slabs}

Composite slab behavior is a function of the interactions amongst the components of the slab. Two of the most important interactions that significantly affect the slab behavior are:

(i) The shear interaction at the interface of steel deck and concrete.

(ii) The interaction between the concrete, steel deck and end condition at supports.

Amongst others, the geometric properties of the steel decks significantly influence the interaction behavior. One of the purposes of understanding the behavior of composite slab is to provide tools suitable for design purposes. Methods based on simple mechanical model have been developed worldwide in the past two decades as reported by (Abdullah, 2004). Despite the complex nature of interactions inside composite slab systems, the models have demonstrated good performance in predicting the slab strength and practical behavior.

Composite slabs under bending can exhibit three major modes of failure:

- Flexure failure at section 1-1

- Vertical shear failure at section 2-2 and

- Horizontal shear failure at section 3-3 as shown in Fig.2.4 (Johnson, 1994).

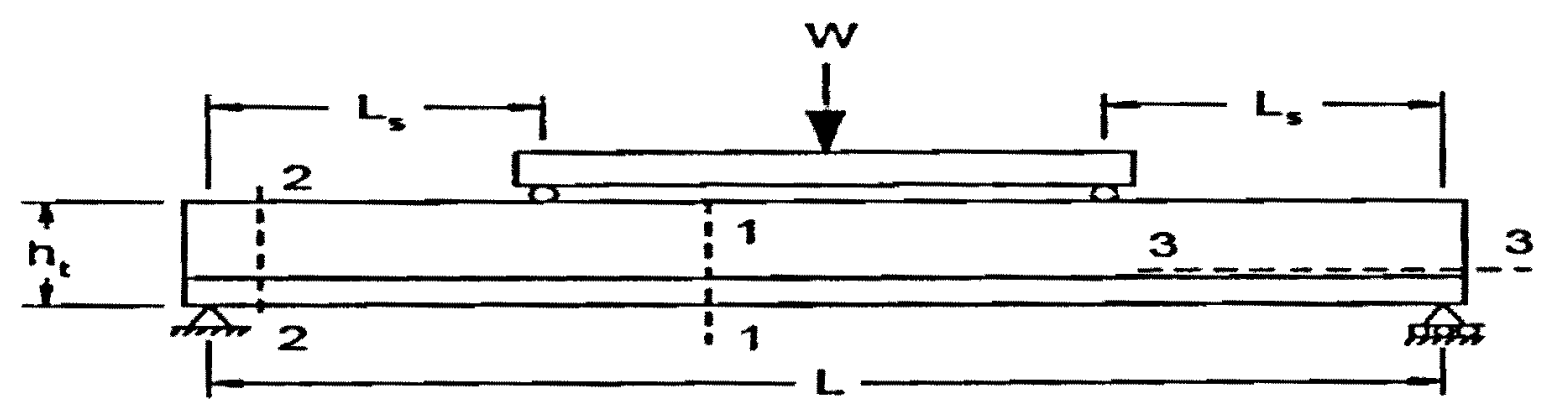

Fig.2.4 Modes of failure of composite slab (Johnson, 1994) 
The flexure failure (mode 1) occurs when complete interaction at the interface between the concrete and steel is achieved. This type of failure usually occurs in long thin slabs. Analysis for this type of failure is quite easy, in which case ordinary reinforced concrete procedures can be followed (ASCE, 1992; Easterling and Young, 1992). The flexural failure however, is not a dominant design criterion because the steel and concrete interaction is usually incomplete and the slab length is always limited by the serviceability (deflection) limit.

The characteristic of the second mode, which is the vertical shear failure, was reported by Abdullah (2004). For this failure mode to be dominant, the slab has to be very short and thick with a high concentrated load near the supports. This is not common in construction practice, therefore, it has not been the subject of much research-and the effect is usually ignored in design.

Failure mode 3, which is a horizontal shear failure or shear bond failure as it is commonly referred to, is the mode more likely to occur for most composite slab systems subjected to vertical loads. This is characterized by the development of an approximate diagonal crack under or near one of the concentrated loads just before failure, followed by an observable end-slip between the steel deck and the concrete within the concrete shear span $\mathrm{L}_{\mathrm{s}}$, as illustrated in Fig.2.5.

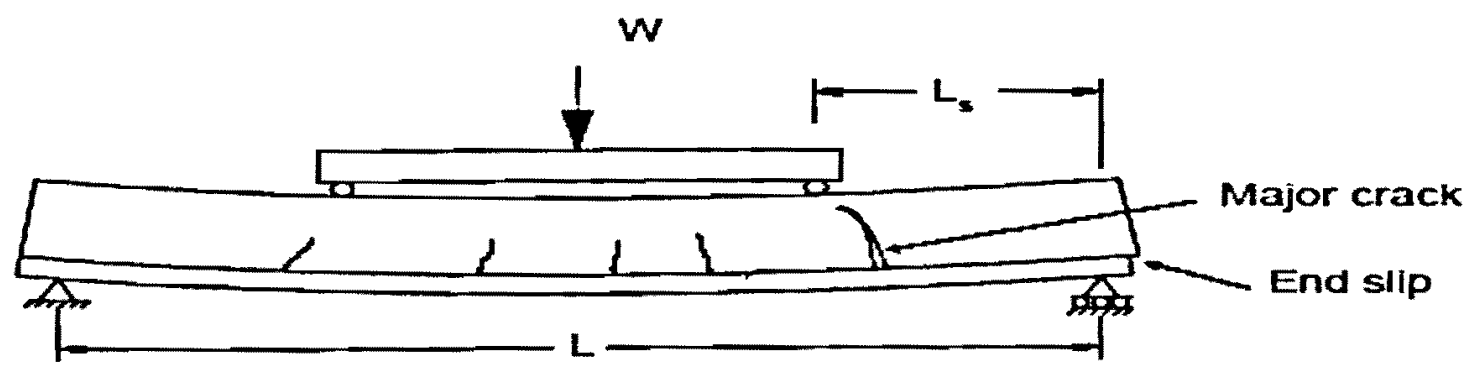

Fig.2.5: Horizontal shear failure (Abdullah, 2004) 
Thus the strength and behavior of composite slabs which fail by horizontal shear depend on several major factors such as shear transfer devices, steel thickness and slab slenderness. The shear transfer devices are usually a combination of steel profile shape, indentations or embossments on the steel surface and end anchorages.

\subsection{Composite Slab Efficiency}

Efficient composite floor systems can be obtained by optimally utilizing materials, which includes the possibility of developing long span composite slab systems. These long span systems require investigation of new deck profiles that can be used to provide an adequate interaction with the concrete slab. However, with the dependency of steel manufacturers on full- scale slab tests, a substantial number of tests have to be performed to develop a new deck profile. Therefore, alternative that can reduce the required number of full-scale tests is required.

This can be achieved by using analytical means supported by elemental tests that are less expensive than the full-scale tests. Many kinds of analytical means are now being made available due to development in the past decade, particularly in the area of nonlinear analysis. By the same means, structural designers will have analytical tools to crossexamine the design calculations. Current design formulations, such as the $\mathrm{m}$ and $\mathrm{k}$ method (Schuster 1970, Porter 1976), do not sufficiently describe the physical behavior of composite slabs. The only way structural designers can verify the design calculation based on load tables generated by the $\mathrm{m}$ and $\mathrm{k}$ method is to look back into the experimental test results. Depending upon the application, these analytical tools may range from a simple hand calculation to a special purpose nonlinear finite element code. 


\subsection{Design of Decking \& Slabs}

Information about design principles and procedures are discussed in this section, codified design rules, and guidance on good practice in design and detailing. Summary boxes are used to highlight particular issues of good practice, or areas where particular attention is needed.

\subsubsection{Steel Decking}

The steel decking has two main structural functions:

1 During concreting, the decking supports the weight of the wet concrete and reinforcement, together with the temporary loads associated with the construction process. It is normally intended to be used without temporary propping.

2 In service, the decking acts 'compositely' with the concrete to support the loads on the floor. Composite action is obtained by shear bond and mechanical interlock between the concrete and the decking. This is achieved by the embossments rolled into the decking - similar to the deformations formed in rebar used in a reinforced concrete slab - and by any re-entrant parts

The decking may also be used to stabilize the beams against lateral torsional buckling during construction, and to stabilize the building as a whole by acting as a diaphragm to transfer wind loads to the walls and columns. (Couchman and Way, 1998). The decking, together with either welded fabric reinforcement placed in the top of the slab or steel/synthetic fibers throughout the slab, also helps to control cracking of the concrete caused by shrinkage effects.in the deck profile (which prevents separation of the deck and the concrete), (Widjaja 1997). 


\subsubsection{Profile Steel Sheeting}

The sheeting is comparatively very thin for economic reasons, usually between $0.8 \mathrm{~mm}$ and $1.2 \mathrm{~mm}$. It has to be galvanized to resist corrosion, and this adds about $0.04 \mathrm{~mm}$ to the overall thickness. It is specified in (British Standards Institution, 1993) that where design is based on the nominal thickness of the steel, the sheet must have at least $95 \%$ of that thickness - but it is not a simple matter for the user to check this. The sheets are either pressed or cold rolled and are typically about $1-\mathrm{m}$ wide and up to $6-\mathrm{m}$ long. They are designed to span in the longitudinal direction only. For many years, sheets were typically $50-\mathrm{mm}$ deep and the limiting span was about $3 \mathrm{~m}$. The cost of propping the sheets during concreting, to reduce deflections, led to the development of deeper profiles; but design of composite slabs is still often governed by a limit on deflection.

The local buckling stress of a flat panel within sheeting should ideally exceed its yield strength; but this requires breadth/thickness ratios of less than about 35 . Modern profiles have local stiffening ribs, but it is difficult to achieve slendernesses less than about 50 , so that for flexure. (i.e., the buckling stress is below the yield stress). Calculation of the resistance to bending then becomes complex and involves iteration.

The specified or nominal yield strength for the flat sheet from which the sheeting is made is lower than in the finished product, the yield strength is higher at every bend and corner, because of work hardening. To enable it to fulfill its second role, as reinforcement for the concrete slab, dimples are pressed into the surface of the sheeting, to act as shear connectors. These dimpled areas may not be fully effective in resisting longitudinal stress, so both they and the local buckling reduce the second moment of area (I) of the sheeting to below the value calculated for the gross steel section. For these reasons, 
manufacturers commission tests on prototype sheets, and provide designers either with test-based values of resistance and stiffness, or with 'safe load' tables calculated from those values.

Decking profiles are produced by a number of manufacturers. Although there are similarities between their profiles, the exact shape and dimensions depend on the particular manufacturer. There are two generic types of shallow decking; re-entrant (dovetail) profiles and trapezoidal profiles. Examples of re-entrant profiles are shown in Fig.2.6 and for trapezoidal profiles with a shoulder height of up to $60 \mathrm{~mm}$ (excluding the crest stiffener) are shown in Fig.2.7,

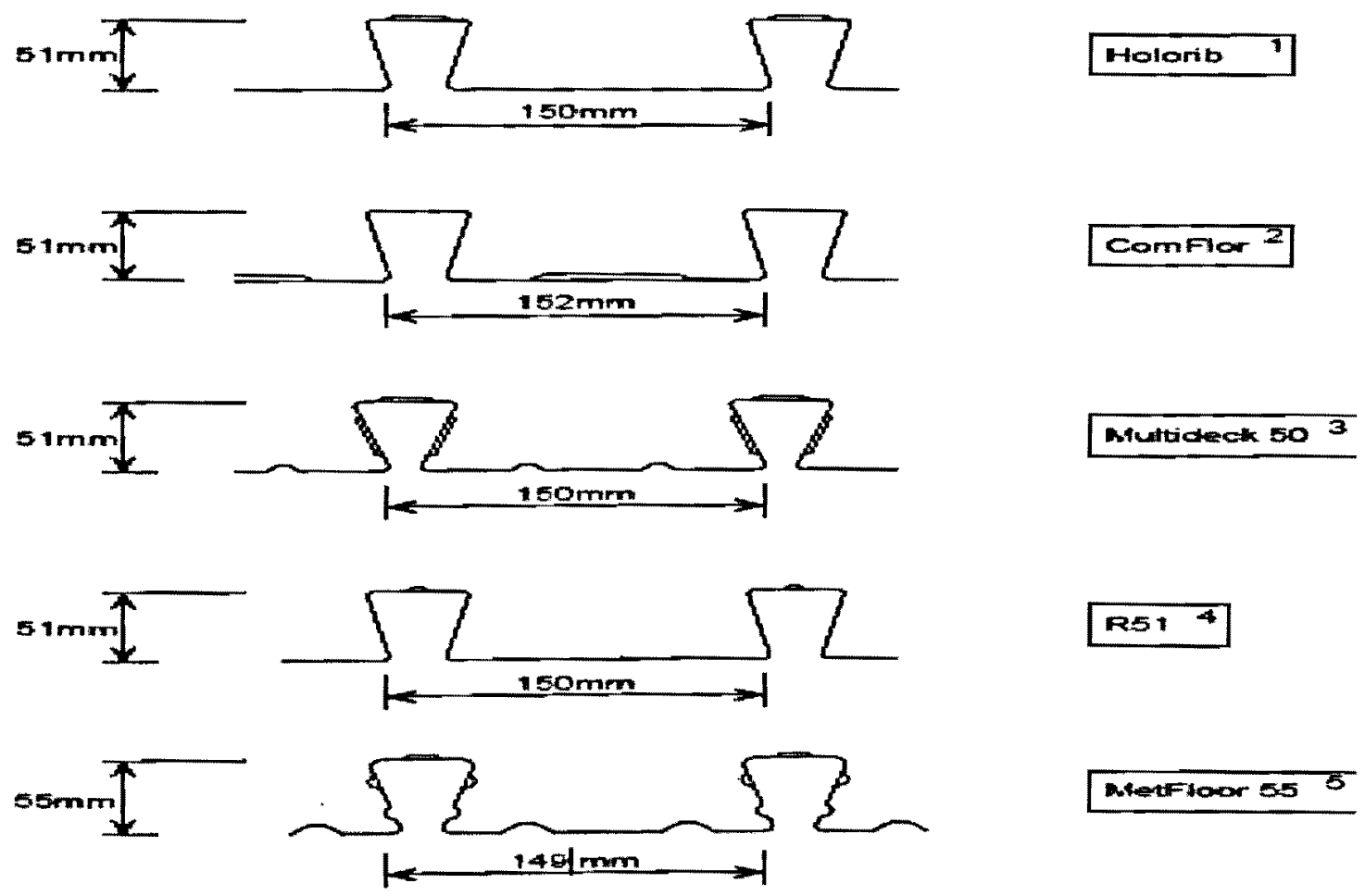

Fig.2.6: Re-entrant profiles Sheeting, (Rackham and Hicks, 2009) 

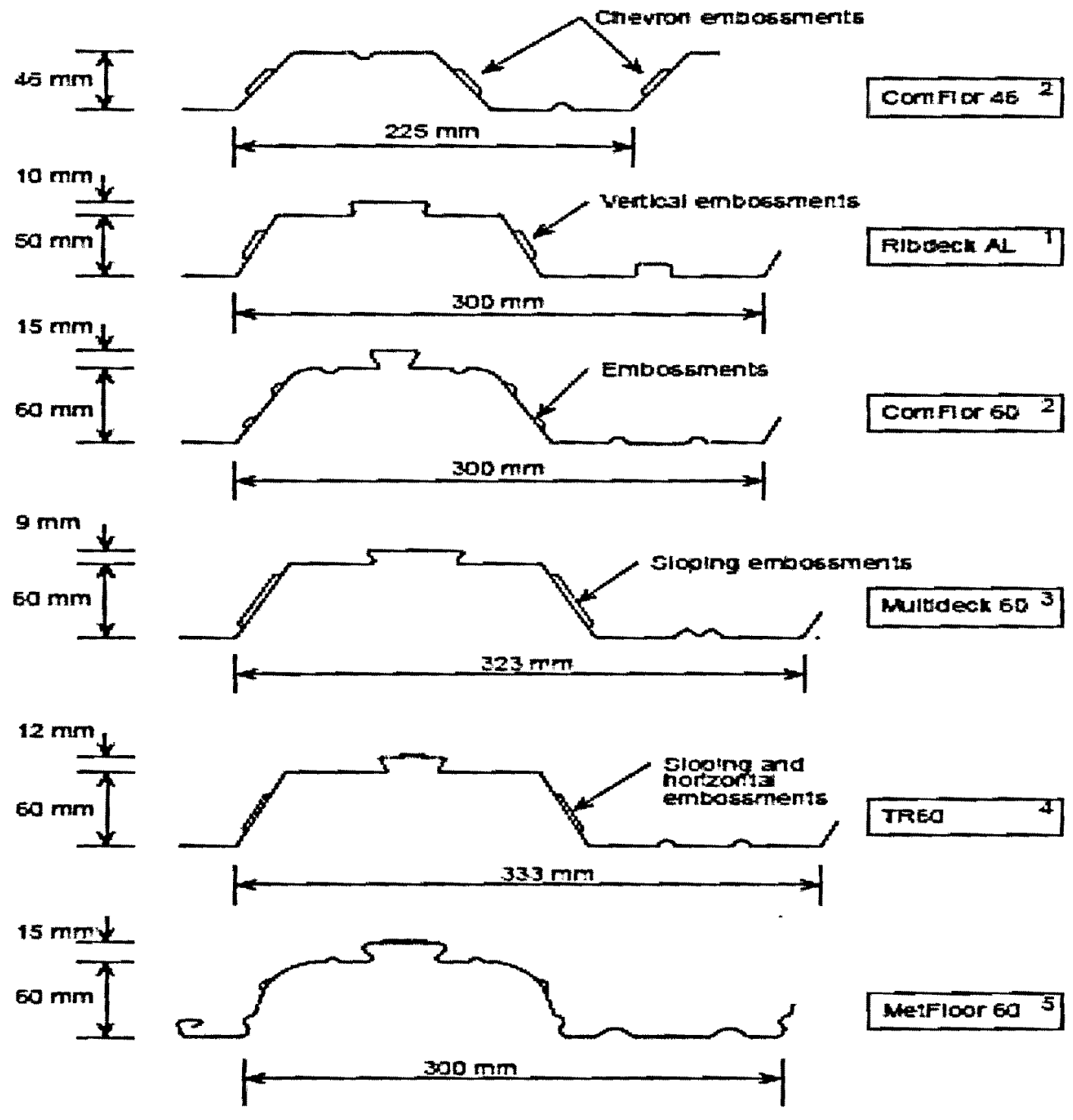

Fig.2.7: Trapezoidal profiles, (Rackham and Hicks, 2009)

\subsubsection{Design of Composite Slab}

The cross-sectional area of steel sheeting that is needed for the construction phase often provides more than enough bottom reinforcement for the composite slab. It is then usual to design the slabs as simply-supported. The concrete is of course continuous over the 
supporting beams, and the sheets may be as well (e.g., if 6-m sheets are used for a succession of 3-m spans). These 'simply-supported' slabs require top longitudinal reinforcement at their supports, to control the widths of cracks. The amount is specified in (British Standards Institution, 1994) as $0.2 \%$ of the cross-sectional area of concrete above the steel ribs for unpropped construction and $0.4 \%$ for propped construction. Longspan slabs are sometimes designed as continuous over their supports.

\subsubsection{Longitudinal Shear in Composite Slabs}

There are three types of shear connection between a profiled steel sheet and a concrete slab. At first, reliance was placed on the natural bond between the two. This is unreliable unless separation at the interface ('uplift') is prevented, so sheets with re-entrant profiles, such as Holorib, were developed. This type of shear connection is known as 'frictional interlock'. The second type is 'mechanical interlock', provided by pressing dimples or ribs into the sheet Fig.2.8.

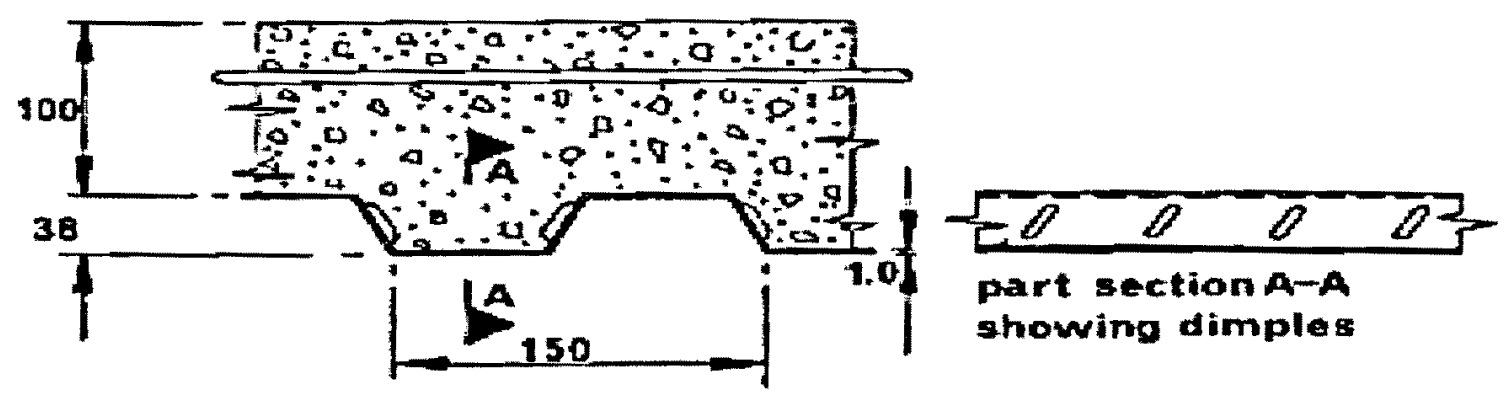

Fig.2.8: Mechanical interlock in composite slab (Johnson, 1994)

The effectiveness of these embossments depends entirely on their depth, which must be accurately controlled during manufacture. The third type of shear connection is 'end 
anchorage'. This can be provided where the end of a sheet rests on a steel beam, by means of shot-fired pins, or by welding studs

\subsubsection{The $\mathrm{m}-\mathrm{k}$ or Shear-bond Test}

The effectiveness of shear connection is studied by means of loading tests on simplysupported composite slabs. Specifications for such tests are given in (British Standard, 1994). The length of each shear span, Ls, is usually $L / 4$, where $L$ is the span. There are three possible modes of failure: The expected mode of failure in a test depends on the ratio of Ls to the effective depth $\mathrm{dp}$ of the slab as shown in Fig.2.9. According to (British Standard, 1994), the results are plotted on a diagram with axes V/bdp and Ap/bLs Fig.2.10, for reasons that are now explained.

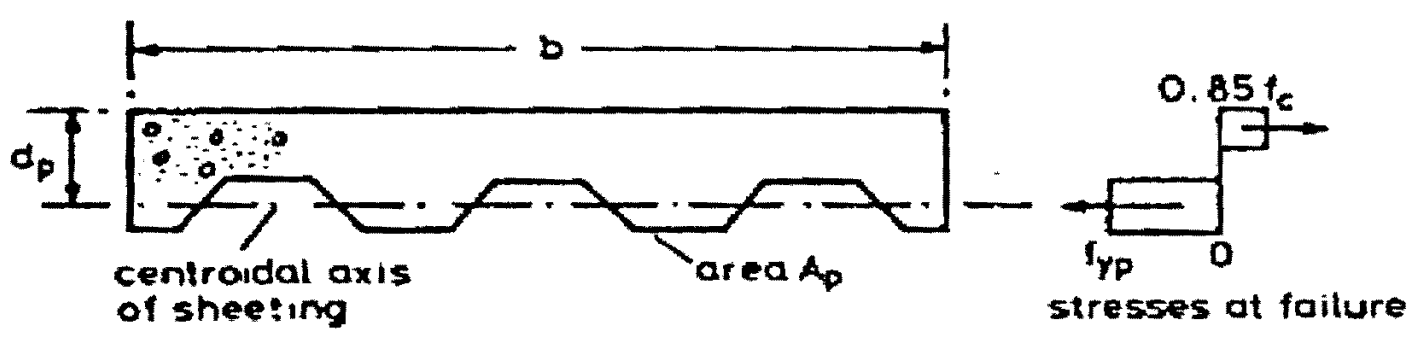

Fig.2.9: Composite slab crossection and stress diagram (Johnson, 1994)

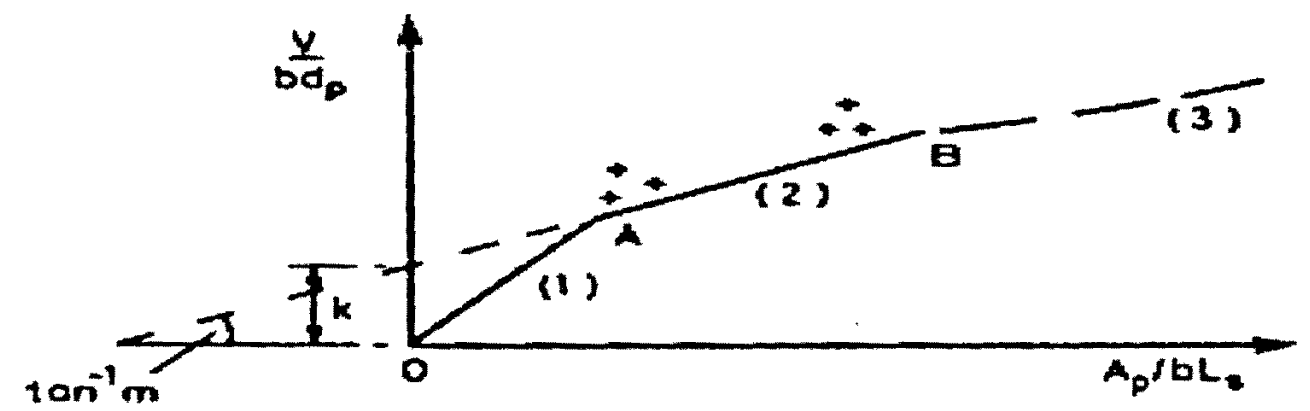

Fig.2.10: Plot showing $\mathrm{m}$ and $\mathrm{k}$ determination (Johnson, 1994) 
At high Ls /dp, flexural failure occurs. The maximum bending moment, $\mathrm{Mu}$, is given by

$$
\mathrm{M}_{\mathrm{u}}=\mathrm{VL}_{\mathrm{s}}
$$

where $\mathrm{V}$ is the maximum vertical shear, assumed to be much greater than the self-weight of the slab. A test specimen, of breadth $b$, should include a number of complete wavelengths of sheeting, of total cross-sectional area $A_{p}$. Flexural failure is modelled by simple plastic theory, with all the steel at its yield stress, $f_{y p}$ Fig.2.9, and sufficient concrete at $0.85 f_{c}$, where $\mathrm{fc}$ is the cylinder strength, for longitudinal equilibrium. The lever arm is a little less than dp, but approximately,

$$
M_{u} \propto A_{p} f_{y p} d_{p}
$$

Therefore, from Eq-1;

$\frac{V}{b d p}=\frac{M u}{b d p L s} \propto \frac{A p f y p}{b L s}$

The strength $f_{y p}$ is not varied during a series of tests, and has no influence on longitudinal shear failure. It is therefore omitted from the axes on Fig. 2.10. Eq.2.2 shows that flexural failure should plot as a straight line through the origin as shown by (1) in Fig.2.10.

At low $L_{s} / d_{p}$, vertical shear failure occurs. The mean vertical shear stress on the concrete is roughly equal to $\mathrm{V} / \mathrm{bd} \mathrm{d}_{\mathrm{p}}$. It is assumed in current codes that the ratio $\mathrm{A}_{\mathrm{p}} / \mathrm{bL}$, has little influence on its ultimate value, so vertical shear failures are represented by a horizontal line. However, Patrick \& Bridge (1993) have shown that this should be a rising curve indicated by (3) in Fig.2.10.

Longitudinal shear failures occur at intermediate values of $\mathrm{L}_{s} / \mathrm{d}_{\mathrm{p}}$, and lienear the line 
as shown by $\mathrm{AB}$ on Fig.2.10, where $\mathrm{m}$ and $\mathrm{k}$ are constants to be determined by testing. Design based on Eq-4 is one of the two methods given in (British Standard, 1994).

$$
\frac{V}{b d p}=m\left\lfloor\frac{A p}{b L s}\right\rfloor+\mathrm{k}
$$

In ' $\mathrm{m}-\mathrm{k}$ method' as defined in (British Standards Institution, 1994), $\mathrm{m}$ and $\mathrm{k}$ are usually defined by the Eq.2.5.

$V=b d p(f c)^{1 / 2}\left[m \frac{A p}{b L s(f c)^{1 / 2}}+k\right]$

where $f_{c}$ is the measured cylinder or cube strength of the concrete. This equation can give unsatisfactory results for $\mathrm{m}$ and $\mathrm{k}$ when $\mathrm{fc}$ varies widely within a series of tests, so $\mathrm{f}_{\mathrm{c}}$ has been omitted from Eq.2.4. A comparison of the two methods by (Johnson and Anderson, 2004) has shown that this has little effect on $\mathrm{m}$; but the two equations give different values for $\mathrm{k}$, in different units.

A value found by, for example, the method of (British Standards Institution, 1994) cannot be used in design to Eurocode 4; but a new value can sometimes be determined from the original test data (Johnson, 2004).

A typical set of tests consists of a group of three, with $L_{s} / d_{p}$ such that the results lie near point A on Fig.2.10, and a second group with lower $L_{s} / d_{p}$, such that the results lie near point $\mathrm{B}$. Values of $\mathrm{m}$ and $\mathrm{k}$ are found for a line drawn below the lowest result in each group, at a distance that allows for the scatter of the test data.

All six failures have to be in longitudinal shear. These failures typically commence when a crack occurs in the concrete under one of the load points, associated with loss of bond 
along the shear span and measurable slip at the end of the span. If this leads to failure of the slab, the shear connection is classified as 'brittle'. Such failures occur suddenly, and are penalised in design to (British Standards Institution, 1994) by a $20 \%$ reduction in design resistance. Where the eventual failure load exceeds the load causing a recorded end slip of $0.1 \mathrm{~mm}$ by more than $10 \%$, the failure is classified as 'ductile'. Recentlydeveloped profiles for sheeting have better mechanical interlock than earlier shapes, which relied more on frictional interlock and were more susceptible to 'brittle' failure. The influence of bond is minimised, in the standard test, by the application of several thousand cycles of repeated loading up to $60 \%$ of the expected failure load, before loading to failure.

When a new profile is developed, values of $\mathrm{m}$ and $\mathrm{k}$ have to be determined, in principle, for each thickness of sheeting, each overall depth of slab to be used, and for a range of concrete strengths. Codes allow some simplification, but the testing remains a long and costly process (Johnson and Anderson, 2004).

\subsubsection{Defects of the $\mathrm{m}-\mathrm{k}$ Method}

The method has proved to be an adequate design tool for profiles with short spans and rather brittle behaviour, which have been widely used in North America. However, to exploit fully the ductile behaviour of profiles now available, with good mechanical interlock and longer spans, it is necessary to use a partial-interaction method, as explained below. 
The defects of the $m-k$ method and of profiles with brittle behaviour are given in papers that set out the new methods, by (Bode \& Sauer born, 1993 and Patrick \& Bridge, 1990). They are as follows.

- The $\mathrm{m}-\mathrm{k}$ method is not based on a mechanical model, so that conservative assumptions have to be made in design when the dimensions, materials or loading differ from those used in the tests.

- Many additional tests are needed before the range of application can be extended; for example, to include end anchorage or the use of longitudinal reinforcing bars.

- The method of evaluation of test data is the same, whether the failure is brittle or ductile. The use in (British Standards Institution, 1994) of a penalty factor of 0.8 for brittle behaviour does not adequately represent the advantage of using sheeting with good mechanical interlock, because the advantage increases with span.

- The method does not allow correctly for the beneficial effect of friction above supports, which is greater in short shear spans.

\subsubsection{Partial-interaction Design}

This method is based on results from shear-bond tests (Bode and Sauer born 1993). For composite slabs of given cross-section and materials, the result of each test on a profile with ductile behaviour enables the degree of partial shear connection in that test to be calculated. This gives the compressive force, $N_{c}$, transferred from the sheeting to the slab within the shear span of known length, $\mathrm{L}_{\mathrm{s}}$. It is assumed that, before maximum load is reached, there is complete redistribution of longitudinal shear stress at the interface, so a value for the mean ultimate shear stress, $\tau u$, can be calculated. This is done for a range of 
shear spans, and the lowest $\tau u$ thus found is the basis for a design value, $\tau u R d$. This is where the greater effect of friction in short spans is neglected. At an end support, the bending resistance of the slab is that of the sheeting alone (unless it is enhanced by the use of end anchorage, as described later). At any cross-section at distance $\mathrm{x}$ from the support, the compressive force in the slab can be calculated from, $\tau u R d$. This force may optionally be increased by $\mu R_{E d}$, where $\mu$ is a coefficient of friction and $R_{E d}$ is the support reaction. The partial-interaction method enables the bending resistance, $M_{R d}$, at that cross-section to be calculated. There may be a mid-span region where full shear connection is achieved and $M_{R d}$ is independent of $x$. For safe design, this curve of $M_{R d}$ as a function of $\mathrm{x}$ (the resistance diagram) must at all points lie above the bending-moment diagram for the applied loading. If the loading is increased until the curves touch, the position of the point of contact gives the location of the cross-section of flexural failure and, if the interaction is partial, the length of the shear span. The resistance diagram can easily be modified to take advantage of any end anchorage or slab reinforcement, and the loading diagram can be of any shape.

The only type of end anchorage for which design rules are given in British or European codes is the headed stud, welded through the sheeting to the top flange of a steel beam. The resistance of the anchorage is based on local failure of the sheeting, as explained elsewhere (Johnson and Anderson, 2004). 


\subsection{Properties of Materials}

Information on the properties of structural steel, profiled sheeting, concrete and reinforcement is readily available. Only that which has particular relevance to composite structures is given here.

In the determination of the bending moments and shear forces in framed structure (known as 'global analysis'), all the materials can be assumed to behave in a linear-elastic manner, though an effective modulus is used for the concrete to allow for its creep under sustained compressive stress. Its tensile strength need not be taken as zero, provided account is taken of reductions of stiffness caused by cracking. The effects of its shrinkage are rarely significant in buildings.

Rigid-plastic global analysis can sometimes be used despite the profound difference between a typical stress-strain curve for concrete in compression and those for structural steel or reinforcement, in tension or compression, that is illustrated in Fig.2.11.

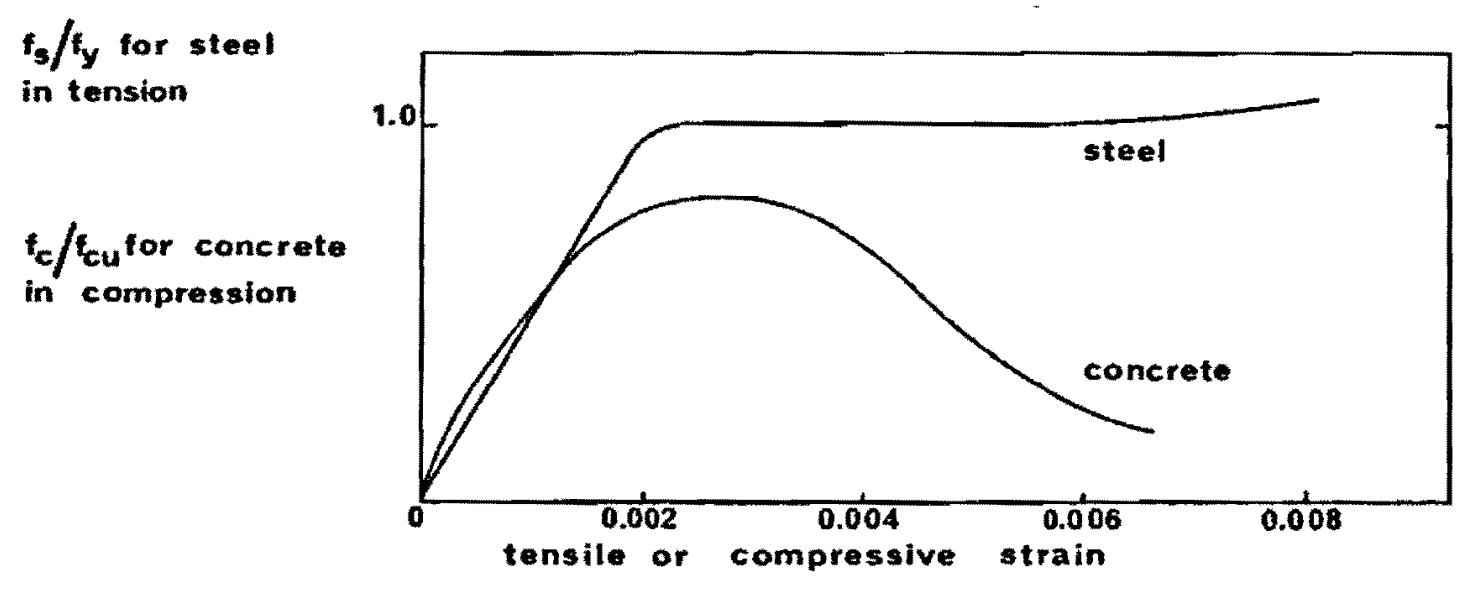

Fig. 2.11. Stress - Strain curve for steel and concrete (Johnson, 1994)

Concrete reaches its maximum compressive stress at a strain of between 0.002 and 0.003 , and at higher strains it crushes, losing almost all of its compressive strength. It is very brittle in tension, having a strain capacity of only about 0.0001 (i.e., $0.1 \mathrm{~mm}$ per meter) 
before it cracks. Fig.2.11 also shows that the maximum stress reached by concrete in a beam or column is well below its cube strength.

Steel yields at a strain similar to that given for the maximum stress in concrete, but on further straining the stress continues to increase slowly, until (for a typical structural steel) the total strain is at least thirty times the yield strain. Its subsequent necking and fracture is of little significance for composite members because the useful resistance of a cross-section is reached when all of the steel has yielded, when steel in compression buckles, or when concrete crushes.

Resistances of cross-sections are determined using plastic analysis wherever possible because results of elastic analyses are unreliable, unless careful account is taken of the cracking, shrinkage, and creep of concrete which is difficult and also because plastic analysis is simpler and leads to more economical design The use of a higher value of $\gamma \mathrm{M}$ for concrete than for steel includes allowance for the higher variability of the strength of test specimens, and the variation in the strength of concrete over the depth of a member, due to migration of water before setting. It also allows for the larger errors in the dimensions of cross-sections, particularly in the positions of reinforcing bars.

\subsection{Criteria for the Testing of Composite Slabs}

Design criteria, based on limit states, for composite slabs made of a structural concrete placed permanently over composite steel deck. See Canadian Steel Sheet Building Institute (CSSBI) 12M: Standard for Composite Steel Deck for information on the steel deck acting as a form during construction. See CSSBI S2-2008: Criteria for the Testing of Composite Slabs for information concerning testing of composite slabs. The full 
capacity of the composite slab is not achieved until the concrete has attained its specified compressive strength.

\subsubsection{Limit State of Strength}

The strength of a composite slab is usually limited by one of the following resistance limit states: (a) shear-bond; (b) flexure of an under-reinforced section; (c) flexure of an over-reinforced section; and (d) punching shear with concentrated loads.

\subsubsection{Loads and Safety Criterion}

All factored resistances determined herein shall be equal to or greater than the effect of the factored loads, determined in accordance with the National Building Code of Canada 2005.

\subsubsection{Resistance Factors}

The following resistance factors shall apply:

Shear - bond $\quad \emptyset v=0.70$

Steel deck $\quad \emptyset s=0.90$

Concrete $\quad \emptyset c=0.65$

\subsubsection{Shear-Bond Resistance}

The ultimate shear-bond resistance of a composite slab section shall be calculated using parameters determined from a testing program of full-scale slab specimens. The factored shear-bond resistance $\left(V_{r}\right)$ of a composite slab shall be determined by the following expression: 


$$
V r=\emptyset v V t
$$

Where,

$V_{\mathrm{r}}=$ factored shear-bond resistance, $\mathrm{N} / \mathrm{m}$ of slab width

$V_{t}=$ tested shear-bond resistance, $N / m$ of slab width

The basic equation used to determine the tested shear-bond resistance is one of the following:

$V t=b d p\left[\frac{k 1 t}{l^{\prime}}+\frac{k 2}{l^{\prime}}+k 3 t+k 4\right]$

Or

$V t=b d p\left[k 5 / l^{\prime}+k 6\right]$

Where,

$\mathrm{b}=$ unit slab width $=1000 \mathrm{~mm}$

$d_{p}=$ effective slab depth (distance from extreme concrete compression fiber to centroidal axis of full cross-section of steel deck), mm

$\mathrm{l}^{\prime}=$ shear span, $\mathrm{mm}$; for uniform load, $\mathrm{l}^{\prime}$ is one quarter of the span

$\mathrm{t}=$ base steel design thickness, $\mathrm{mm}$

$\mathrm{k} 1, \mathrm{k} 2, \mathrm{k} 3$, and $\mathrm{k} 4$ are shear-bond coefficients obtained from a multi-linear regression analysis of test data from three or more deck thicknesses

$\mathrm{k} 5$ and $\mathrm{k} 6$ are shear-bond coefficients obtained from a linear regression analysis of test data for one individual deck thickness testing procedures used to determine the shearbond coefficients are given in CSSBI S2- 2008 Criteria for the Testing of Composite Slabs. 


\subsubsection{Flexural Resistance}

Composite slabs subject to flexural failure are generally classified as under-reinforced or over-reinforced slabs depending on the compression depth ratio, (c/d). Slabs with (c/d) less than the balanced condition ratio (c/d)b are considered under-reinforced, whereas slabs with (c/d) greater than or equal to (c/d)b are considered over reinforced. The actual ratio is:

$c / d=\frac{\emptyset s A s f y}{\alpha 1 \emptyset c f c^{\prime} d p b \beta 1}$

Whereas the ratio that denotes a balanced condition is:

$$
(c / d) b=\frac{711(h-d p)}{(711+f y) d p}
$$

. Where,

$A_{s}=$ area of steel deck, $\mathrm{mm} 2 / \mathrm{m}$ of slab width

$b=$ unit width of compression face of composite slab (1000 mm)

$\mathrm{c}=$ distance from extreme compression fiber to composite neutral axis, $\mathrm{mm}$

$\mathrm{d}=$ distance from extreme compression fiber to centroid of steel deck, $\mathrm{mm}$

$d_{p}=$ overall depth of steel deck profile, $\mathrm{mm}$

$\mathrm{f}_{\mathrm{c}}{ }^{\prime}=$ specified compressive strength of concrete, $\mathrm{MPa}$

$f_{y}=$ specified yield strength of steel deck, MPa

$\mathrm{h}=$ nominal out-to-out depth of slab, $\mathrm{mm}$

$1=0.85-0.0015 f_{c}{ }^{\prime} \geq 0.67$

$1=0.97-0.0025 f_{\mathfrak{c}}{ }^{\prime} \geq 0.67$ 


\subsubsection{Factored Moment resistance}

\subsubsection{Under-reinforced Slabs $(c / d)<(c / d) b$}

The factored moment resistance, in positive bending, of an under-reinforced composite slab shall be taken as:

$M r u=\emptyset s A s f y(d-a / 2)$

Where,

$$
a=\frac{\emptyset s A s f y}{\alpha 1 \emptyset c f c^{\prime} b}
$$

Eq.2.10 is valid only for composite slabs capable of developing the yield stress over the entire deck section. In some instances the strain compatibility of the slab cross-section or the ductility of the steel does not permit yielding over the entire deck section. Eq-10 does not account for steel reinforcement in addition to the steel deck and does not account for the case where a portion of the deck section lies on the compression side of the composite slab neutral axis. For those cases where Eq.2.10 does not apply, the factored moment resistance shall be based on a detailed strain compatibility analysis.

\subsubsection{Over-reinforced Slabs $(c / d) \geq(c / d) b$}

The factored moment resistance, in positive bending, of an over-reinforced composite slab shall be determined by:

Mro $=\alpha 1 \emptyset c f c^{\prime} b \beta 1 c(c-\beta 1 c / 2)$

Where,

$c=d\left\{\sqrt{\rho m+\left(\frac{\rho m}{2}\right)^{2}}-\rho m / 2\right\}$ 
$\rho=\frac{A s}{b d p} ; \quad m=\frac{\emptyset s E s \varepsilon c u}{\alpha 1 \emptyset c f c^{\prime} \beta 1}$

$\mathrm{E}_{\mathrm{s}}=203000 \mathrm{MPa} ; \varepsilon \mathrm{cu}=0.0035$

Eq.2.11 is valid only for composite slabs where no part of the steel deck has yielded. If yielding of the steel deck does occur, $\mathrm{M}_{\mathrm{ro}}$ may be determined by a detailed strain compatibility analysis and/or test.

\subsubsection{Continuous Slabs}

Where composite slabs are designed for continuity over supports, the factored moment resistance in negative bending shall be determined as in conventional reinforced concrete design in accordance with CSAA23.3, Design of Concrete Structures. The contribution of the portion of the composite steel deck in compression may be neglected.

\subsubsection{Two-Way Action}

In slabs requiring two-way action for load distribution, the flexural resistance in the direction transverse to the deck corrugations needs to be calculated. The following two cases apply for the determination of this resistance:

a) Where no supplementary transverse reinforcement is provided, the flexural strength shall be taken as that of the plain concrete section above the corrugations. Any contribution from the steel deck is neglected.

b) Where supplementary transverse reinforcement is provided in the tension zone, Eq-10 shall be used if the slab is under-reinforced. The area of steel, As, shall consist entirely of the supplementary reinforcement, and only the concrete section above the deck corrugations shall be considered effective, unless tests indicate conclusively that other assumptions are valid. The effective width of the slab in the transverse direction shall be determined from tests or detailed analysis. 


\subsubsection{Punching Shear Resistance}

The critical surface for calculating punching shear shall be perpendicular to the plane of the slab and located outside of the periphery of the concentrated load or reaction area but not further than $0.50 \mathrm{hc}$ from the periphery of the concentrated load or reaction area.

The factored punching shear resistance, $\mathrm{Vpr}$, shall be determined as follows:

$V p r=(1+2 / \beta c) 0.2 \varnothing c \lambda \sqrt{f c^{\prime}} b o h c$

Where,

$\mathrm{bo}=$ perimeter of critical section, $\mathrm{mm}$

hc=thickness of concrete cover above steel deck, $\mathrm{mm}$

$\beta c \quad$ = ratio of long to short side of concentrated load or reaction area

$\lambda=1.00$ for normal density structural concrete

$=0.85$ for semi-low density structural concrete

$=0.75$ for low density structural concrete.

In lieu of Eq.2.12, the punching shear resistance may be determined from tests.

\subsubsection{Deflection Criteria}

\subsubsection{Flexural Properties for Deflection Calculations}

Composite flexural section properties needed to determine vertical deflections of composite slabs shall be computed in accordance with conventional elastic theory applied to reinforced concrete, transforming steel areas to equivalent areas of concrete.

The following assumptions permit derivation of the necessary relationships:

1 Plane sections remain plane after bending;

2 Stresses are proportional to strain in both concrete and steel at specified loads; 
3 The entire steel cross section is utilized except as reduced by holes;

4 The moment of inertia used in deflection calculations, Id, shall be taken as the average of the cracked, Ic, and uncracked sections, Iu, using the design depth of the slab.

\subsubsection{Deflection Limitations}

Consideration needs to be given to both immediate and long-time loading. Computed maximum deflections shall be based on the assumptions of 2.7.10.1. Maximum permissible computed deflections are listed in Table.2.1. Additional deflection caused by creep shall be calculated by multiplying the immediate deflection due to the sustained load by the following factor:

$2.0:$ for load duration of 3 months

2.2 : for load duration of 6 months

2.4 : for load duration of 1 year

$3.0:$ for load duration of 5 years or more.

\begin{tabular}{|c|c|c|}
\hline Type of Member & Deflection to be Considered & $\begin{array}{l}\text { Deflection } \\
\text { Limitation }\end{array}$ \\
\hline $\begin{array}{l}\text { Floors not supporting or attached to } \\
\text { nonstructural elements likely to } \\
\text { damage by large deflection }\end{array}$ & $\begin{array}{l}\text { Immediate deflection due to specified live load. } \\
\qquad L\end{array}$ & Span $/ 360$ \\
\hline $\begin{array}{l}\text { Roof or floor construction supporting } \\
\text { or attached to nonstructural elements } \\
\text { likely to damage by large deflection }\end{array}$ & \multirow{2}{*}{$\begin{array}{l}\text { The part of the total deflection occurring after } \\
\text { attachment of nonstructural elements (sum of } \\
\text { long time deflection due to all sustain loads and } \\
\text { the immediate deflection due to additional live } \\
\text { load }\end{array}$} & Span $/ 480$ \\
\hline $\begin{array}{c}\text { Roof or floor construction supporting } \\
\text { or attached to nonstructural elements } \\
\text { not likely to damage by large } \\
\text { deflection }\end{array}$ & & Span $/ 240$ \\
\hline
\end{tabular}

Table.2.1: Maximum permissible deflection 
Table 2.1 is duplicate of Table 9-3 of CSA-A23.3-04 except with minor changes. The following applies for Table 2.1:

- (Limit not intended to safeguard against ponding. Ponding should be checked by suitable calculations of deflection, including added deflections due to ponded water, and considering long-time effects of all sustained loads, and reliability of provisions for drainage.

- Limit may be exceeded if adequate measures are taken to prevent damage to supported or attached elements.

- Long-time deflections are determined in accordance with Clause 9.8.2.5. or 9.8.4.4 in CSA-A23.3-04 and may be reduced by the amount of deflection calculated to occur before the attachment of nonstructural elements. This amount shall be determine on the basis of accepted engineering data relating to time deflection characteristics of composite slab systems similar to those being considered.

\subsubsection{NBC Concentrated Load Criteria}

The National Building Code of Canada requires that floors be designed for specified concentrated live load acting on an area of 750 by $750 \mathrm{~mm}$. With a composite slab system, there will be some lateral distribution of a concentrated load due to the steel deck acting as slab reinforcement. The exact extent to which a concentrated load is distributed depends on a number of factors; however, it can be assumed that the load is distributed down to the center of gravity of the steel deck. This will give a resulting load distribution area of $(750+2 d)$ by $(750+2 d) \mathrm{mm}$. Fig. 2.12 illustrates this loading condition. 


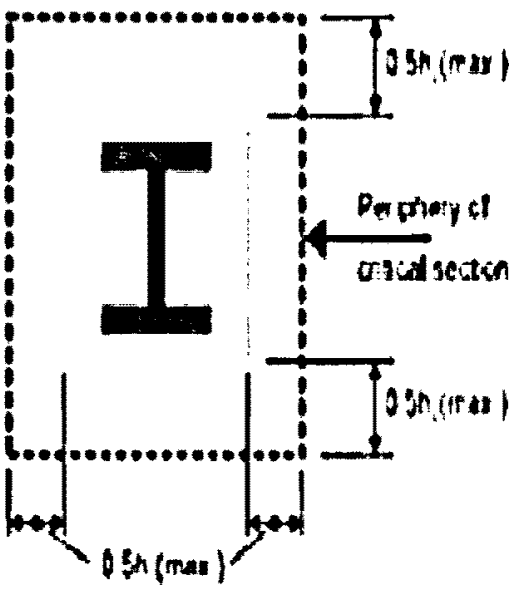

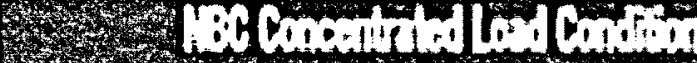

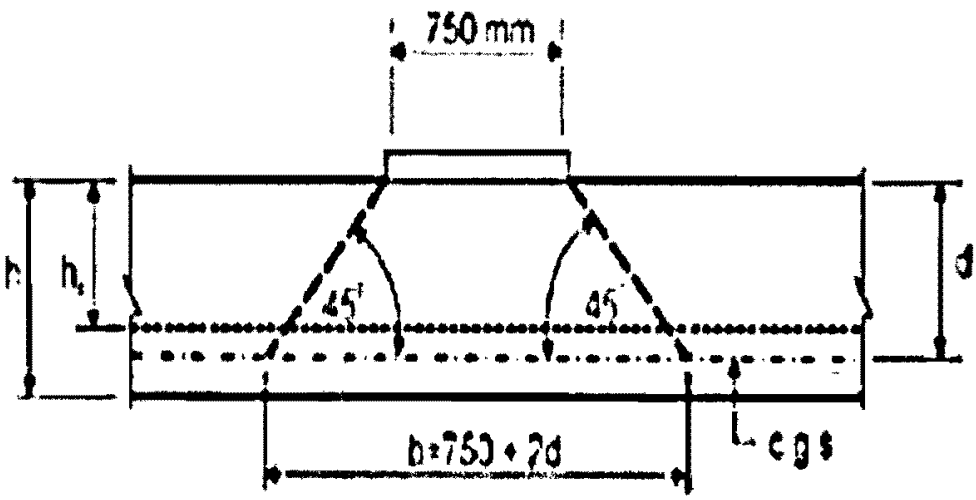

Fig.2.12: Loading condition 


\subsubsection{Repeated or Vibratory Loading}

Where repeated or vibratory loading is a factor, adequate test data to substantiate the suitability of the composite slab involved is necessary.

\subsubsection{Shrinkage and Crack Control Reinforcement}

Composite slabs shall have minimum shrinkage and temperature reinforcement in accordance with Table.2.2 unless a greater amount is required by the specified fire resistance rating. Where designed for continuity over structural supports, composite slabs shall have negative moment reinforcement as required in conventional reinforced concrete. When the composite slab is not designed for continuity over structural supports, the effects of cracking of the concrete shall be considered and adequate crack control measures shall be taken where necessary.

\begin{tabular}{|c|c|}
\hline \multicolumn{2}{|c|}{ Minimum Shrinkage and Temperature Rein forcement } \\
\hline Concrete Cover $h_{\mathfrak{c}}=\left(\mathrm{h}-\mathrm{d}_{\mathrm{d}}\right)(\mathrm{mm})$ & $\begin{array}{c}\text { Minimum Area of Reinforcement Required } \\
\left(\mathrm{mm}^{2} / \mathrm{m} \text { of slab width }\right)\end{array}$ \\
\hline $\mathrm{h}_{\mathrm{c}} \leq 80$ & 60 \\
\hline $80 \leq \mathrm{h}_{\mathrm{c}} \leq 80$ & $(3 \mathrm{hc}-180)$ \\
\hline $150 \leq \mathrm{h}_{\mathrm{c}}$ & Span $/ 240$ \\
\hline
\end{tabular}

Table.2.2: Minimum shrinkage and temperature reinforcement for composite slabs

The following notes apply:

- Shrinkage and temperature reinforcement alone is not intended to resist negative bending moments. Additional reinforcement must be provided as required by a structural design if negative bending is to be resisted. 
- The recommended minimum temperature and shrinkage reinforcement, usually in the form of welded wire mesh, if properly placed and if good concreting practices such as low water/cement ratio, low slump and proper curing are followed, will often be sufficient to cause the shrinkage and temperature stresses to be relieved in small local cracks rather than accumulating over greater distances. It is recommended that the mesh be placed approximately $25 \mathrm{~mm}$ below the top surface of the concrete, particularly in areas of negative moments, such as over supports where bending stresses in the top portion of the concrete add to the shrinkage.

- For applications where a higher degree of crack control is required, the designer should refer torecognized standards of concrete practice and design such as CSAA23.3. 


\section{Chapter 3: Experimental Investigations}

\subsection{Introduction}

In this study, Composite slabs were fabricated with two different types of profiled steel sheeting supplied by CANAM, Canada in combination with two different HPC concrete topping. This chapter provides experiments conducted on composite slabs to studying the steel-concrete interface shear bond and its influence on the overall structural behavior of the system (such as shear resistance, interface slippage, deflection, failure modes) taking into account concrete and steel sheet types and variable shear span.

\subsection{Profile Steel Sheeting}

Two types of profiled steel sheeting with different specifications designated as Type-A and Type-B were used to construct composite slab specimens in Structures and Materials Laboratories of Ryerson University.

\subsubsection{Specifications of Sheet Type-A (P-3012):}

Type A sheet was P-3012 deck manufactured by Canam Canada. The sheet is galvanized according to the standard ASTM A 653M with zinc thickness corresponding to Z275 (G90) having standard thicknesses of $0.38 \mathrm{~mm}$. The flutes are $14 \mathrm{~mm}$

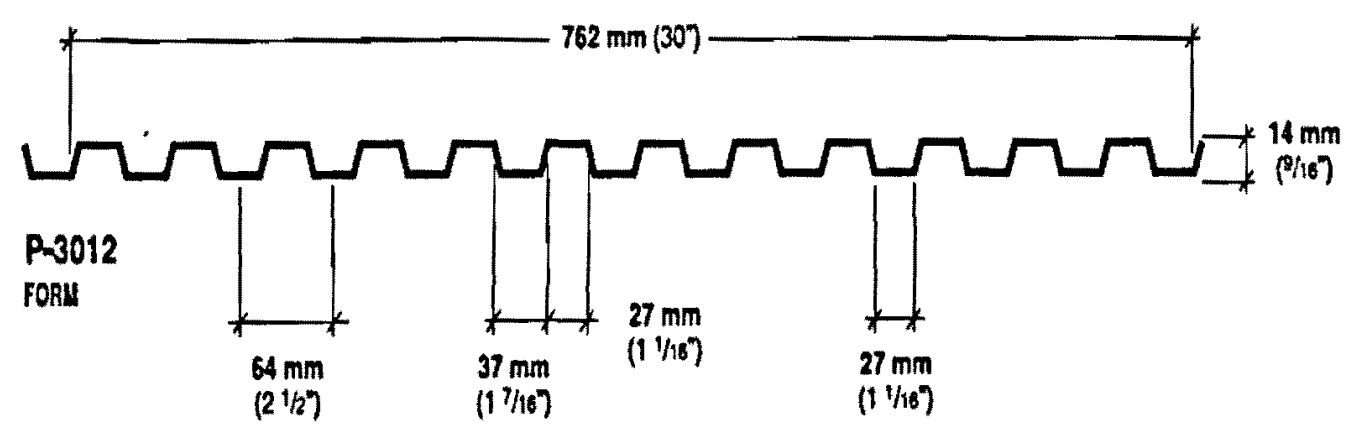

Fig.3.1 Sheet Type - A (Continue) 


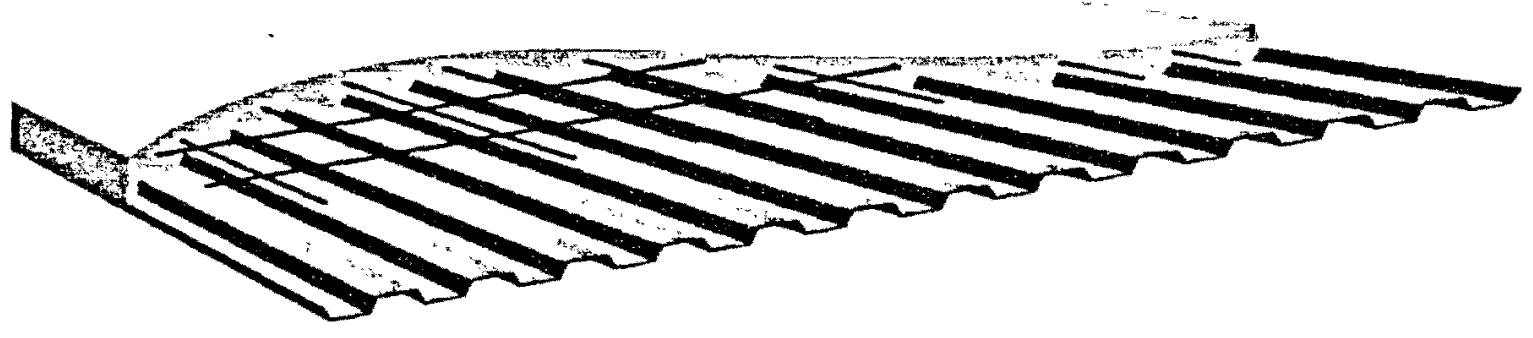

Fig.3.1 Sheet Type - A

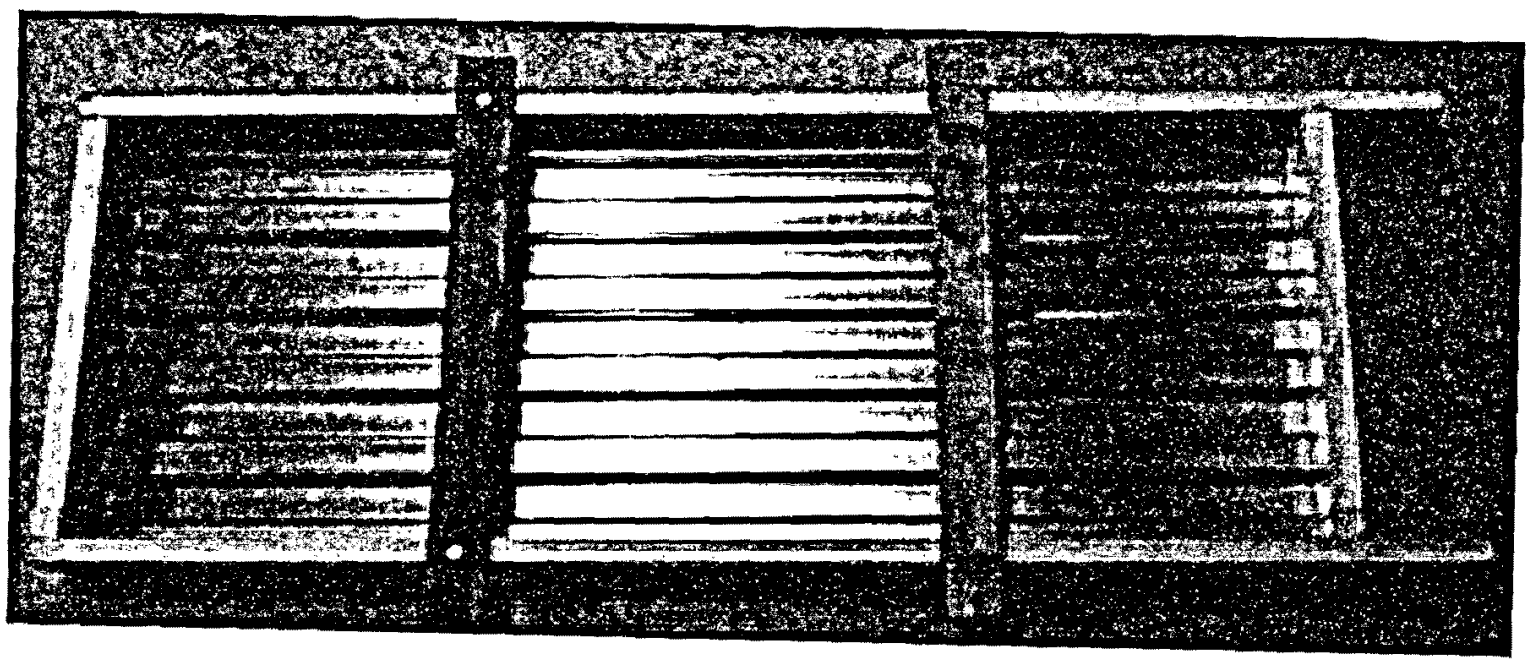

Fig.3.2 Sheet Type - A

(9/16 in.) deep and are spaced at $64 \mathrm{~mm}$ ( 2.5 in.) center to center. The sheet length deck can be rolled to lengths as per the requirement or stocked in $6200 \mathrm{~mm}$ (20 ft. $4 \mathrm{in}$.) length to cover multiple spans. Steel grade conforms to ASTM A $653 \mathrm{M}$ with a minimum yield strength of $410 \mathrm{MPa}$ (60 ksi). 


\subsubsection{Specifications of Sheet Type-B (P-3165):}

This is Canam P-3165 deck with embossemnts. The deck is available with a galvanized coating according to the standard ASTM A $653 \mathrm{M}$ with zinc thickness corresponding to Z275 (G90) nominal thicknesses of $0.76 \mathrm{~mm}$ (0.030 in.), $0.91 \mathrm{~mm}(0.036 \mathrm{in}$.) and 1.21 $\mathrm{mm}(0.048 \mathrm{in}$.). The flutes are $38 \mathrm{~mm}(1.5 \mathrm{in}$.) deep and are spaced at
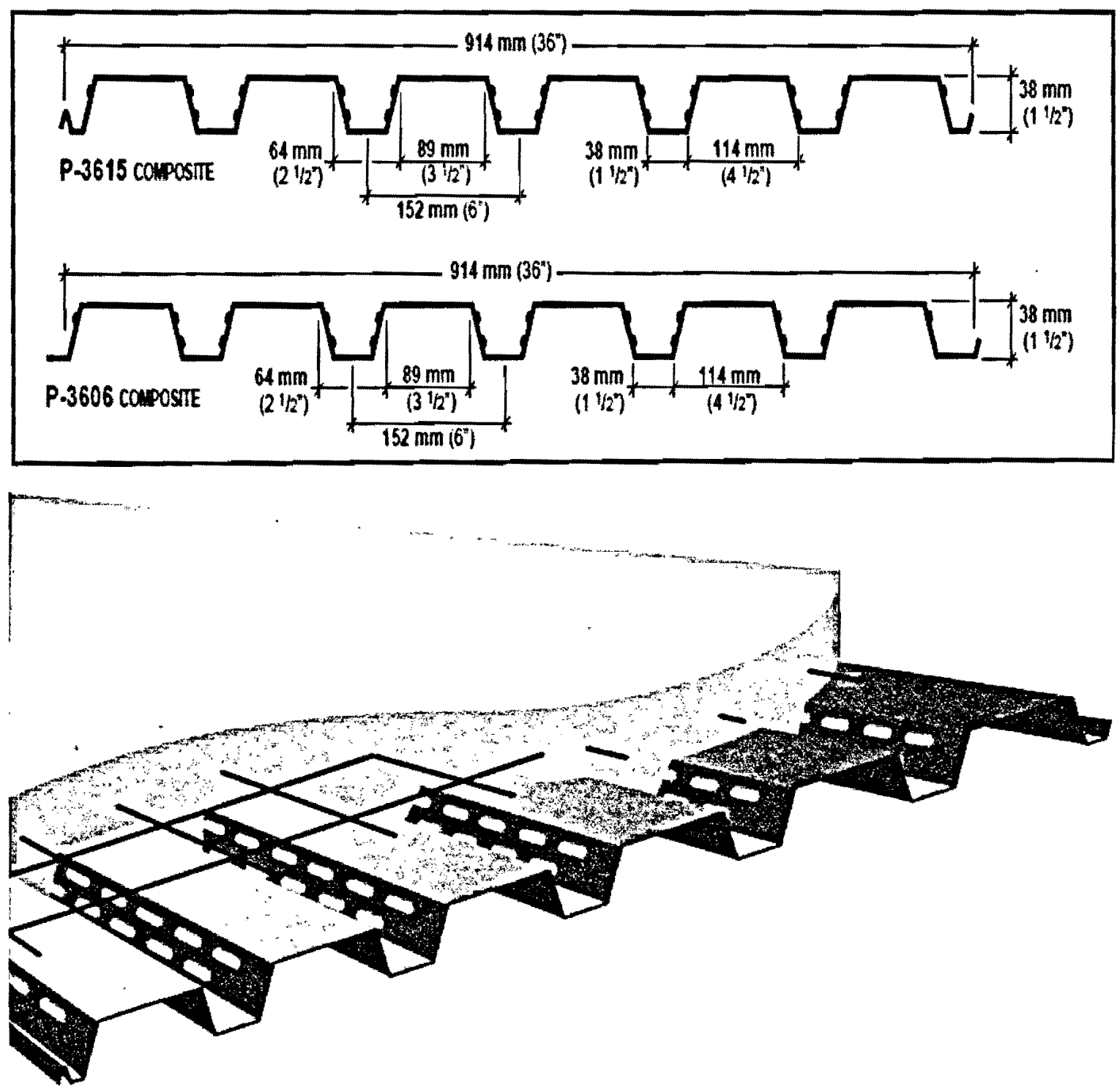

Fig.3.3: Sheet Type-B 
$152 \mathrm{~mm}(6 \mathrm{in}$.) center to center. The deck can be rolled to lengths from $1800 \mathrm{~mm}(6 \mathrm{ft}$.) to $12200 \mathrm{~mm}$ ( $40 \mathrm{ft}$.). Standard steel grade conforms to ASTM A 653M SS Grade 230 with a yield strength of $230 \mathrm{MPa}(33 \mathrm{ksi})$

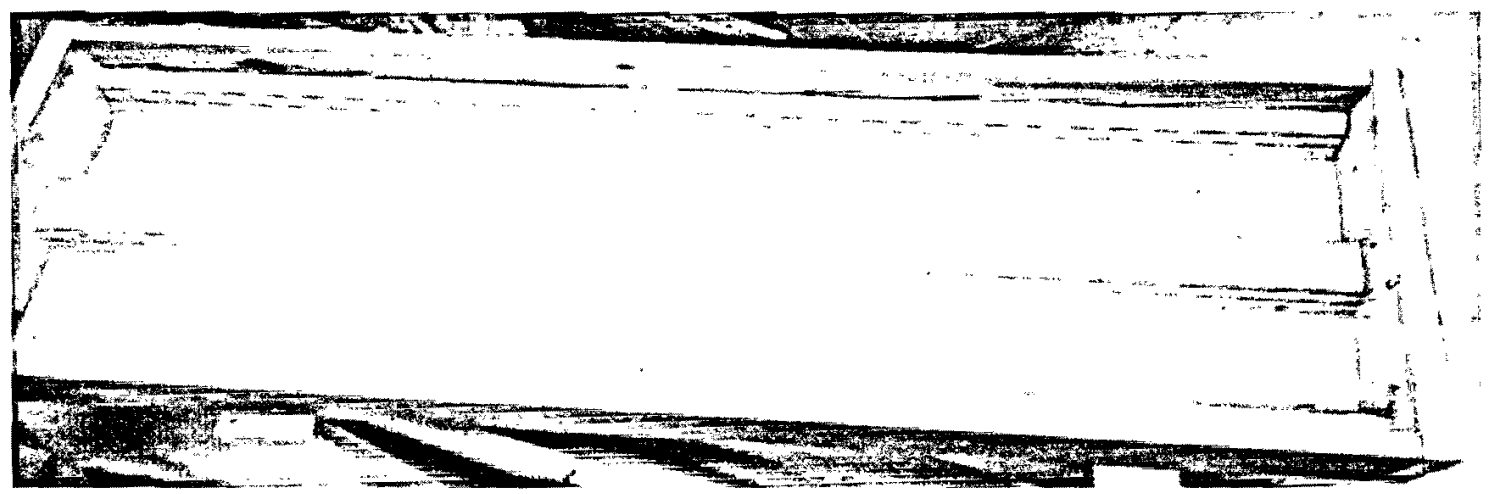

Fig.3.4: Sheet Type-B

\subsection{HPC Concrete Materials}

Two types of HPC mixes were used- one Self Consolidating Concrete (SCC) and the other Engineered Cementitious composites (ECC).

SCC was made with Type GU Portiand cement (Type 1), Types S slag cement (GranCem), $8 \mathrm{~mm}$ maximum size crushed limestone, Edgar sand, air-entraining admixtures and SP-1466 super plasticizer. SCC was designed to have target compressive strength of $40 \mathrm{MPa}$.

ECC mix was made with Type I Portland cement $\left(375 \mathrm{~kg} / \mathrm{m}^{3}\right)$, Fly ash $\left(823 \mathrm{~kg} / \mathrm{m}^{3}\right)$, polyvinyl alcohol fiber (PVA) $\left(26 \mathrm{~kg} / \mathrm{m}^{3}\right)$, sand $\left(435 \mathrm{~kg} / \mathrm{m}^{3}\right)$, super-plasticizer $\left(2 \mathrm{~kg} / \mathrm{m}^{3}\right)$ and water binder ratio of 0.27 . Solid ingredients, including cement, fly ash (FA), and sand, were first mixed for a minute. Water and chemical admixtures (super-plasticizer, SP) were then added into the dry mixture and mixed for two minutes and then PVA fiber 
was added in last and mixed for an additional three minutes. ECC mix was defined to achieve a target compressive strength of 55MPa.

\subsection{Composite Slabs details, Instrumentation and Testing}

A total of 15 composite slabs with $820 \mathrm{~mm}$ length and $320 \mathrm{~mm}$ width were fabricated and tested. Typical composite slab specimens are shown in Fig.3.5.
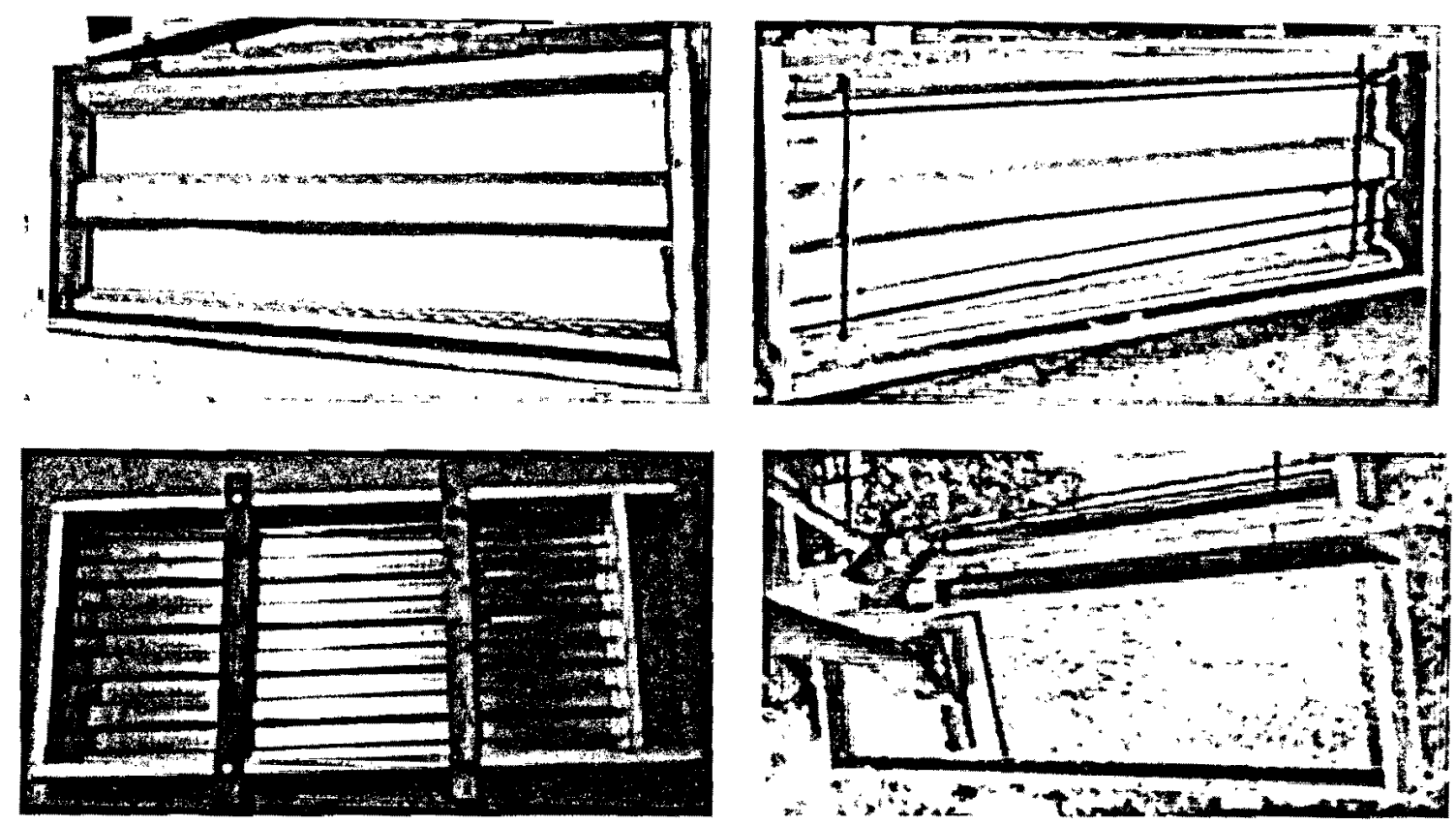

Fig.3.5: Composite slab specimens

The slabs were divided into two sets as per concrete mix design, profile sheeting, slab depth and different shear spans as tabulated in Table.3.1. The slabs were designed according to the requirements of the (British Standard Institution, 1994).

\begin{tabular}{|c|c|c|c|c|}
\hline \multicolumn{3}{|c|}{ Concrete sample with Sheet type (P-3012) } & \multicolumn{2}{c|}{ Concrete sample with Sheet type (P-3012) } \\
\hline R/F without welding & R/F With Welding & $\begin{array}{c}\text { R/F without } \\
\text { welding }\end{array}$ & R/F without welding & RF without welding \\
\hline $1 . S C C-01-90-30$ & $4 . E C C W-01-90-30$ & $7 . E C C-01-90-30$ & $10 . S C C-E N-01-90-50$ & $13 . E C C-E N-01-90-50$ \\
\hline $2 . S C C-02-175-30$ & $5 . E C C W-02-175-30$ & $8 . E C C-02-175-30$ & $11 . S C C-E N-02-175-50$ & $14 . E C C-E N-02-175-50$ \\
\hline $3 . S C C-03-175-30$ & $6 . E C C W-03-90-30$ & $9 . E C C-03-90-30$ & $12 . S C C-E N-03-175-50$ & $15 . E C C-E N-03-90-50$ \\
\hline
\end{tabular}

* Temperature and shrinkage reinforcements are spot welded to sheet

Table.3.1: Composite slab specifications 
The test profiled sheet type A: P-3012 and type B: P-3615 had overall depth (Ds) and depth of the profiled sheet $(\mathrm{Dp})$ as shown in e Table. 3.2 .

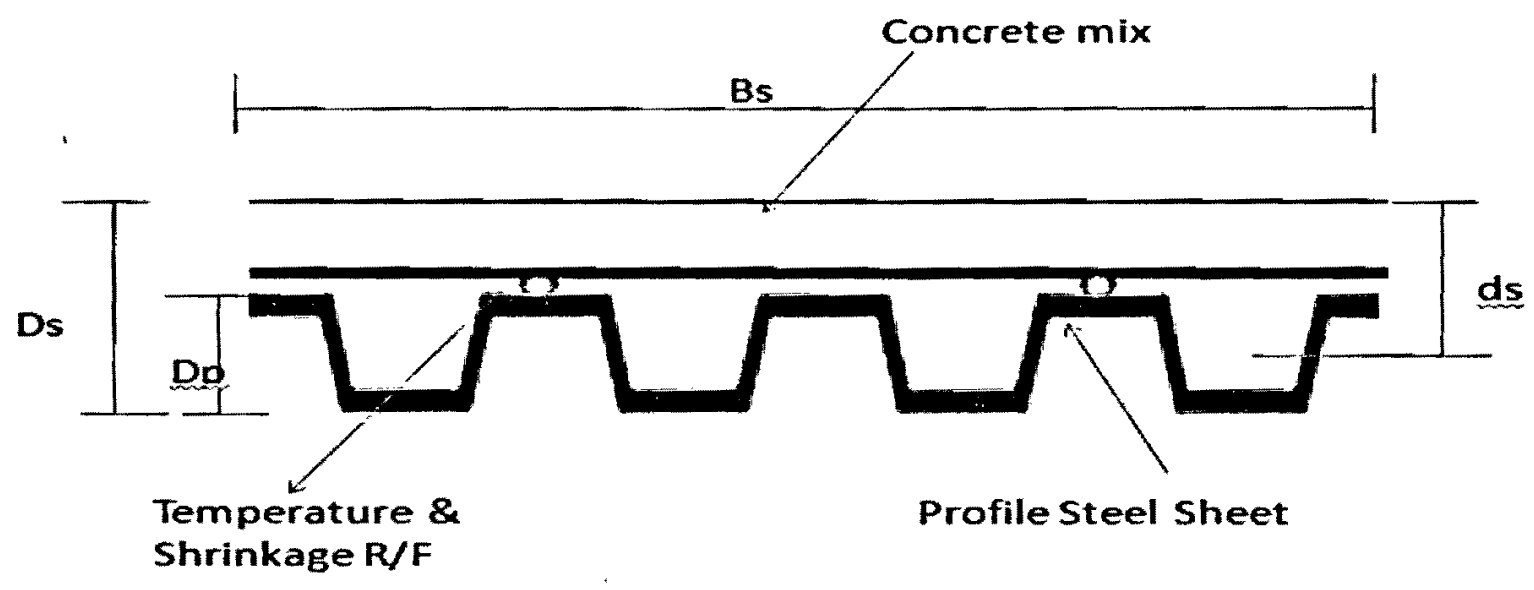

Fig.3.6: Details of a test composite slab

Details of a typical composite slab specimen is shown in Fig. 3.6. Each slab is designated Table.3.1. First number of the designation represents test slab number, followed by letters representing type of concrete, W represents "welded", EN represents "embossed sheet", $90 / 175$ represents shear span length and 30 represents depth of concrete topping. Slabs are designed to study the influence of concrete types (SCC or ECC), sheet types, interface shear transfer mechanisms (through welded reinforcement (R/F), embossments) and variable shear span (90 to $175 \mathrm{~mm}$ ) and slab thickness ( 30 and $50 \mathrm{~mm}$ ).

Water tight formworks were fabricated and used to cast all the slabs Fig.3.5. All the slabs were cured in a curing room for 28 days in the laboratory maintained at $26 \pm 4^{\circ} \mathrm{C}$ and $65-$ $84 \%$ relative humidity.

Composite slabs were tested under simply supported four point loading conditions. Before testing, strain gauges were installed at the center of the steel sheeting soffit and at the center of the concrete surface to capture the strain during loading history. 


\begin{tabular}{|c|c|c|c|c|c|c|c|}
\hline \multirow{2}{*}{$\begin{array}{c}\text { Concrete } \\
\text { Mix } \\
\text { Design }\end{array}$} & $\begin{array}{c}\text { Profile } \\
\text { steel } \\
\text { sheeting } \\
\text { type }\end{array}$ & $\begin{array}{c}\text { Slab } \\
\text { Thickness }\end{array}$ & $\begin{array}{c}\text { Profile } \\
\text { steel }\end{array}$ & $\mathrm{D}_{\mathrm{s}}(\mathrm{mm})$ & $\begin{array}{c}\mathrm{d} \\
\mathrm{d}\end{array}$ & $\begin{array}{c}\text { Cross- } \\
\text { sectional } \\
\text { Area of } \\
\text { sheet }\end{array}$ & \multicolumn{2}{|c|}{ Shear Span } \\
\hline SCC & $\mathrm{m}-3012$ & 30 & 14 & 23 & 382 & 90 & 175 \\
\hline & $\mathrm{P}-3615$ & 50 & 38 & 36 & 1016 & 90 & 175 \\
\hline ECC & $\mathrm{P}-3012$ & 30 & 14 & 23 & 382 & 90 & 175 \\
\hline & $\mathrm{P}-3615$ & 50 & 38 & 36 & 1016 & 90 & 175 \\
\hline
\end{tabular}

Table.3.2: Dimensions of test composite slabs

The vertical deflection (at the center of the slab) and the end slip (between steel and concrete) values at both ends of the slab were measured by LVDTs (linear voltage displacement transducers). All strain gauges and LVDTs were connected to a computerized data logger. The two point load was applied incrementally at the rate $2 \mathrm{~mm}$ vertical deflection per minute up to the failure. The experimental set-up for the composite slab is shown in Fig.3.7a \& Fig.3.7b. Load, central deflection, cracking, crack propagation, strain development in concrete/steel, end slip and overall failure models of the composite slab system were monitored during the entire loading history,

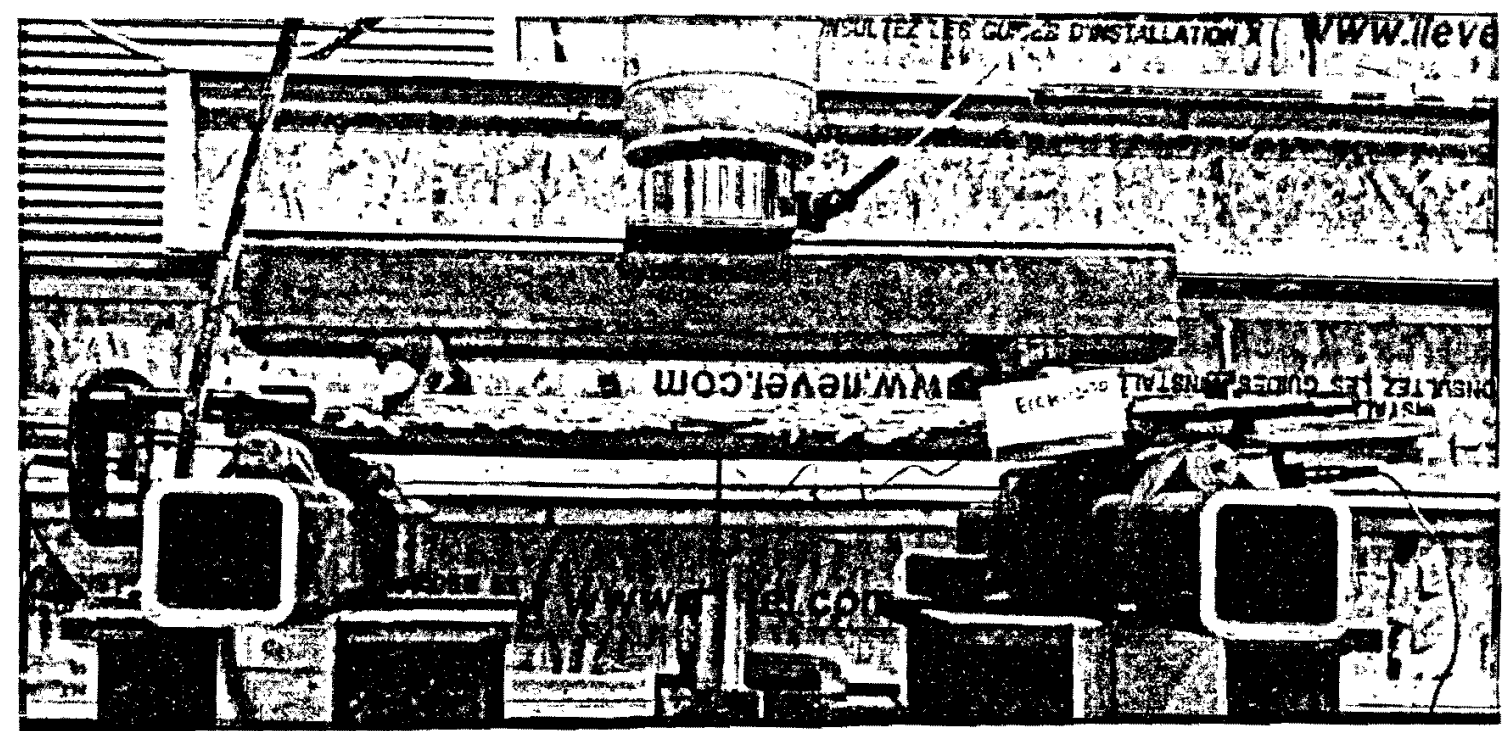

Fig.3.7(a): Experimental test-set: composite slab under four point loading 


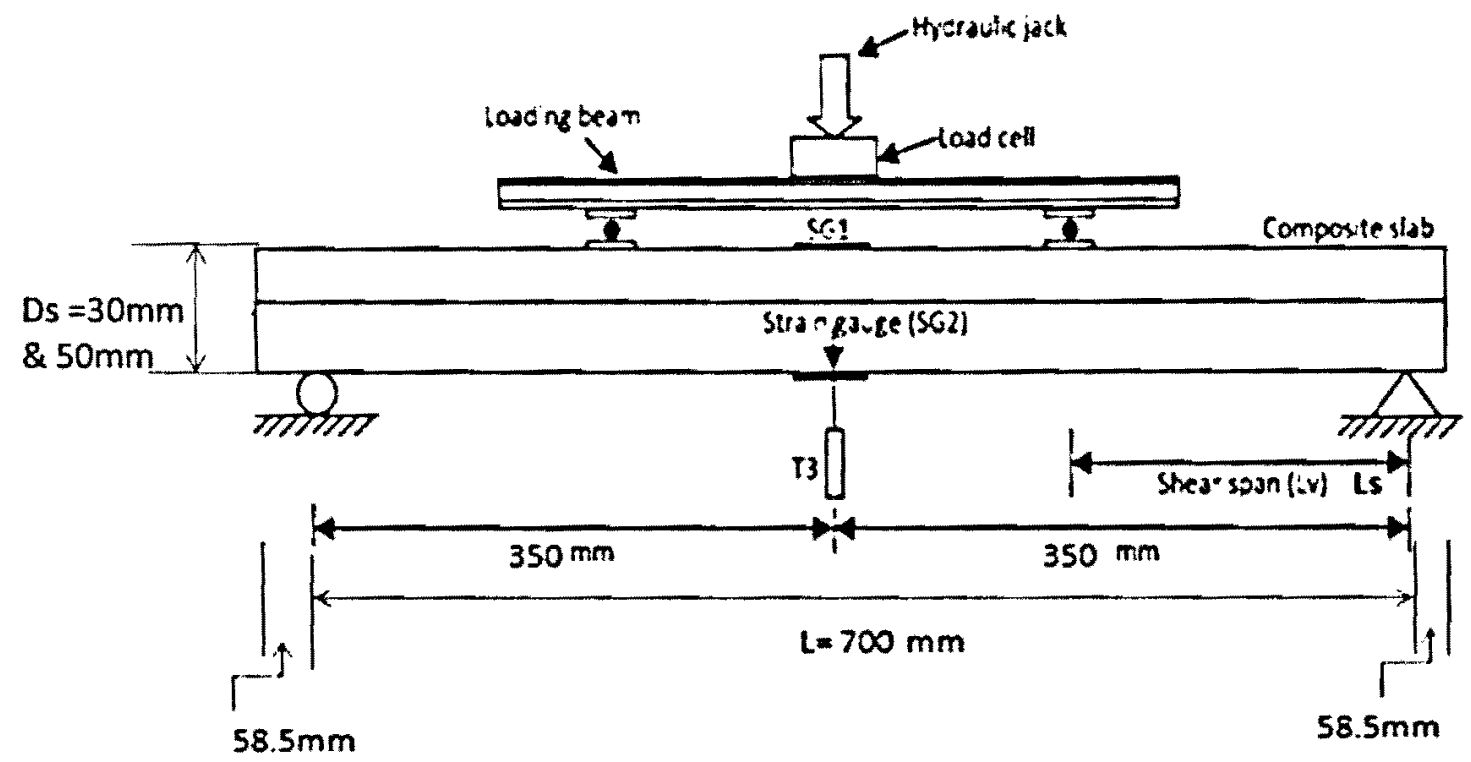

Fig.3.7(b): Experimental test-set: composite slab under four point loading

\subsection{Results and Discussions}

\subsubsection{General observations}

Generally, more steel-concrete slip was observed in ECC slab compared to SCC slab. It was noted that before the initiation of crack, the chemical bond between concrete and profile sheeting become weaker as shown in Fig.3.8. When the load continued to increase, longitudinal cracks across the width of slabs were detected at the interface between profiled steel sheeting and concrete. Cracks began to appear from the interface extending up towards the loading points as load was kept increasing.

The end support began cracking showing signs of loss bond after the first crack. Longitudinal cracks and slips continued to increase extensively below and around the loading points as load increased as shown in Fig. 3.8. Generally, at the moderate load the profiled sheet carried the tensile stresses, which are transferred from the concrete by the 
bond between the two materials. When this bond became not adequate, the separation started to occur between the concrete and the profiled sheet and the slab stopped behaving as a composite section, therefore, the longitudinal cracks (between the profiled sheet and the concrete) had curved up (near the loading point) due to the combination of shear and bending stress in concrete.
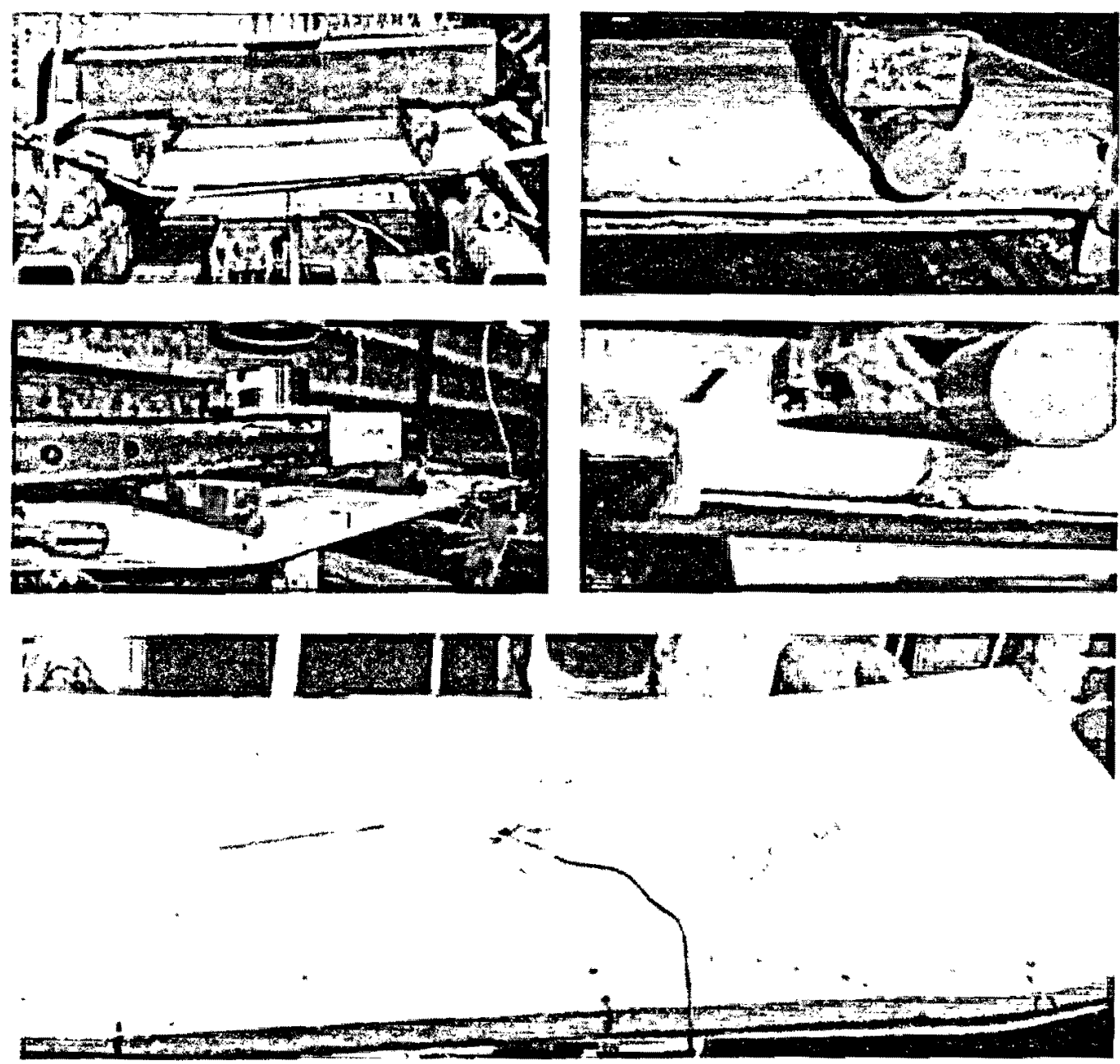

Fig.3.8: Failure mode, steel-concrete separation, cracking and slippage of composite slabs 
Sample-14 with ECC having a shear span $L_{v}=175 \mathrm{~mm}$, had shown slight end slippage at the initiation of the test only. Whereas the maximum slippage at failure load was observed in sample $\# 7$ with ECC having $30 \mathrm{~mm}$ slab thickness and $\mathrm{L}_{\mathrm{v}}=90 \mathrm{~mm}$.

In sample-12 with SCC having $50 \mathrm{~mm}$ slab thickness and $\mathrm{L}_{v}=175 \mathrm{~mm}$, it was observed that as load increased, sound of cracking was heard and longitudinal cracks were propagated from one end of the slab as the end slippage at one end was greater than the other. As load continued to increase, concrete cracking stretched towards the center where they began to crawl up at the middle of the transfer length and area below the point loads. Signs of flexural cracks were more obvious in this slab

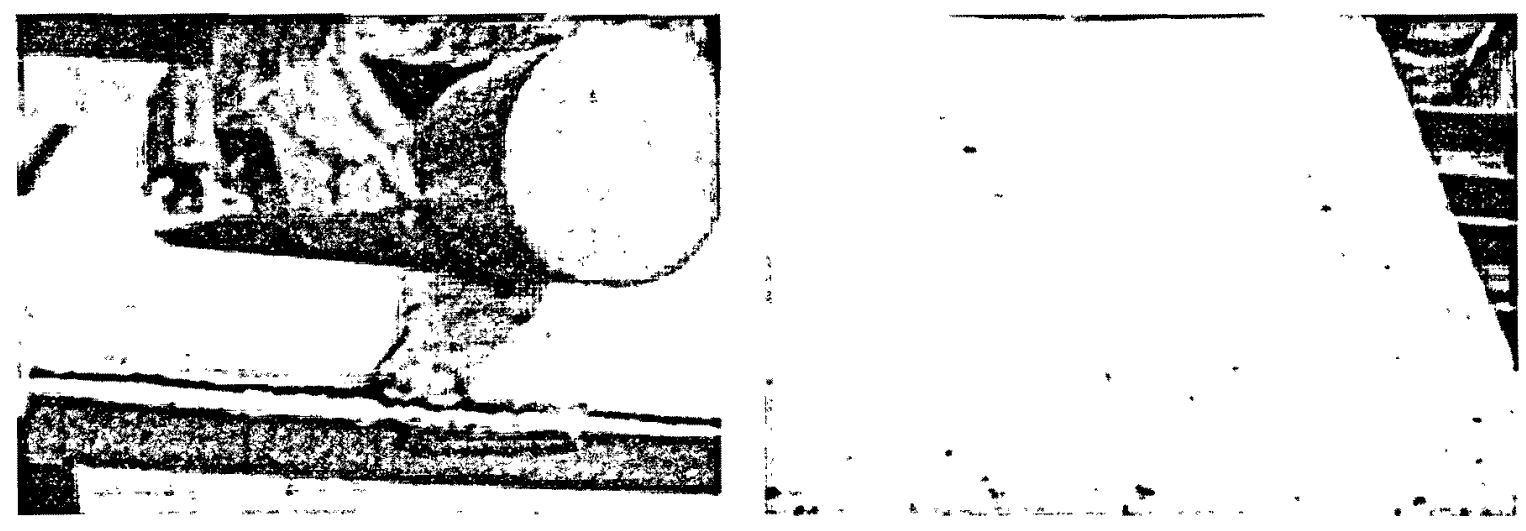

Fig.3.9: Failure of composite slabs

Fig.3.9 illustrates that cracks were also found at the corner of the slab indicating the loss of shear bond. Vertical shear cracks below the loading points were also observed. 


\subsubsection{Load Deflection Behavior}

According to Eurocode-4 (Lawson and Rackham, 1989), the failure load is taken as the load causing a mid-span deflection of $L / 50$ unless failure has already taken place.

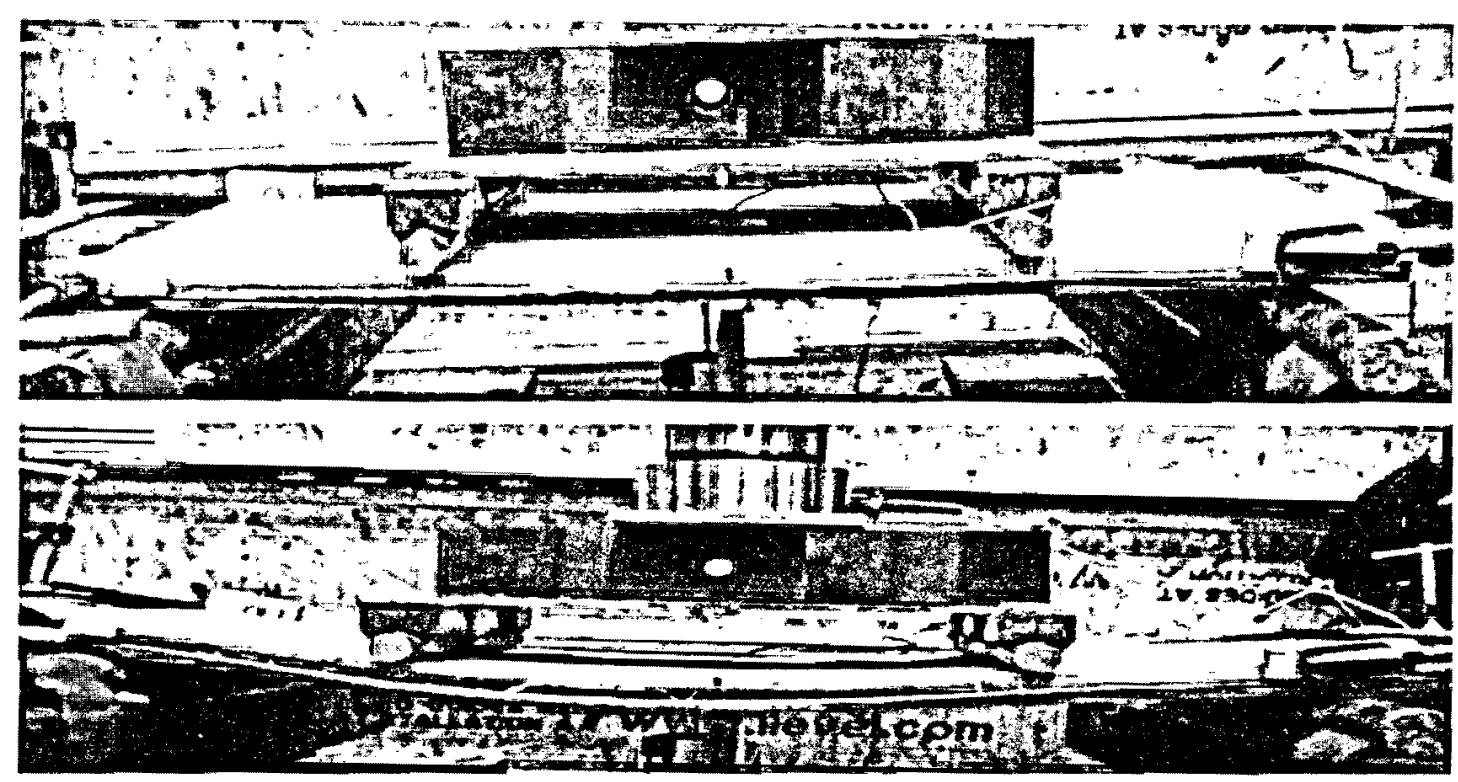

Fig.3.10: Deflection of composite slab under load

Generally slabs with ductile ECC underwent more deflection compared to SCC slabs before failure Fig.3.10. Load-central deflection responses of composite slabs are presented in Fig.3.11. Initially, in all slabs, loss of linear load-deflection behavior was identified at one or two stage load before signs of cracks or immediate longitudinal slippage were detected. It has been observed from the analysis of deflection data that shorter shear span samples $\left(L_{v}=90 \mathrm{~mm}\right)$ showed more deflection than the longer shear span samples $\left(L_{v}=175 \mathrm{~mm}\right)$ i.e. shorter shear span slabs had the tendency for more apparent repression Fig.3.12. In some cases, there were at least two repressions signifying that the slabs were undergoing differential movement of the concrete steel interface and displacement under load. 

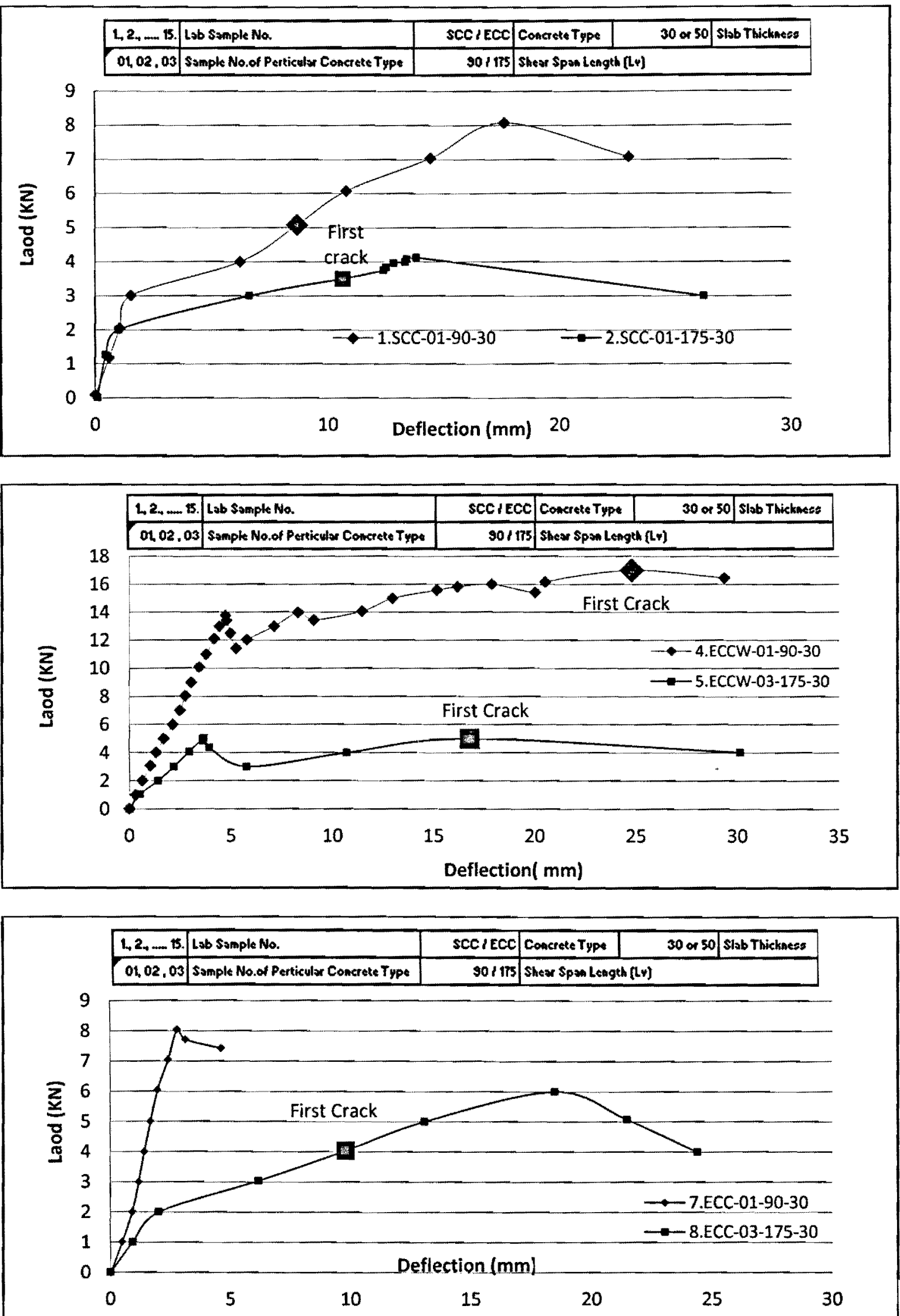

Fig. 3.11: Load-deflection behavior of composite slabs (Continue..) 

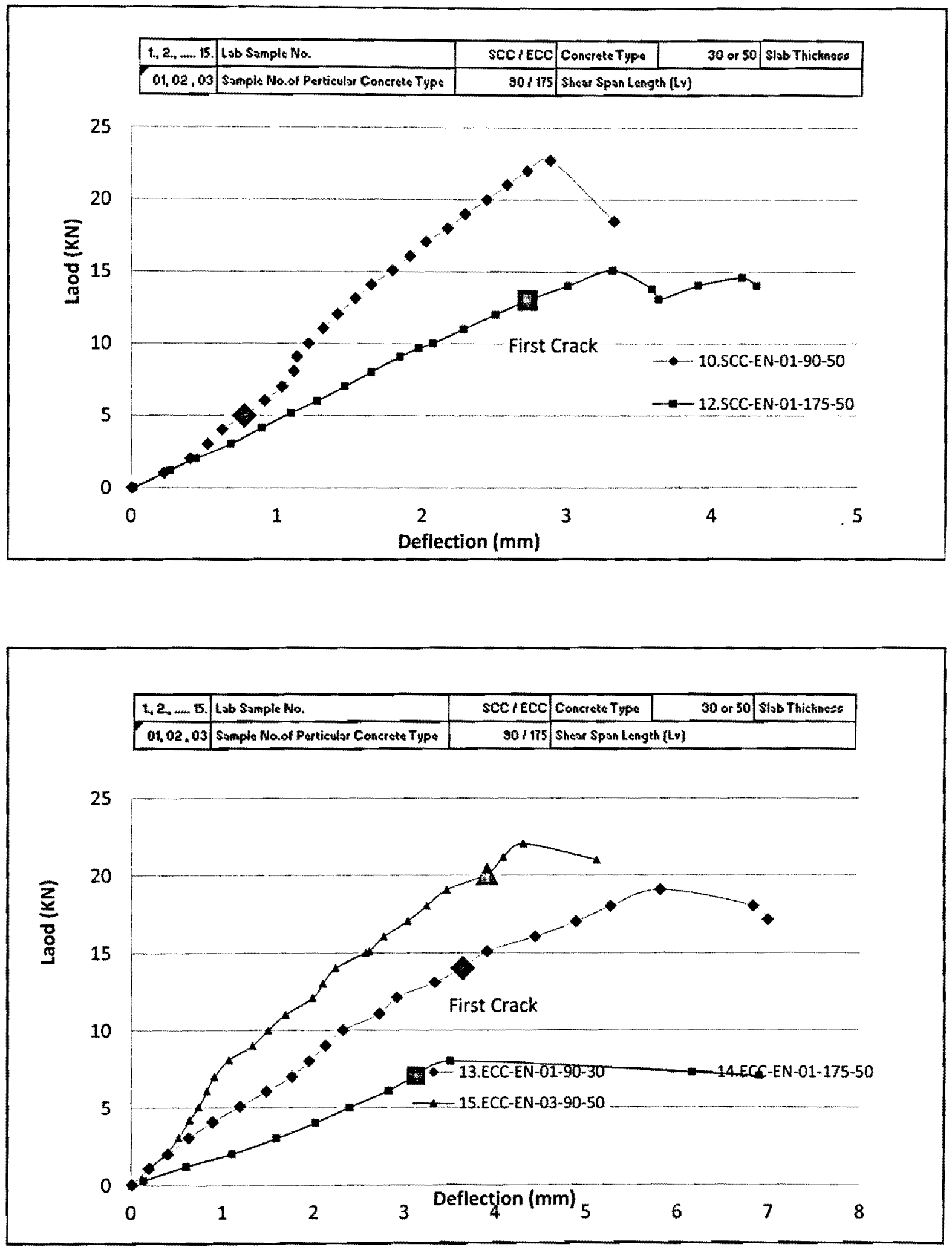

Fig. 3.11: Load-deflection behavior of composite slabs 
Through the results, it is also revealed that deflection of sample with profile sheet type-B (with embossments) have a linear behavior till failure with a tendency of resisting higher loading with lesser deflection at mid span. On the other hand with Type-A sheets (without embossments) the behavior is first linear and then there is sudden change in pattern with higher deflection at lesser loading as compared to type-B sheeting.

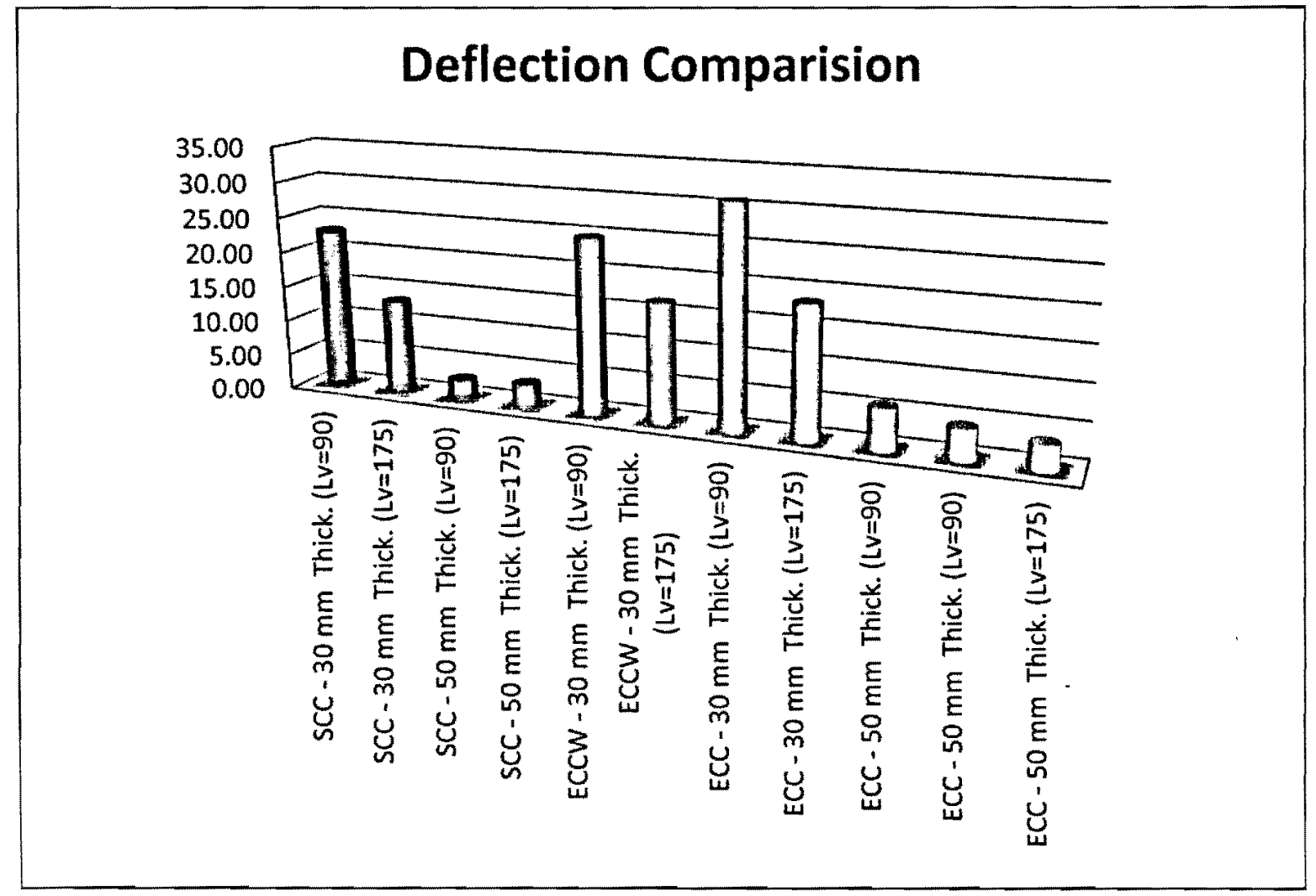

Fig.3.12: Effect of shear span and concrete types on deflection

Composite slabs with welded reinforcement exhibited higher failure load and ductility compared to non-welded reinforcing slabs Fig.3.11. This can be attributed to the stronger interface shear bond between steel concrete. However, slabs with embossed sheet produces higher failure load with lower ductility Fig.3.11. Failure load also increases with the decrease of shear span. 


\subsubsection{End Slip Behavior of Slabs}

According to Eurocode 4, composite slab behavior is considered ductile if the maximum load exceeds the load causing the first $0.5 \mathrm{~mm}$ of the end slip by more than $10 \%$.
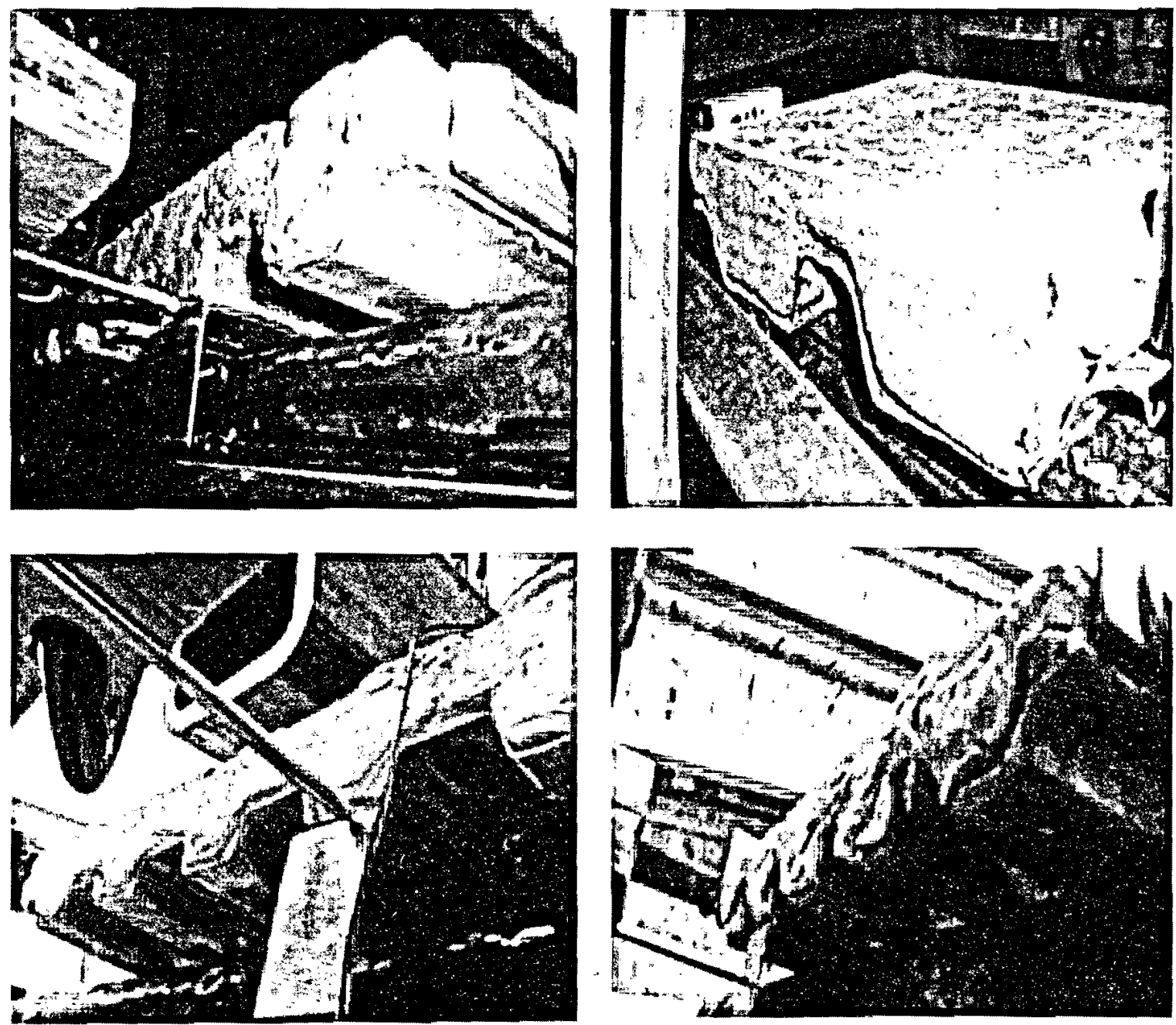

Fig 3.13: End slip between steel and concrete in composite slabs

All the composite slabs showed end slips between steel and concrete before failure representing a shear bond failure Fig.3.13. Samples with SCC had showed less slippage between concrete and steel sheeting as compared to those with ECC. This may be attributed to the development of better shear bond due to the presence coarser material 
(better mechanical interlock with welded reinforcement/embossments) and comparatively rough surface of SCC compared ECC Fig. 3.14.

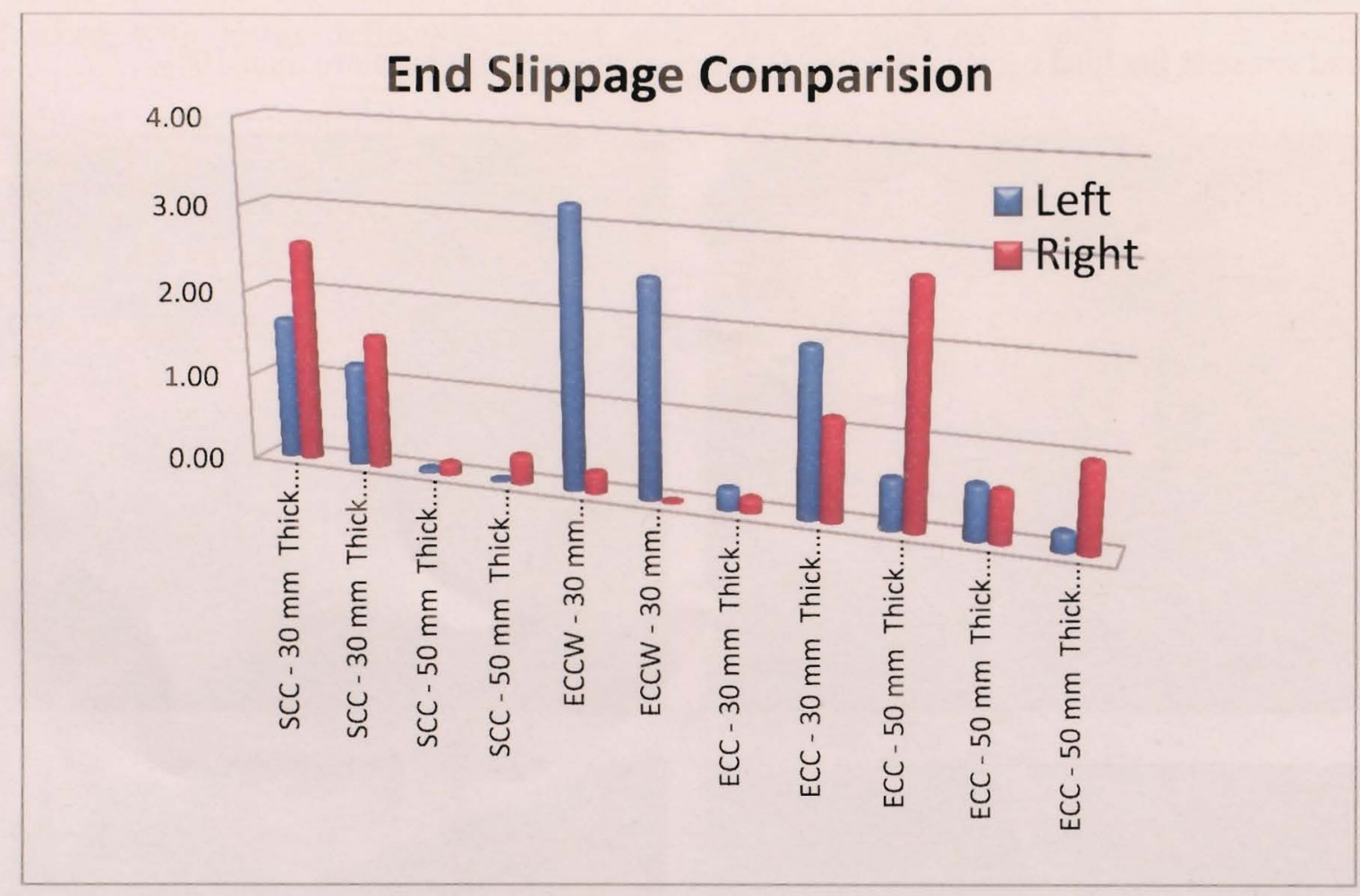

Fig. 3.14: Comparison of end slips

When compare the slip results in line with sheeting type, composite slabs with type-A sheeting (without embossments) exhibit more slip slippage between steel and concrete than those with sheet type-B (with embossments) as shown in Fig.3.14 and 3.15. This is expected as embossed sheets higher shear bond and hence, lower slips. Fig.3.15 presents the development of end slips throughout the loading history. The load-slip pattern shows that there was no slip development up to certain load (interface shear bond remain intact). At the onset of the deterioration of interface shear bond at certain load, slip start to increase at higher rate. It was also observed that there was more slippage at one end of the slabs compared to the other end, due to initiation of shear bond failure at that particular end Fig.3.15. 

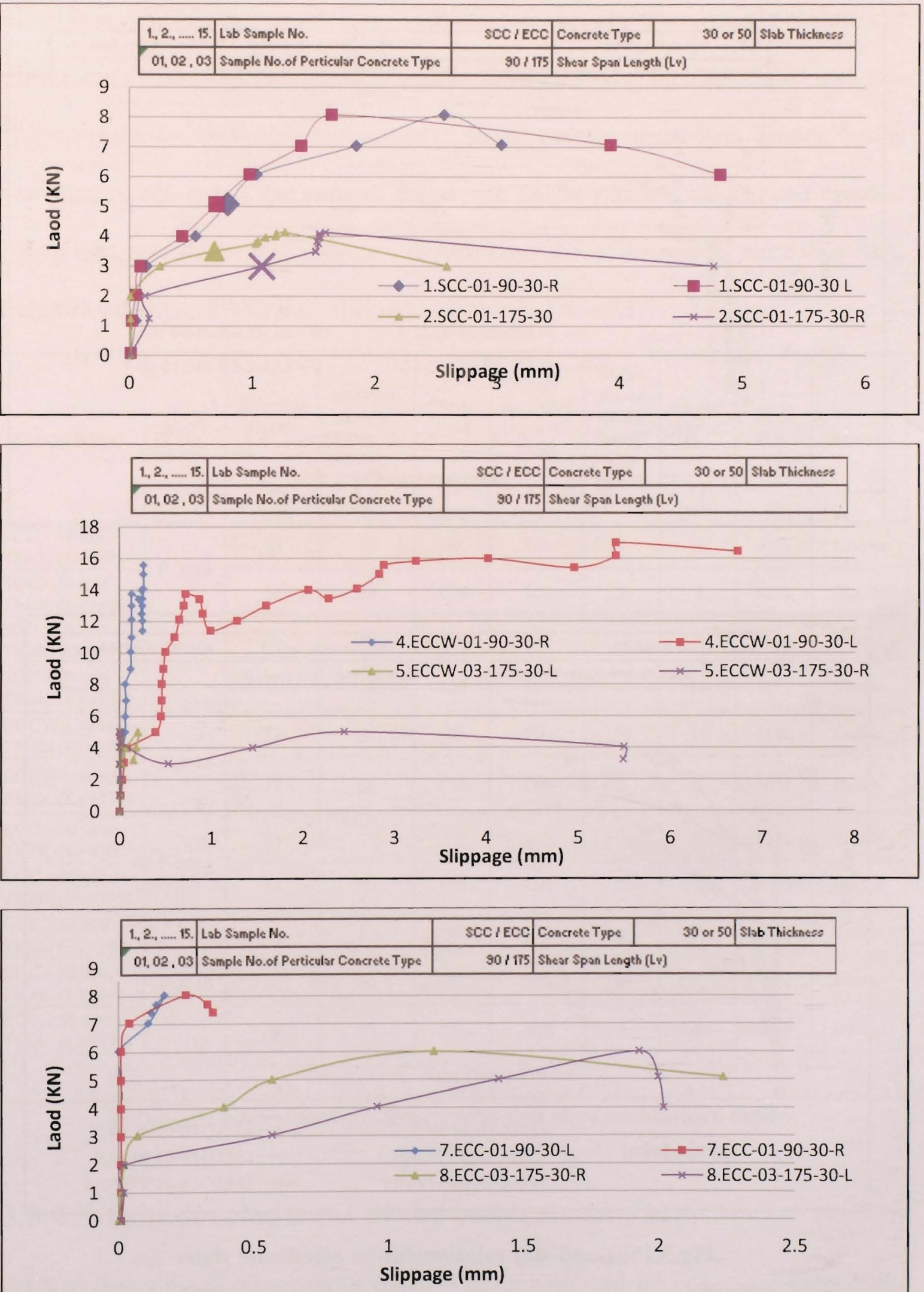

Fig.3.15: Load-slip relationship in composite slabs. (Contnue..) 

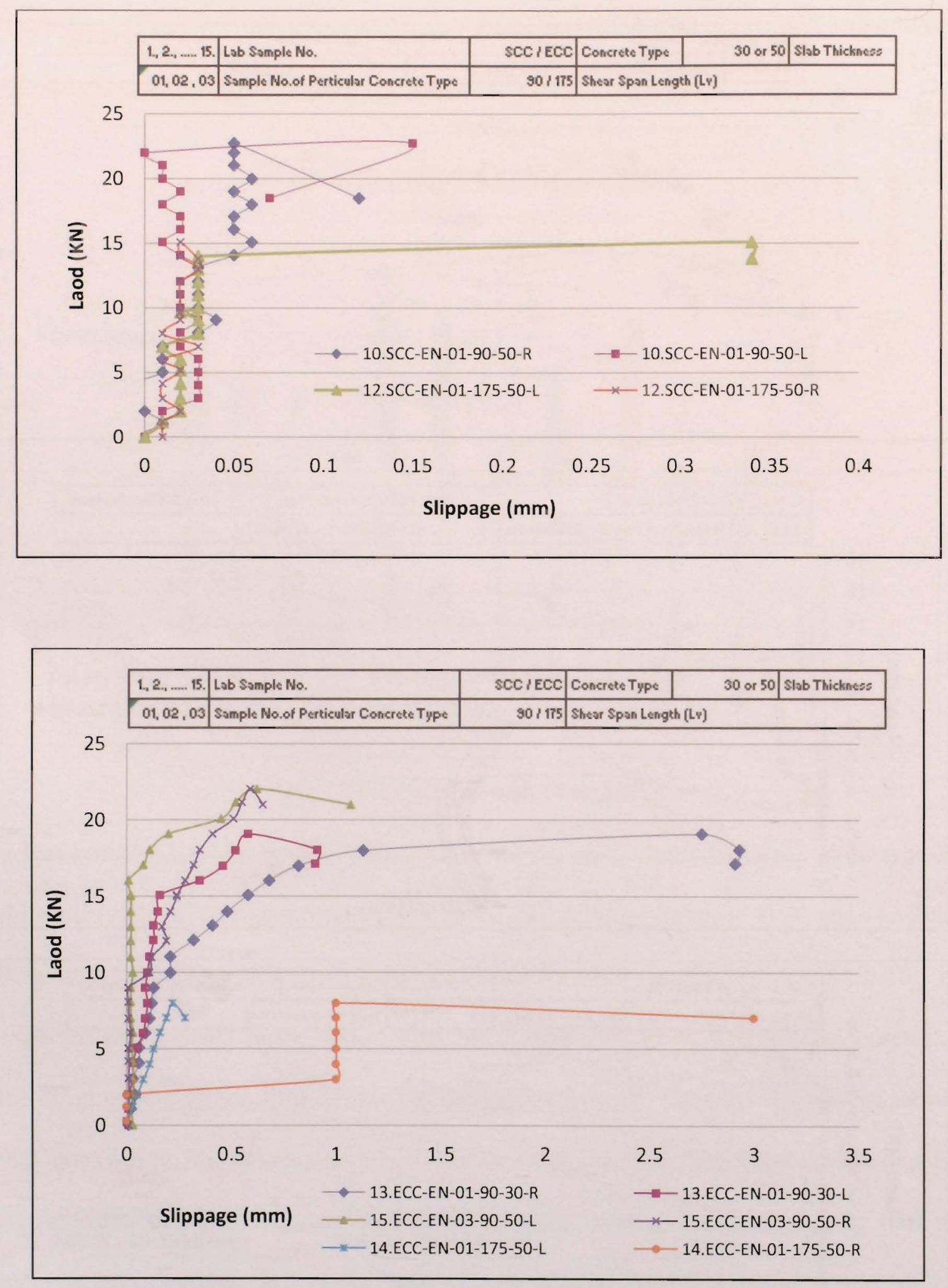

Fig.3.15: Load-slip relationship in composite slabs 
All failures were in longitudinal shear in all samples. These failures typically commenced when a crack occurred in the concrete under one of the load points, associated with loss of bond along the shear span and measured slip at the end of the span. During testing procedure, it was noted that none of the sample failure was not sudden, and eventual failure load exceeds the load causing a recorded end slip of $0.1 \mathrm{~mm}$ by more than $10 \%$, therefore, failure is classified as 'ductile' as shown in Table.3.3.

\begin{tabular}{|c|c|c|c|c|c|c|c|c|c|}
\hline \multirow[t]{2}{*}{ Sample Type } & \multirow[t]{2}{*}{$\begin{array}{l}\text { Sheet } \\
\text { Type }\end{array}$} & $\begin{array}{l}\text { Effective } \\
\text { Depth }\end{array}$ & $\begin{array}{l}\text { Concert. } \\
\text { Comp. } \\
\text { Strength }\end{array}$ & $\begin{array}{l}\text { Shear } \\
\text { span }\end{array}$ & $\begin{array}{c}\text { Cross } \\
\text { sectional } \\
\text { area of } \\
\text { sheet }\end{array}$ & $\begin{array}{c}\text { Shear } \\
\text { Force } \\
\text { (a) } 0.1 \\
\text { mm } \\
\text { slip }\end{array}$ & $\begin{array}{l}\text { Shear } \\
\text { Force }\end{array}$ & \multirow[t]{2}{*}{$\begin{array}{l}\text { V0.1/ } \\
\text { VE } \\
(\%)\end{array}$} & \multirow[t]{2}{*}{ Behavior } \\
\hline & & $\begin{array}{c}\mathrm{ds} \\
(\mathrm{mm})\end{array}$ & $\begin{array}{c}\mathrm{fcm} \\
\left(\mathrm{N} / \mathrm{mm}^{2}\right)\end{array}$ & $\underset{(\mathrm{mm})}{\mathbf{L v}}$ & $\underset{\left(\mathrm{mm}^{2}\right)}{\mathbf{A p}}$ & $\begin{array}{c}(\mathrm{V} 0.1) \\
(\mathrm{kN})\end{array}$ & $\begin{array}{l}\text { VE } \\
(\mathrm{KN})\end{array}$ & & \\
\hline $\begin{array}{l}\text { SCC }-30 \mathrm{~mm} \\
\text { Thick. }(\mathrm{Lv}=90)\end{array}$ & \multirow{2}{*}{ P-3012 } & 23 & 38 & 90 & 160 & 4 & 8 & $\mathbf{5 0} \%$ & Ductile \\
\hline $\begin{array}{l}\text { SCC }-30 \mathrm{~mm} \\
\text { Thick. }(\mathrm{Lv}=175)\end{array}$ & & 23 & 39 & 175 & 160 & 2 & 4 & $52 \%$ & Ductile \\
\hline $\begin{array}{l}\text { SCC }-50 \mathrm{~mm} \\
\text { Thick. }(\mathrm{Lv}=90)\end{array}$ & \multirow{2}{*}{ P-3615 } & 36 & 39 & 90 & 355 & 19 & 23 & $19 \%$ & Ductile \\
\hline $\begin{array}{l}\text { SCC }-50 \mathrm{~mm} \\
\text { Thick. }(L v=175)\end{array}$ & & 36 & 39 & 175 & 355 & 13 & 15 & $13 \%$ & Ductile \\
\hline $\begin{array}{l}\text { ECCW - } 30 \mathrm{~mm} \\
\text { Thick. (Lv=90) }\end{array}$ & \multirow{2}{*}{ P-3012 } & 23 & 56 & 90 & 160 & 10 & 17 & $41 \%$ & Ductile \\
\hline $\begin{array}{l}\text { ECCW - } 30 \mathrm{~mm} \\
\text { Thick. }(\mathrm{Lv}=175)\end{array}$ & & 23 & 58 & 175 & 160 & 3 & 5 & $40 \%$ & Ductile \\
\hline $\begin{array}{l}\text { ECC - } 30 \mathrm{~mm} \\
\text { Thick. }(\mathrm{Lv}=90)\end{array}$ & \multirow{2}{*}{ P-3012 } & 23 & 58 & 90 & 160 & 7 & 8 & $12 \%$ & Ductile \\
\hline $\begin{array}{l}\text { ECC - } 30 \mathrm{~mm} \\
\text { Thick. }(\mathrm{Lv}=175)\end{array}$ & & 23 & 59 & 175 & 160 & 3 & 6 & $49 \%$ & Ductile \\
\hline $\begin{array}{l}\text { ECC }-50 \mathrm{~mm} \\
\text { Thick. }(\mathrm{Lv}=90)\end{array}$ & \multirow{3}{*}{ P-3615 } & 36 & 54 & 90 & 355 & 8 & 19 & $58 \%$ & Ductile \\
\hline $\begin{array}{l}\text { ECC - } 50 \mathrm{~mm} \\
\text { Thick. }(\mathrm{Lv}=90)\end{array}$ & & 36 & 56 & 90 & 355 & 10 & 22 & $55 \%$ & Ductile \\
\hline $\begin{array}{l}\text { ECC - } 50 \mathrm{~mm} \\
\text { Thick. }(\mathrm{Lv}=175)\end{array}$ & & 36 & 54 & 175 & 355 & 4 & 8 & $50 \%$ & Ductile \\
\hline & & & th of & abs ( & $=320 \mathrm{~mm}$ & & & & \\
\hline
\end{tabular}

Table 3.3: Experimental shear force, end slips and failure modes

\subsubsection{Strain development at the concrete surface}

Fig.3.16 shows the development of concrete strain with load for composite slabs. Slabs with profile sheeting type A (without embossment|) with shorter shear spans had shown 
elastic strain compared to longer shear span slabs. All samples with ECC developed higher and quicker increase in concrete strain compared to the other slabs Fig. 3.16 and 3.17. This is because ECC is considerably ductile compare to SCC. Majority of ECC slabs showed high strain values than SCC slabs. Longer shear span had yielded greater strain readings compared to shorter shear span slabs, especially during its plastic deformation stage. This is because of the loading points are closer to the center of the slab, where its effect is more significant.
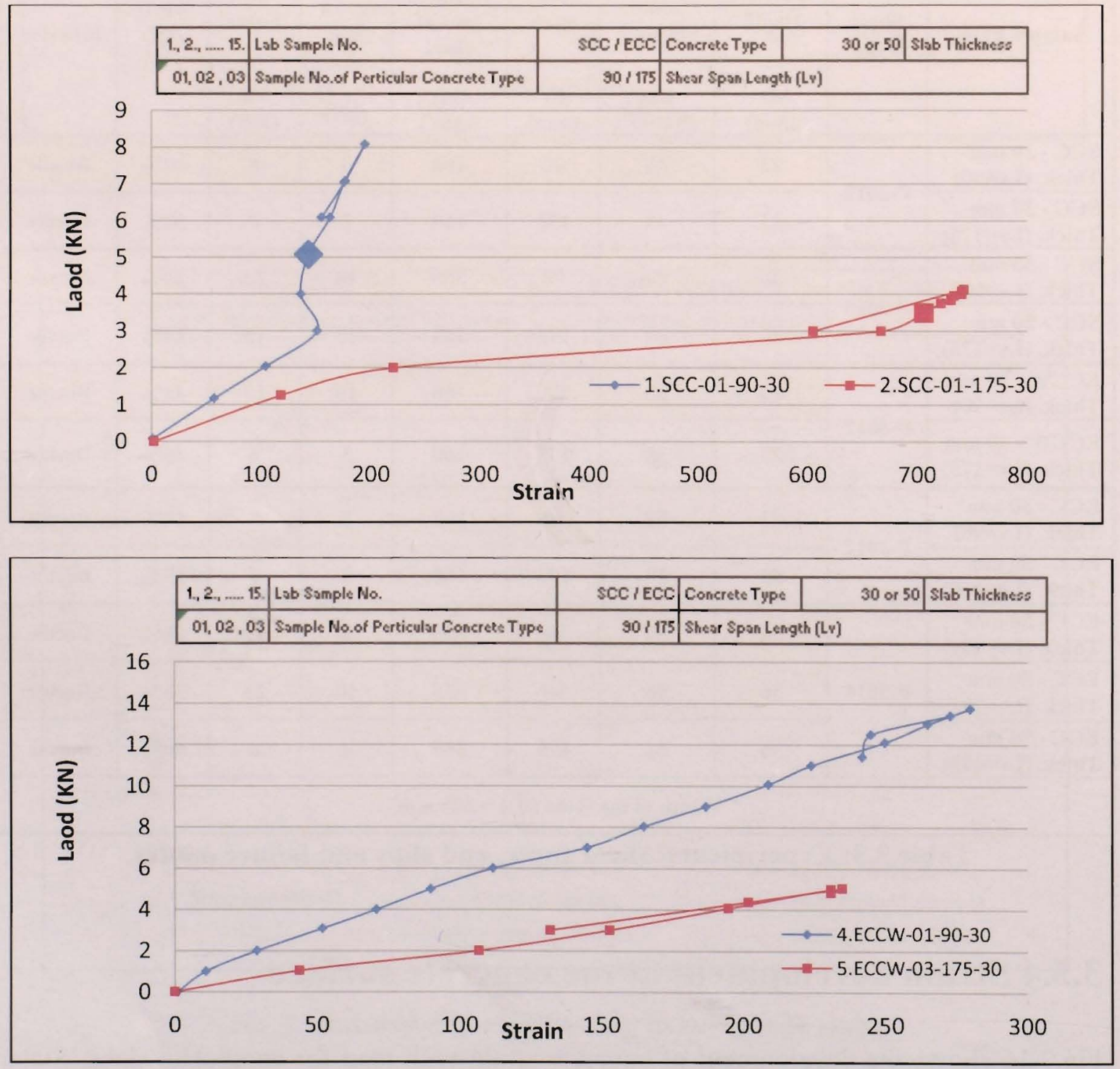

Fig.3.16: Strain development in concrete (Continue..) 

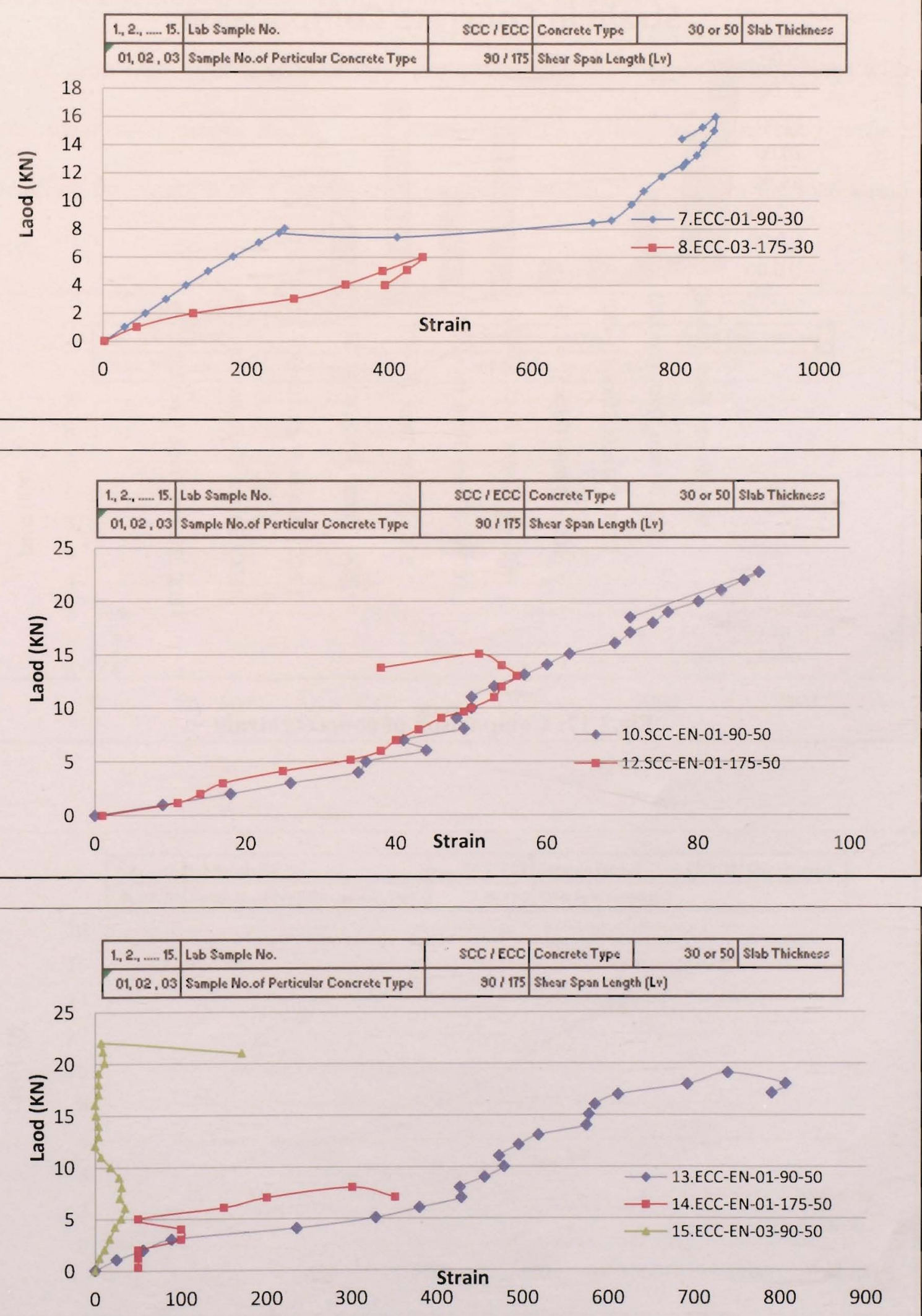

Fig.3.16: Strain development in concrete 


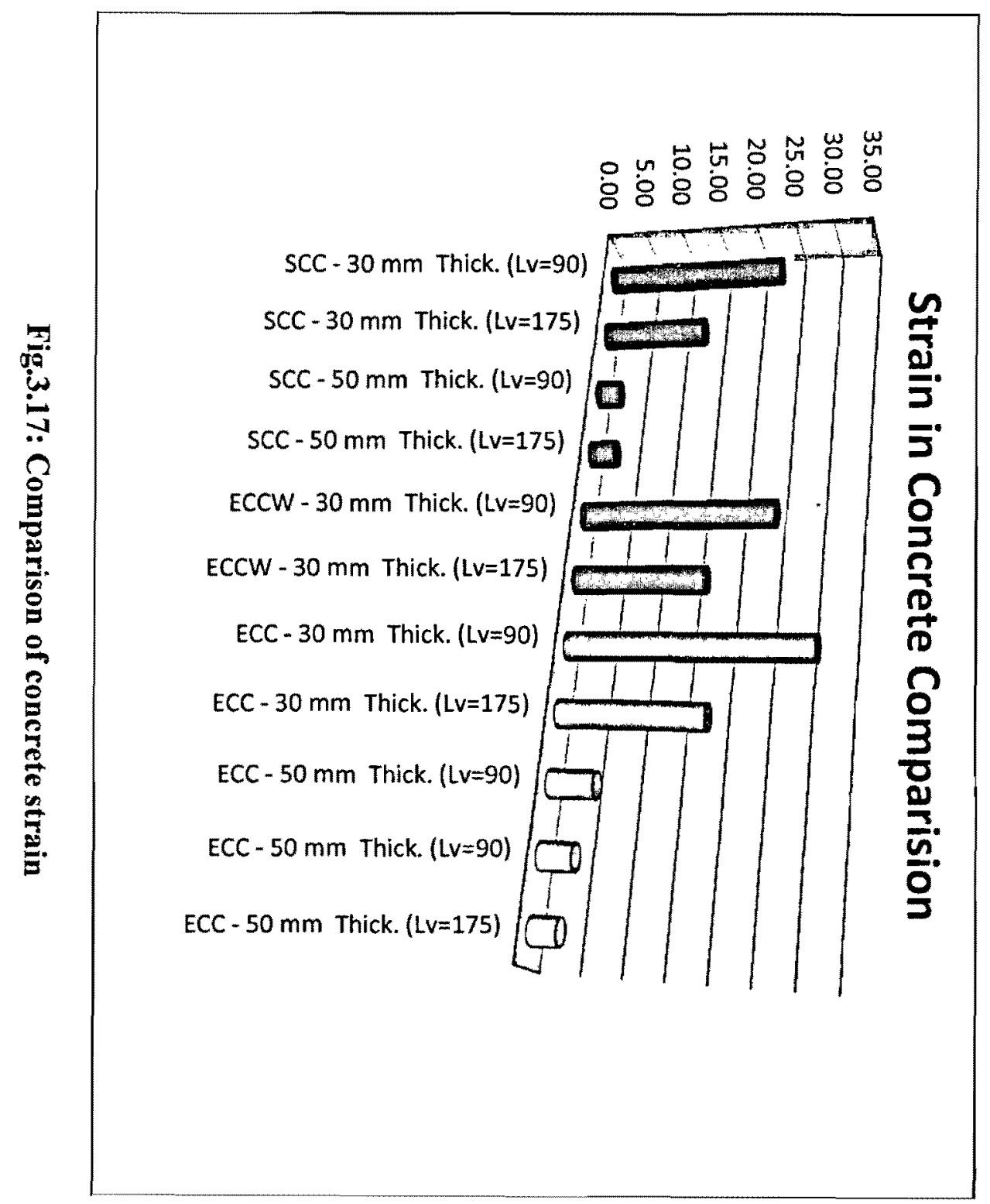




\subsubsection{Strain development in profiled steel sheet}

Fig.3.18 shows the development of steel strain with load for composite slabs.Slabs with lower shear span shows higher steel strain Fig.3.19. After steel-concrete interface seperation, the strain in steel significantly increased as can be seen from the load-strain curves.
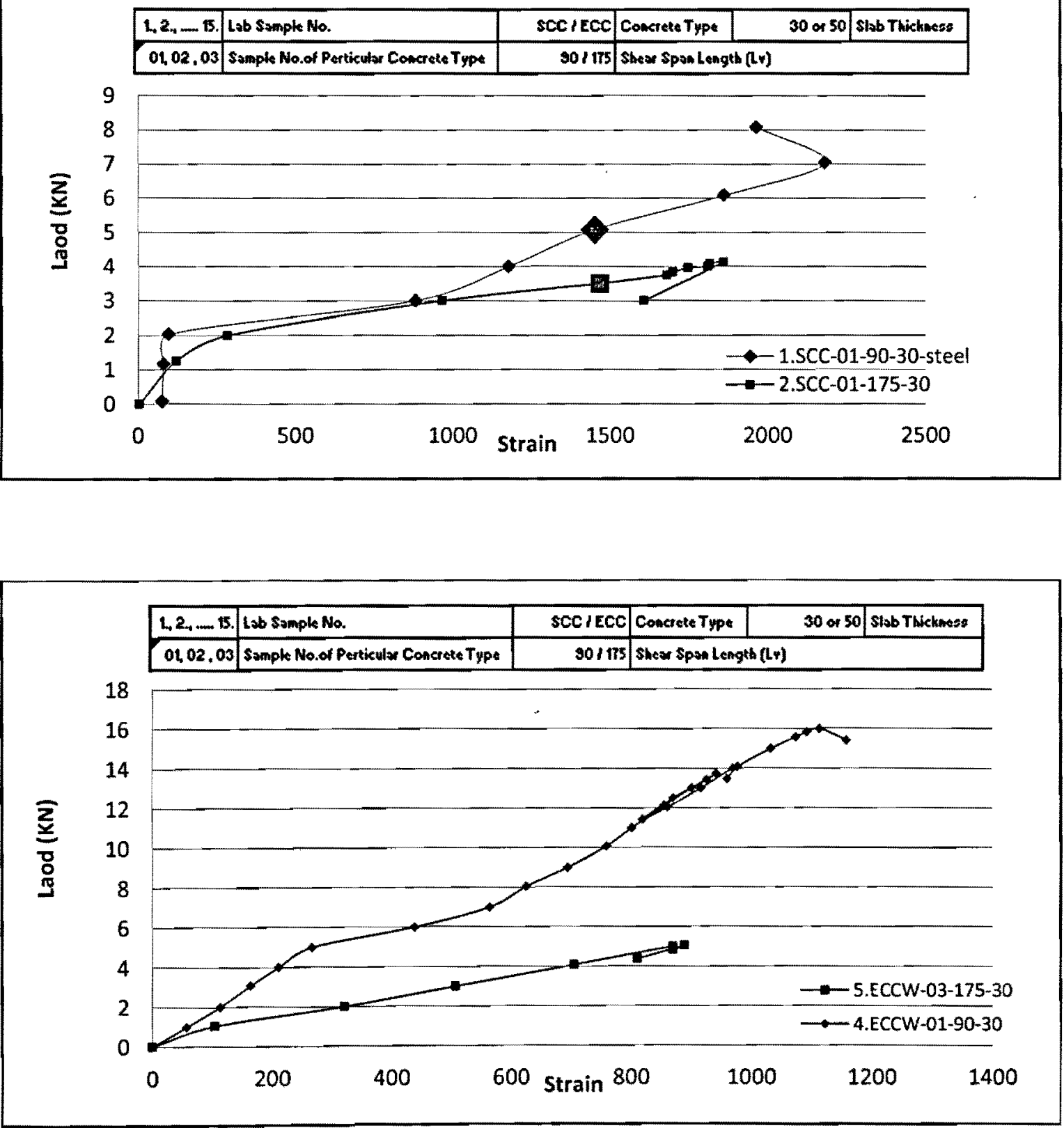

Fig.3.18: Strain development in steel sheet(Continue..) 

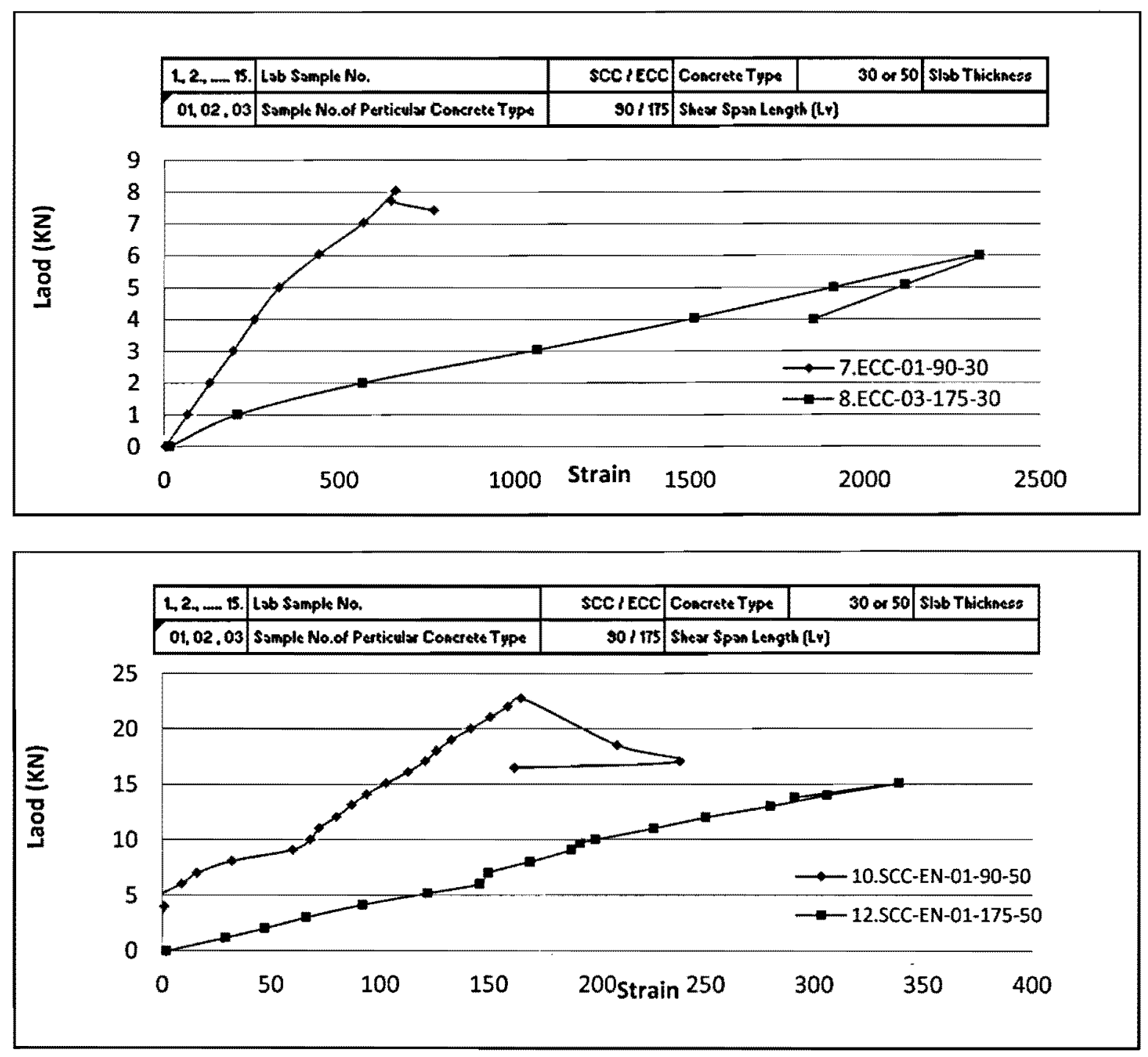

\begin{tabular}{|c|c|c|c|c|c|}
\hline $1,2 n-15$ & Lob Ssmple No. & scolece & Concrete Type & 30 or 50 & Stab Thickness \\
\hline $04,02,03$ & Somple No. of Perticular Concrete Type & 501 ins & Shear Spsa Lene & & \\
\hline
\end{tabular}

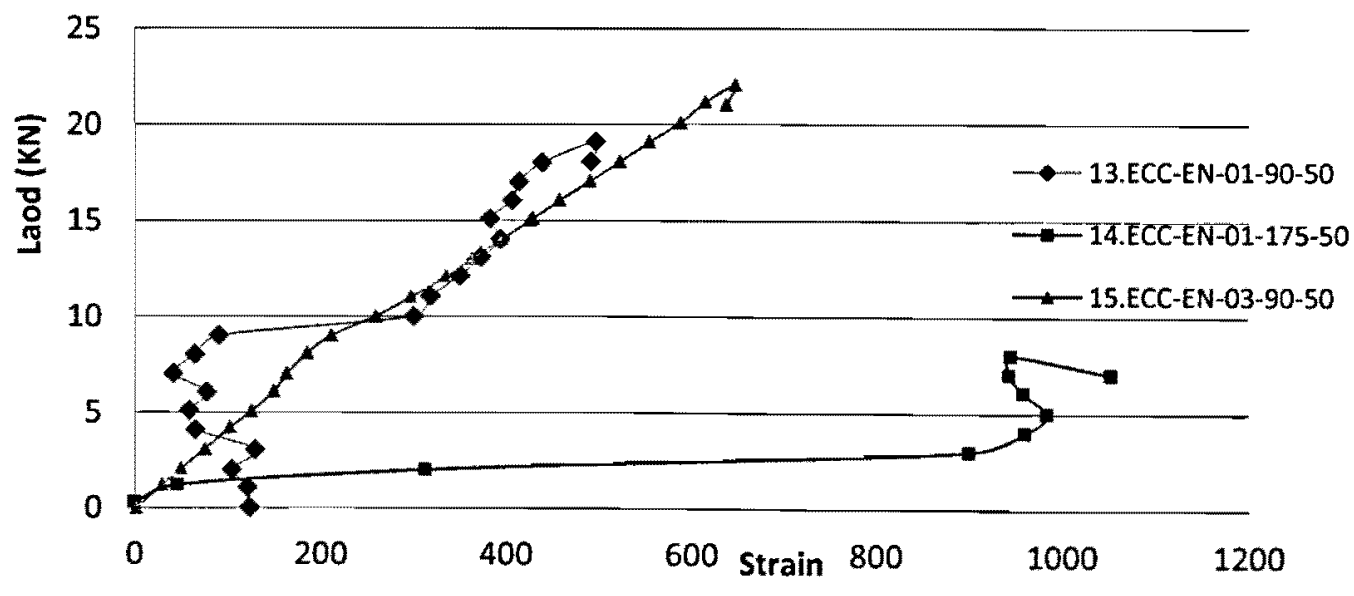

Fig.3.18: Strain development in steel sheet 


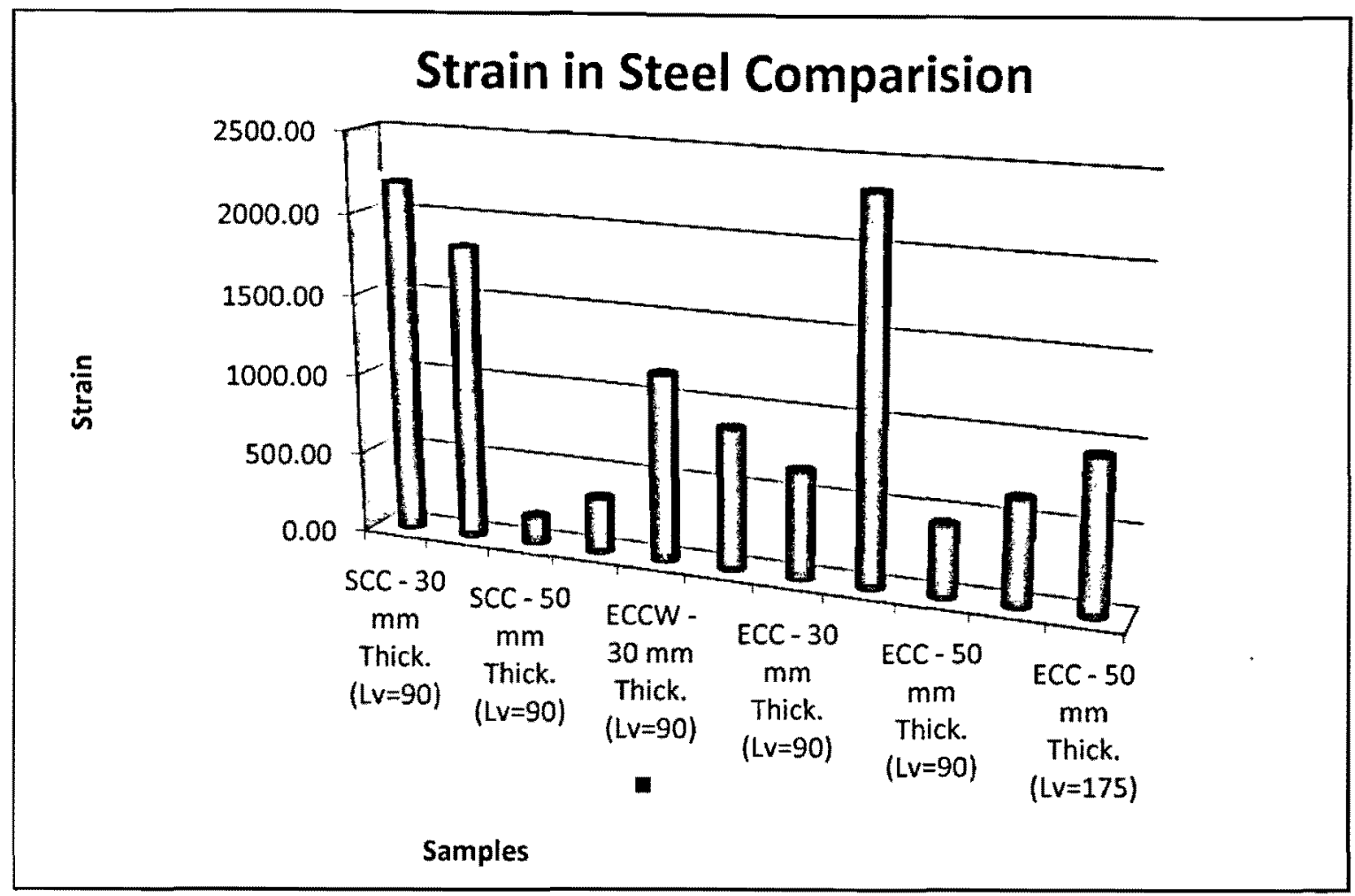

Fig.3.19: Comparison of steel strain

\subsubsection{Evaluation of $m-k$ values and shear bond stress}

Method detailed in the British Standards Institution: 1994 has been used to evaluate the $\mathrm{m}$ and $\mathrm{k}$ values which define the shear transferring capacity of the profiled sheet $\mathrm{m}$ represents an empirical value of mechanical interlocking between concrete and profiled steel sheeting and $\mathrm{k}$ represents for the empirical value for friction between concrete and steel.

The length of each shear span, $L \mathrm{v}$, was taken minimum as $3 \mathrm{~h}=90 \mathrm{~mm}$ and $L / 4=175 \mathrm{~mm}$, where $L$ is the span $=820 \mathrm{~mm}$. The expected mode of failure in a test depends on the 
ratio of $L_{\mathrm{v}}$ to the effective depth $d_{s}$ of the slab. At high $L_{v} / d_{s}$, flexural failure occurs (Fisher, 1970) and at low $L_{v} / d_{s}$, vertical shear failure occurs.

Table 3.3 and Table 3.4 show the necessary parameters for plotting the graphs for calculating $\mathrm{m}$ and $\mathrm{k}$ values using the experimental results.

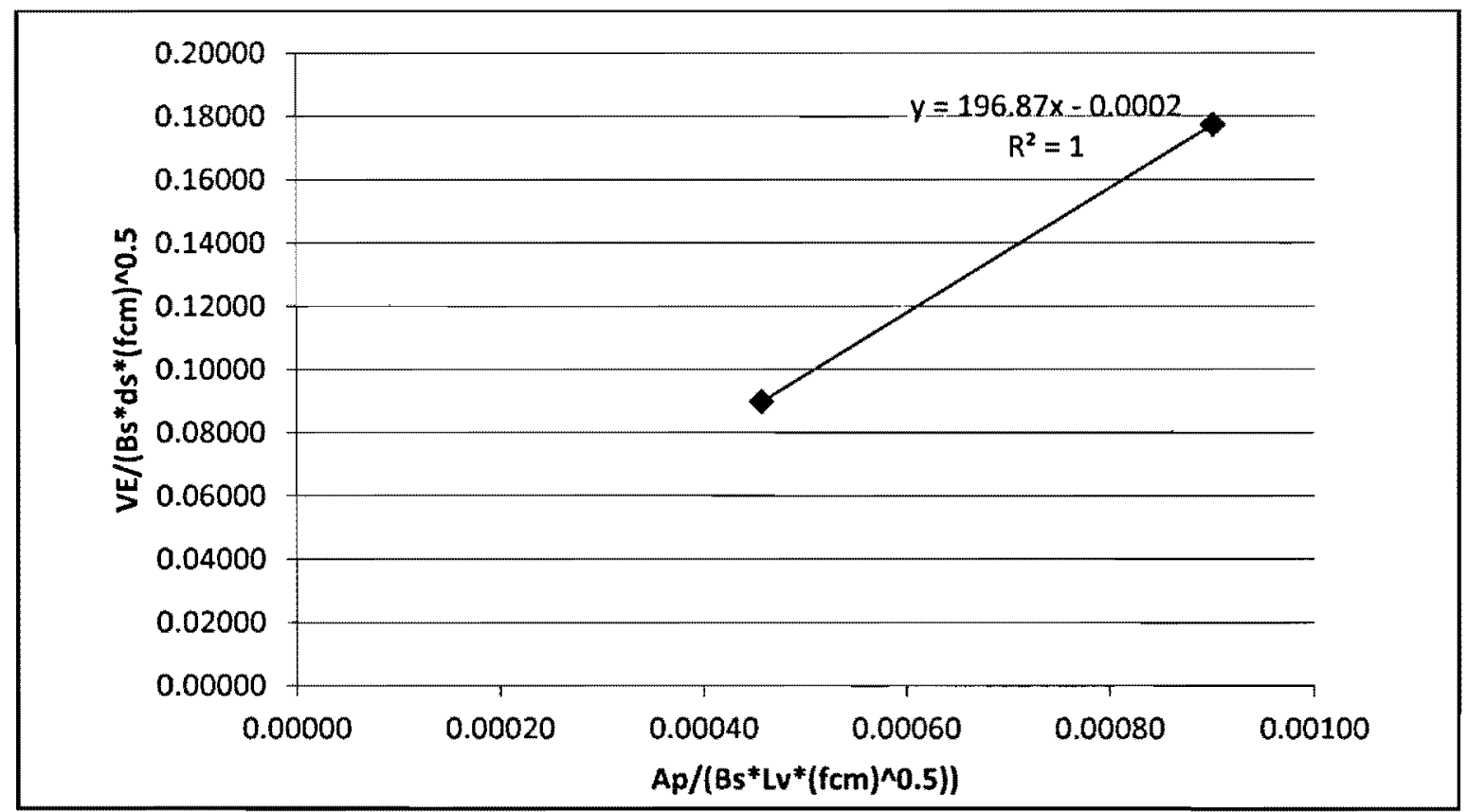

\section{Fig.3.20: Typical m-k curve}

Bs is the width of the composite slab, ds is the effective depth slab to the centroid of the profiled steel sheeting, $\mathrm{f}_{\mathrm{cm}}$ is the concrete cube strength (average of three cubes) and VE is the maximum experimental shear force. Typical $\mathrm{m}-\mathrm{k}$ curve plotted from the experimental data is shown in Fig.3.20. $\mathrm{m}$ and $\mathrm{k}$ values for each group of slab with graphs are presented in Appendix A. m and $\mathrm{k}$ values for all composite slabs are summarized in Table.3.4 and compared in Fig.3.21. 


\begin{tabular}{|c|c|c|c|c|c|c|}
\hline \multirow{2}{*}{ Sample Type } & \multirow{2}{*}{$\begin{array}{l}\text { Sheet } \\
\text { Type }\end{array}$} & \multirow{2}{*}{$\begin{array}{l}\text { Shear } \\
\text { Length Lv } \\
(\mathbf{m m})\end{array}$} & \multirow{2}{*}{$\begin{array}{l}\text { Exp. Shear } \\
\text { Force VE } \\
(\mathrm{KN})\end{array}$} & \multirow[b]{2}{*}{$\mathbf{m}$} & \multirow[b]{2}{*}{$\mathbf{k}$} & \multirow{2}{*}{$\begin{array}{c}\text { Shear bond capacity } \\
\tau_{\mathrm{u}, \mathrm{RD}} \\
\mathrm{MPa}\end{array}$} \\
\hline & & & & & & \\
\hline $\begin{array}{l}\text { SCC - } 30 \mathrm{~mm} \\
\text { Thick (Lv=90) }\end{array}$ & \multirow{2}{*}{ P-3012 } & 90 & 8 & \multirow{2}{*}{196.87} & \multirow{2}{*}{-0.0002} & 1.09 \\
\hline $\begin{array}{l}\text { SCC }-30 \mathrm{~mm} \\
\text { Thick. }(\mathrm{Lv}=175)\end{array}$ & & 175 & 4 & & & 0.56 \\
\hline $\begin{array}{l}\text { SCC - } 50 \mathrm{~mm} \\
\text { Thick. }(\text { Lv=90) }\end{array}$ & \multirow{2}{*}{ P-3615 } & 90 & 23 & \multirow{2}{*}{112.37} & \multirow{2}{*}{0.0944} & 1.97 \\
\hline $\begin{array}{l}\text { SCC }-50 \mathrm{~mm} \\
\text { Thick. (Lv=175) }\end{array}$ & & 175 & 15 & & & 1.30 \\
\hline $\begin{array}{l}\text { ECCW - } 30 \mathrm{~mm} \\
\text { Thick. }(\mathrm{Lv}=90)\end{array}$ & \multirow{2}{*}{ P-3012 } & 90 & 17 & \multirow{2}{*}{597.59} & \multirow{2}{*}{-0.1350} & 2.30 \\
\hline $\begin{array}{l}\text { ECCW }-30 \mathrm{~mm} \\
\text { Thick. }(\mathrm{Lv}=175)\end{array}$ & & 175 & 5 & & & 0.69 \\
\hline $\begin{array}{l}\text { ECC }-30 \mathrm{~mm} \\
\text { Thick. }(\mathrm{Lv}=90)\end{array}$ & \multirow{2}{*}{ P-3012 } & 90 & 8 & \multirow{2}{*}{54.68} & \multirow{2}{*}{0.0196} & 0.45 \\
\hline $\begin{array}{l}\text { ECC }-30 \mathrm{~mm} \\
\text { Thick. }(\mathrm{Lv}=175)\end{array}$ & & 175 & 6 & & & 0.31 \\
\hline $\begin{array}{l}\text { ECC - } 50 \mathrm{~mm} \\
\text { Thick. }(\text { Lv=90) }\end{array}$ & \multirow{3}{*}{ P-3615 } & 90 & 19 & \multirow{3}{*}{181.69} & \multirow{3}{*}{-0.0615} & 1.78 \\
\hline $\begin{array}{l}\text { ECC }-50 \mathrm{~mm} \\
\text { Thick. }(\mathrm{Lv}=90)\end{array}$ & & 90 & 22 & & & 1.78 \\
\hline $\begin{array}{l}\text { ECC }-50 \mathrm{~mm} \\
\text { Thick. }(\mathrm{Lv}=175)\end{array}$ & & 175 & 8 & & & 0.70 \\
\hline
\end{tabular}

Table.3.4: $\mathrm{m}-\mathrm{k}$ values and shear bond capacity

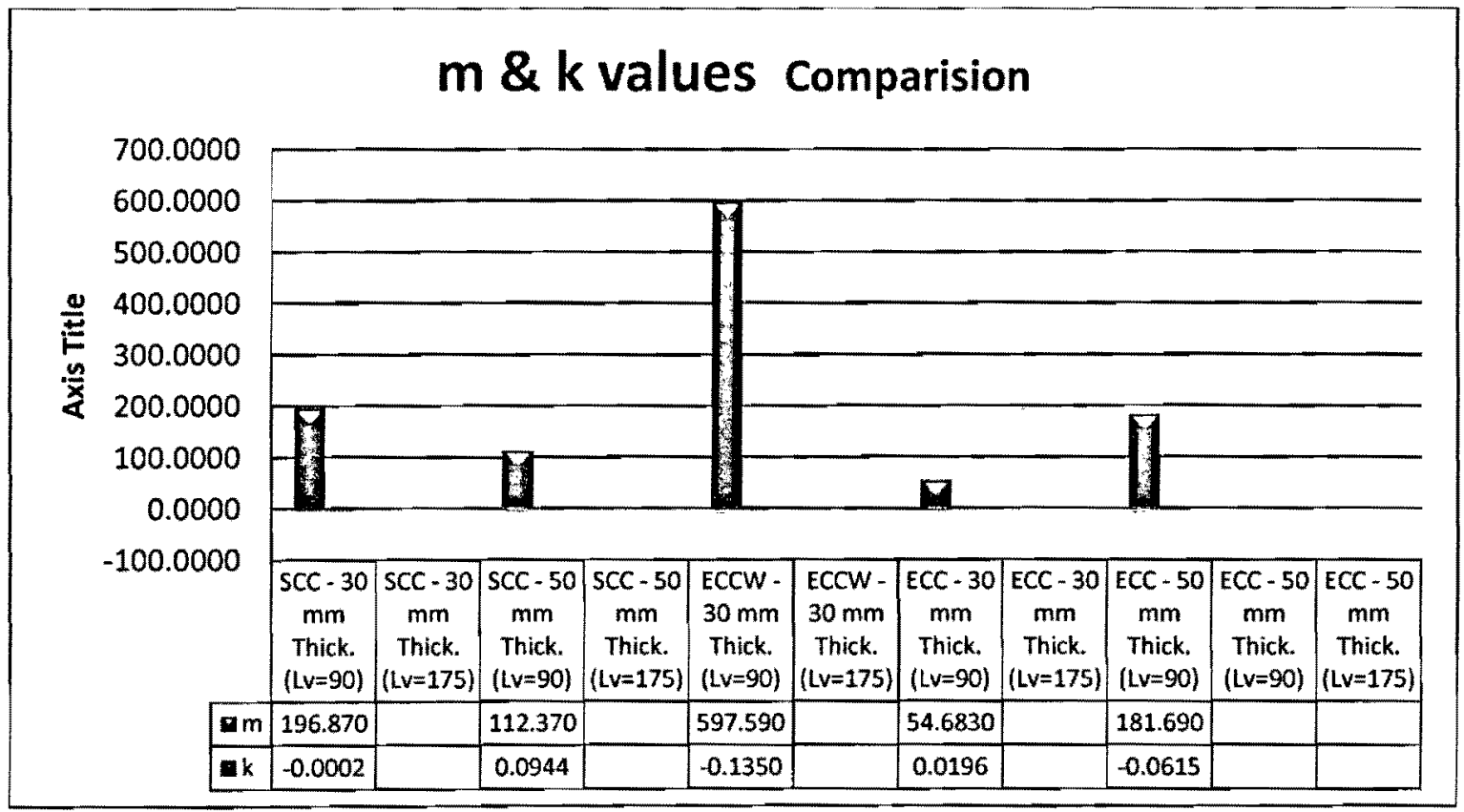

Fig.3.21: Comparison $m$ and $k$ values 
Fig.3.21 shows that the shear bond due to mechanical interlock as represented by $\mathrm{m}$ values significantly improved with the use of welded reinforcement in composite slabs. Influence of concrete types on $\mathrm{m}$ and $\mathrm{k}$ values are not conclusive and more investigations are needed with the use of stud shear connector.

Once $m$ and $k$ values are obtained, the shear bond capacity $\tau_{\mathrm{uRD}}$ of composite deck slabs are calculated from the design equation (Johnson, 2004):

$\frac{V E}{b d}=\tau u, R d=\left(\frac{m A p}{b L v}\right)+K \sqrt{f c m}$

Shear bond capacities for all composite slabs are presented in Table.3.4. Fig.3.22 and Fig.3.23 show calculated shear bond capacities of composite slabs as well as experimental shear capacity.

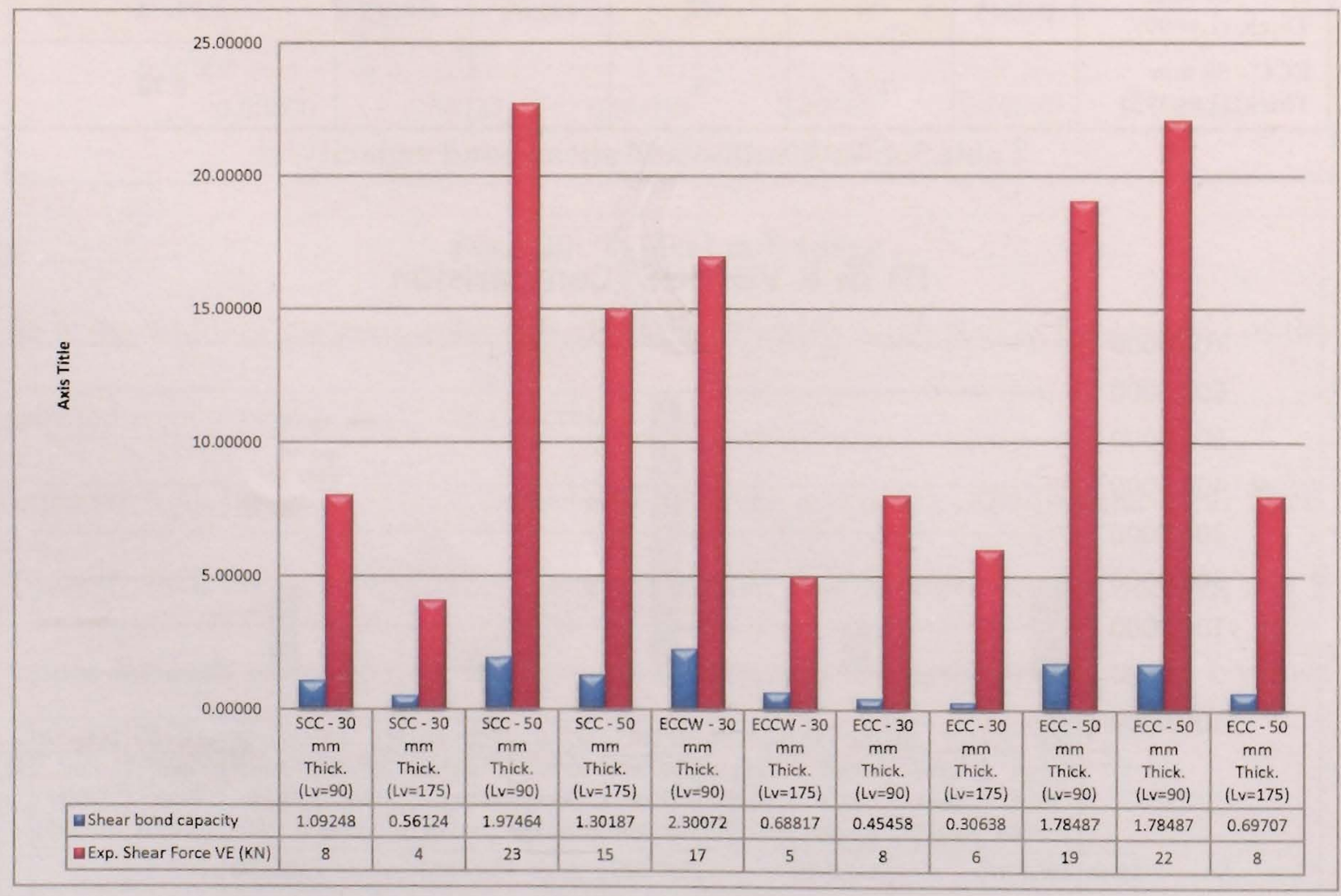

Fig.3.22: Computed shear bond capacity (MPa) and experimental shear capacity $(\mathbf{k N})$ of composite slabs 


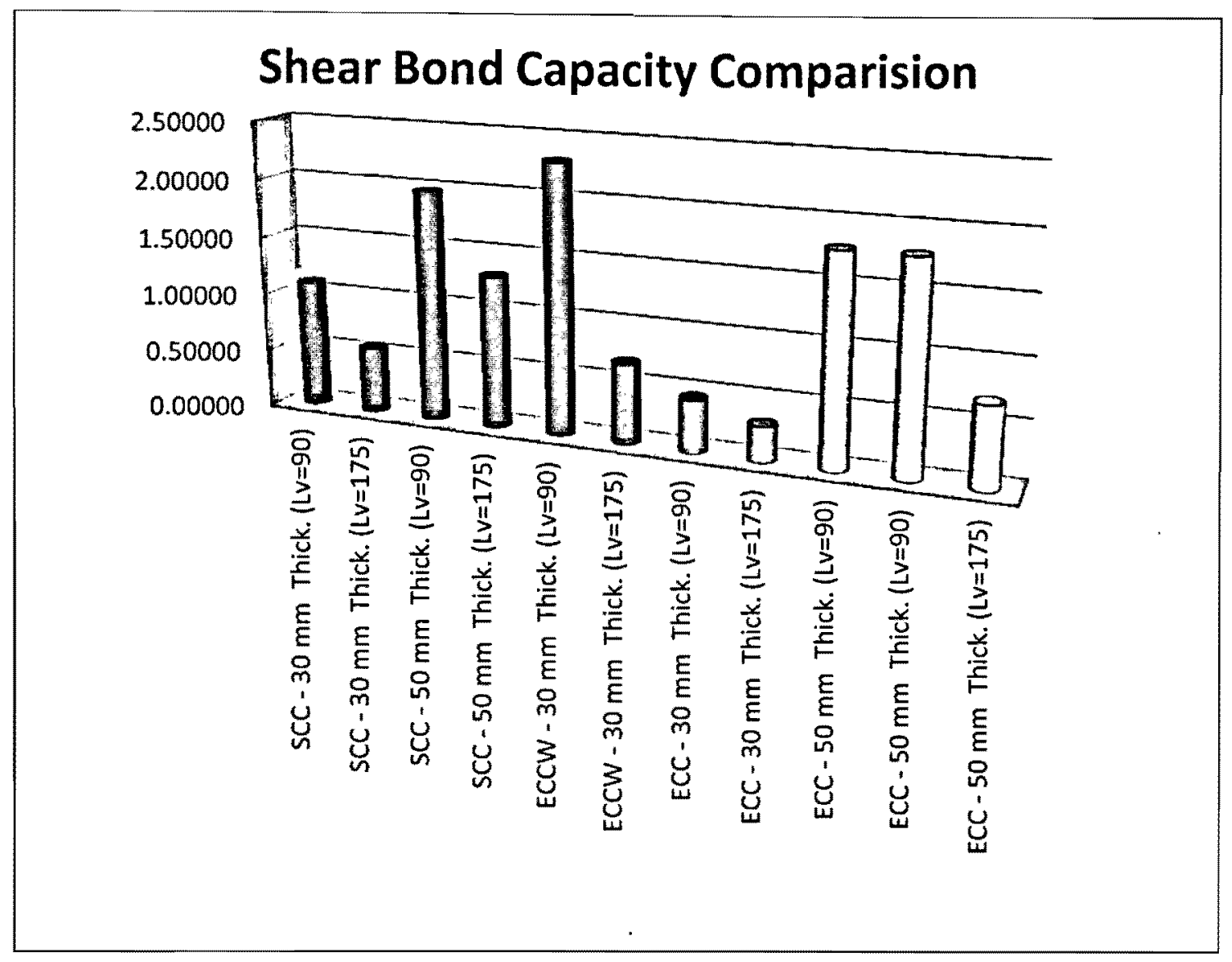

Fig.3.23: Shear bond capacity (in MPa) of composite slabs

From Fig.3.23, it can be concluded that the composite slabs with profile steel sheeting Type-B (with embossment) have shown higher shear bond capacity compared to those with profile sheet Type-A without embossment. 


\section{Chapter 4}

\subsection{Conclusions and Future Recommendations}

\subsection{Conclusions}

This project studied the structural performance of composite slabs with high performance concrete (HPC) through experimental and theoretical investigations. The influences of profiled steel deck types (embossed and non-embossed), HPC types (self-consolidating concrete "SCC" and engineered Cementitious composites "ECC"), variable shear span on load-defection response, strength, failure modes, steel-concrete slip, cracking/crack propagation and steel-concrete shear bond are investigated. The following conclusions can be drawn from this study:

1. The ultimate failure loads of composite slabs with shorter shear span yielded higher failure load compared to slabs with longer shear span.

2. The SCC slabs failed before the concrete developed its full strain capacity (0.0030.0035), while the ECC design mix slabs has developed a higher strain reading before failure.

3. Samples with ECC attained higher strains in profile steel sheeting than the samples with SCC design mix.

4. All slabs achieved the ductility requirements of the Eurocode 4.

5. Samples with embossed profile steel sheeting had lower initial linear (elastic) deflection as compared to these with non embossed profile steel sheeting. 
6. The values of shear bond parameters ( $\mathrm{m}$ and $\mathrm{k}$ ) of all composite slabs are determined from the experimental results and presented which can be useful for finding the design shear bond capacity of composite slabs with HPC.

The shear bond capacity obtained by $\mathrm{m}-\mathrm{k}$ method for the composite slabs with profile embossed profile steel sheeting have shown higher values as compared to those with non embossed sheets.

\subsection{Recommendations for Future Studies}

More investigations are needed to study:

- The inlfuence of stud connector on the shear bond capacity and shear bond paramaters of composite slabs with various HPC.

- The degradaion of shear bond capacity under fatigue loading in HPC composite slabs with embossed profiled sheets and strud shear connectors 


\section{References}

Abdullah, Redzuan (2004). "Experimental Evaluation and Analytical Modeling of Shear Bond in Composite Slab". Ph.D. Thesis. Virginia Polytechnic Institute and State University, Blacksburg, USA.

An, L. (1993). "Load Bearing Capacity and Behavior of Composite Slabs with Profiled Steel Sheet," Ph.D. Thesis. Chalmers University of Technology, Sweden.

ASCE (1992). Standard for the structural Design of composite slabs. ANSI / AASCE 3-91. American Society of Civil Engineers, New York.

Bashar S. Mohammed, (2010), "Structural behavior and $\mathrm{m}-\mathrm{k}$ value of composite slab utilizing concrete containing crumb rubber". Universiti Tenaga Nasional, Civil Engineering Department, kM7, Jalan Kajang-Puchong, 43009 Kajang, Selangore, Malaysia

Barker, R. M. and Puckett, J.A. (1997). "Design of highway bridges." J. WileyBode, H. and Sauerborn, J. (1992). "Modern design concept for composite slabs with ductile behavior."Composite Construction in Steel and Concrete II, Proceedings of an Engineering Foundation Conference, ASCE. Ed.: W. S. Easterling, W. K. M. Roddis, 125-141.

Bode, H. \& Sauerborn, I. (1993) Modern design concept for composite slabs with ductile behaviour. In Composite construction in steel and concrete II (Easterling, W.S. \& Roddis, W.M.K., eds), Proc. Engineering Foundation Conference, Amer. Soc. Civ. Engrs, New York. 30.

British Standards Institution (1990) BS 5950. Part 3, Section 3.1: Code of practice for design of simple and continuous composite beams and (1994) Part 4: Code of practice for design of floors with profiled steel sheeting. British Standards Institution, London.

British Standards Institution BS EN 1993. Design of steel structures. Part 1-1, General rules and rules for buildings., British Standards Institution, London.

British Standards Institution BS-5950. (1994). Structural Use of Steelwork in Building - Part 4: Code of Practice for Design of Composite Slabs with profiled Steel Sheeting, British Standard Institution, and London.

Couchman, G. \& Way, A. (1998) Joints in steel construction, Composite connections, Publication 213, Steel Construction Institute, Ascot.

Easterling, W. S. and Young, C. S. (1992). "Strength of Composite Slabs." Journal of Structural Engineering, ASCE,118, 9, 2370-2389. 
Ekberg, C. E. and Schuster, R. M. (1968). "Floor Systems with Composite Form Reinforced Concrete Slabs.”IABSE New York, Final Report, 385-394.

Ellingwood, B. and Ang, A. H. S. (1974). "Risk-based evaluation of design criteria."ASCE Journal of the Structural Division,100, ST9, 1771-1789.

Finzi, L. (1968). "Light gage steel floor systems provided to include utilities proposal and experiments."IABSE New York, Final Report, 367-374.

Fisher, J. M. and Buettner, D. R. (1979). "Application of light gauge steel in composite construction."Handbook of Composite Construction Engineering. Ed.: G. M. Sabnis, 80-96.

Fisher, J.W. (1970) Design of composite beams with formed metal deck. Eng. J. Amer. Inst. Steel Constr., 7, July, 88-96.

Hogan, T. J. (1976). "Composite Steel Beams in Buildings." Australian Institute of Steel Construction, Australia.

Johnson, R.P. \& Anderson, D. (2004) Designers' Guide to EN 1994- 1-1: Eurocode 4, Design of Composite Steel and Concrete Structures.Part 1-1, General rules and rules for buildings. Thomas Telford

Johnson, R.P. (1994). Composite Structures of Steel and Concrete. Volume 1 (Beams, Slabs, Columns and Frames for buildings). Oxford: Blackwell Scientific Publication.

Oudheusden, A. J. (1971). "Composite construction-applications."Proc. 1st. International Specialty Conference on Cold-Formed Steel Structures.Ed.: W. W. $\mathrm{Yu}, 173-178$.

Patrick, M. \& Bridge, R.Q. (1990) Parameters affecting the design and behaviour of composite slabs. Symposium, Mixed structures, including new materials, Brussels. Reports, Int. Assoc. for Bridge and Struct. Engrg, 60, 221-225.

Patrick, M. \& Bridge, R.Q. (1993) Design of composite slabs forvertical shear. In Composite construction in steel and concrete II (Easterling, W.S. \& Roddis, W.M.K., eds), Proc. Engineering Foundation Conference, Amer. Soc. Civ. Engrs, New York.

Porter, M. L. and Ekberg, C. E. (1976). "Design recommendations for steel deck floor slabs." Journal of the Structural Division, 102, ST11, 2121-2136.

Schuster, R. M. (1970). "Strength and Behavior of Cold-Rolled Steel-DeckReinforced Concrete Floor Slabs." PhD Dissertation, Iowa State University. 
Widjaja Budi Ryanto (1997). "Analysis and Design of Steel Deck-Concrete Composite Slabs". Ph.D. Thesis. Virginia Polytechnic Institute and State University, Blacksburg, USA.

Widjaja, B. R. and Easterling, W. S. (1995). "Evaluation of Composite Slabs Using Versa-Dek

Widjaja, B. R. and Easterling, W. S. (1996). "Strength and stiffness calculation procedures for composite slabs."Proc. 13th. International Specialty Conference on Cold-Formed Steel Structures. Ed.:W. W. Yu, 389-401.

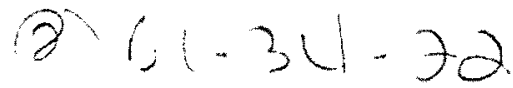

